Aus der Klinik für Psychiatrie und Psychotherapie

(Prof. Dr. Wiltfang)

im Zentrum Psychosoziale Medizin

der Medizinischen Fakultät der Universität Göttingen

\title{
Untersuchungen über die Auswirkungen von Geschlecht und genetischem Hintergrund auf die Alzheimerpathologie im 5xFAD-Mausmodell
}

\author{
INAUGURAL - DISSERTATION \\ zur Erlangung des Doktorgrades \\ der Medizinischen Fakultät der \\ Georg-August-Universität zu Göttingen
}

vorgelegt von

Philipp Johannes Nordmeyer

aus Hannover

Göttingen 2014 
Dekan: Prof. Dr. rer. nat. H. K. Kroemer

I. Berichterstatter: Prof. Dr. Thomas Bayer

II. Berichterstatter/in: PD Dr. Walter Joachim Schulz-Schaeffer

III. Berichterstatter/in: Prof. Dr. Margarete Schön

Tag der mündlichen Prüfung: 10.06.2015 
Inhaltsverzeichnis

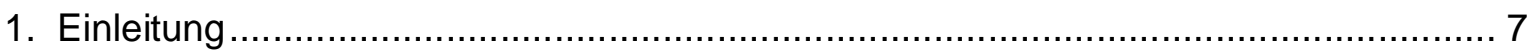

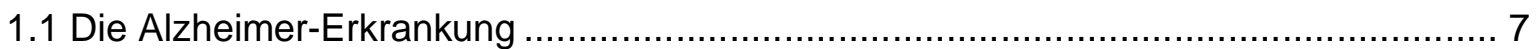

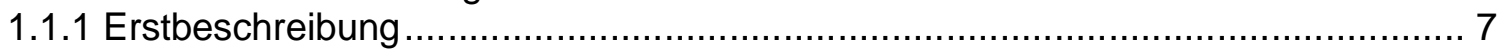

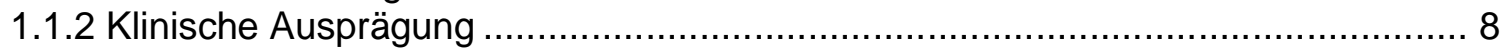

1.1.3 Einordnung in den Formenkreis der Demenzen .......................................... 10

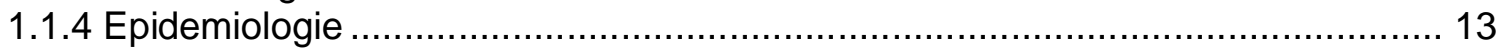

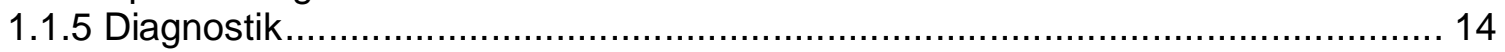

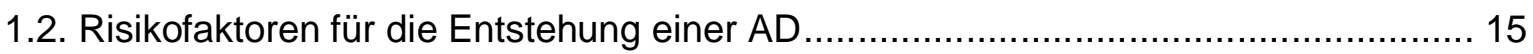

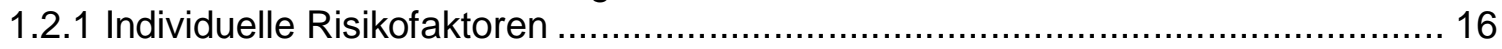

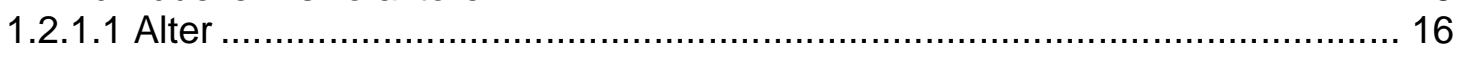

1.2.1.2 Lebensstil und kardiovaskuläres Risiko............................................... 16

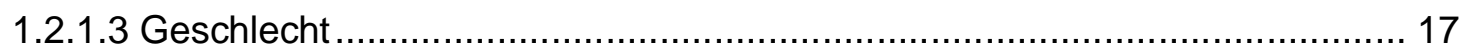

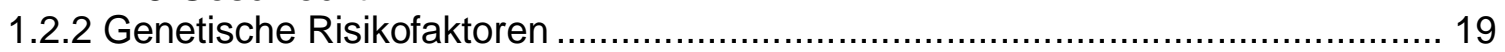

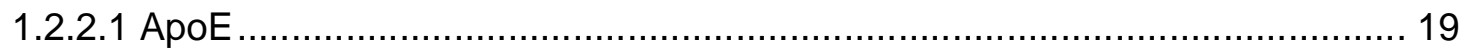

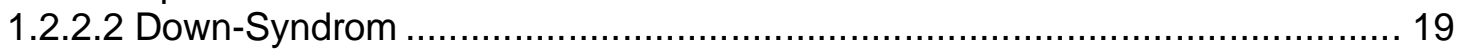

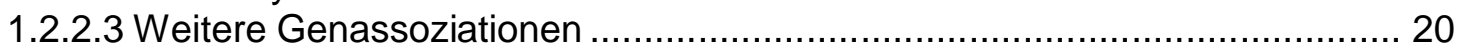

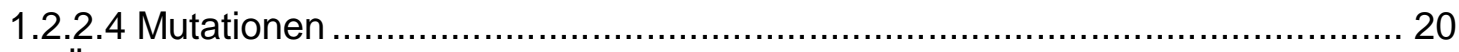

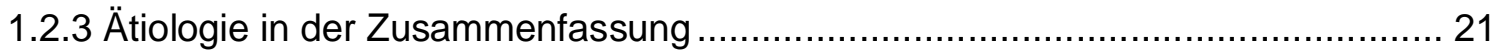

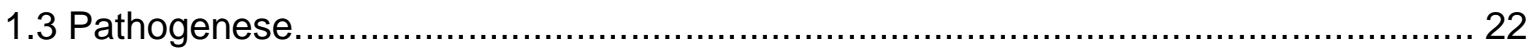

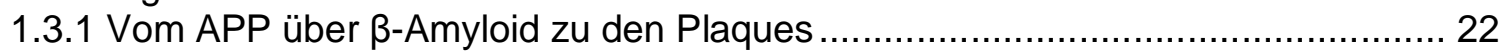

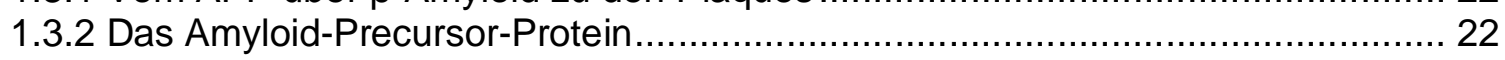

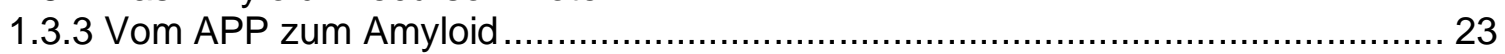

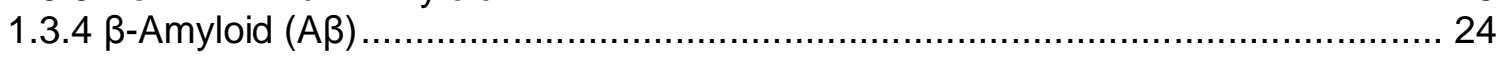

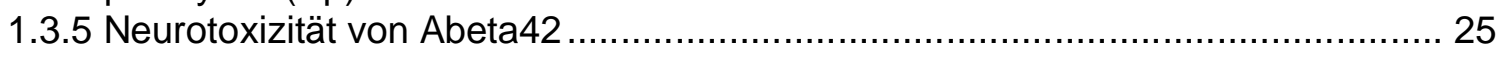

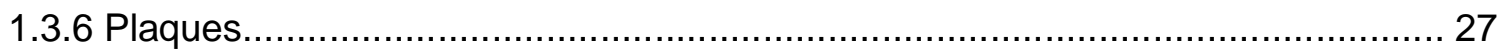

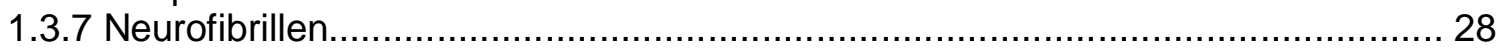

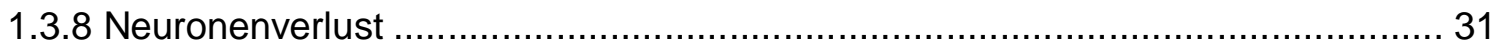

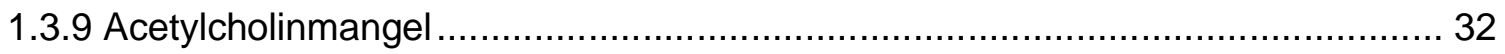

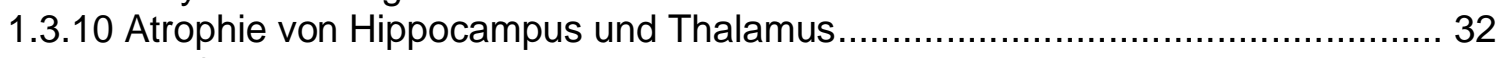

1.3.11 Die $\beta$-Amyloid-Kaskaden-Hypothese und ihre Modifizierung ........................... 34

1.3.12 Inflammatorische und immunologische Reaktionen ...................................... 35

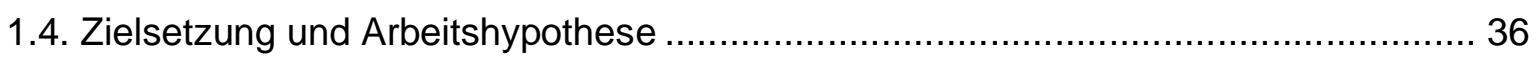

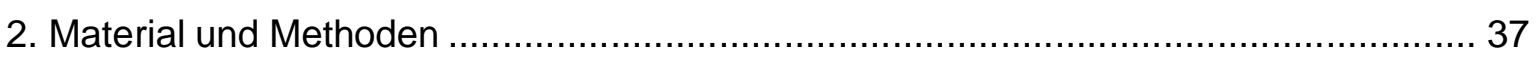

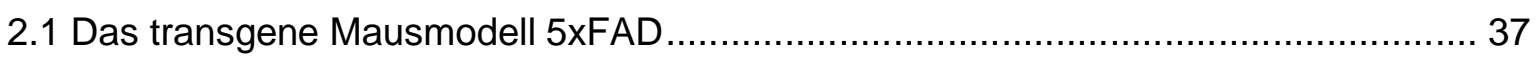

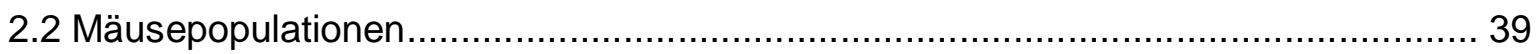

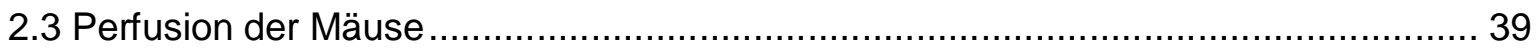

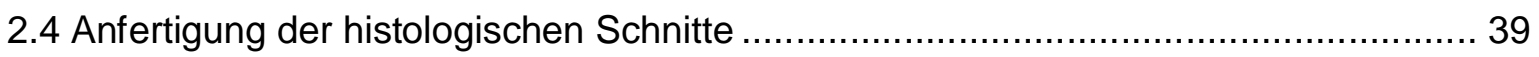

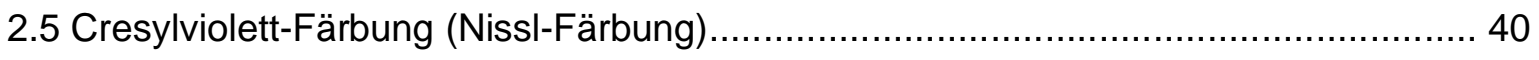

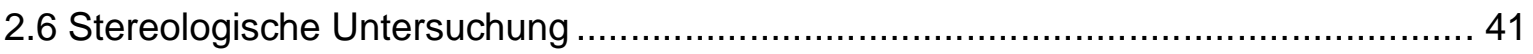

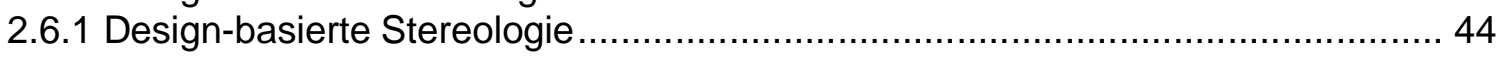

2.6.2 Berechnung der Neuronenzahlen von CA1-Hippocampus und Thalamus.............. 45

2.6.3 Berechnung der Volumina von CA1-Hippocampus und Thalamus ....................... 46 
2.7 Herstellung von histologischen Schnitten für den Plaqueload und die immunhistochemische Färbung

2.7.1 Bestimmung des Plaqueload (quantitative $A \beta$-Bestimmung) und intraneuronale

$A \beta$-Aggregation

2.8 Statistik

3. Ergebnisse

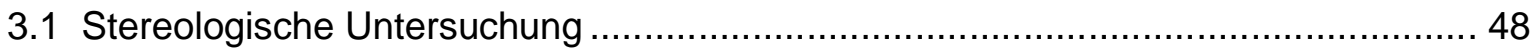

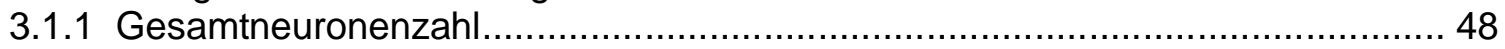

3.1.1.1 Gesamtneuronenzahl im Hippocampus............................................... 48

3.1.1.2 Gesamtneuronenzahl im Thalamus..................................................... 50

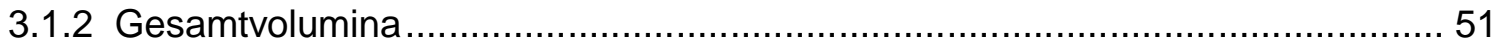

3.1.2.1 Gesamtvolumina im CA1-Hippocampus ........................................... 51

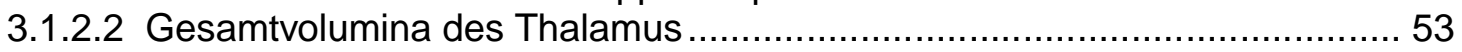

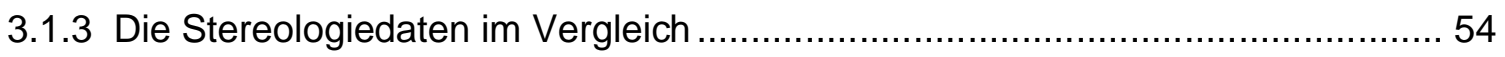

3.2 Untersuchung der $A \beta$-Belastung (Plaqueload) ............................................... 55

3.2.1 Quantitative Auswertung des Plaqueloads ................................................ 55

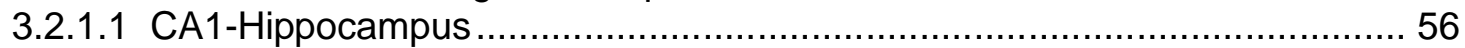

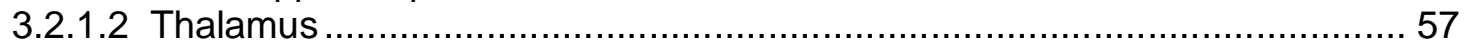

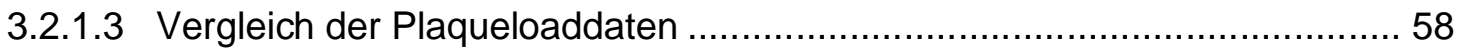

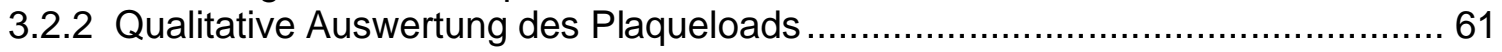

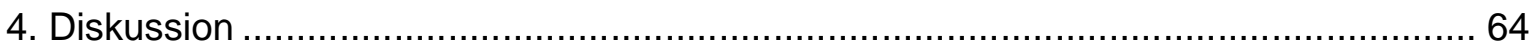

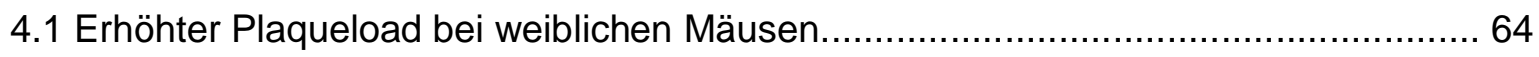

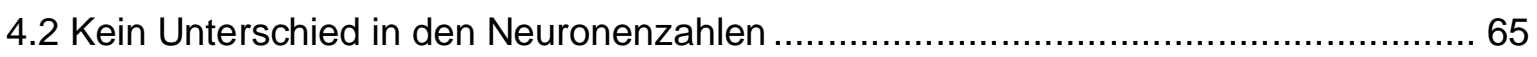

4.3 Hirnvolumen in Abhängigkeit des genetischen Hintergrundes................................66

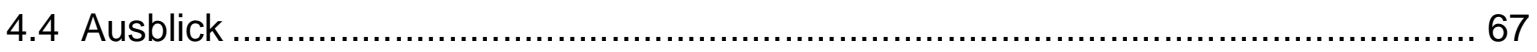

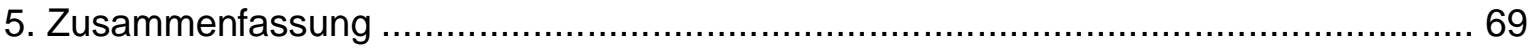

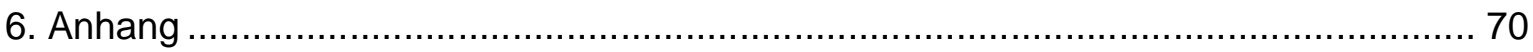

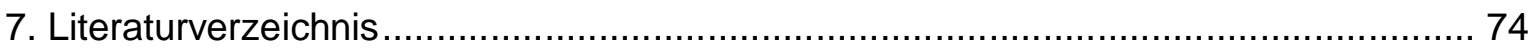


Abkürzungsverzeichnis

$A \beta \quad \beta$-Amyloid

Abb.

Abbildung

AD

Alzheimerdemenz

ADDLs

$A \beta$-derived diffusible ligands

AICD

$A P P$ intracellular domain

ApoE

Apo-Lipoprotein E

APP

Amyloid-Precursor-Protein

BACE

beta-site APP-cleaving enzyme

bzw.

beziehungsweise

CERAD

Consortium to Establish a Registry for Alzheimer's Disease

Ca. circa

$\mathrm{CA}$

Cornu ammonis (Ammonshorn)

CJD

Creutzfeldt-Jakob-Krankheit

$\mathrm{DAB}$

3,3-Diaminobenzidin

DGN

Deutsche Gesellschaft für Neurologie

DEMTECT

Demenz-Detektionstest

FAD

familiäre Alzheimer-Erkrankung

FCS

Fetal Calf Serum

GWA

genome-wide association analyses

$\mathrm{GnRH}$

gonadotropin releasing hormone

HET

Hormonersatztherapie

histolog.

histologisch

HIV

Humanes Immundefizienzvirus

ICD

International Classification of Diseases

LOAD

Late Onset Alzheimer Disease

LTP

Langzeitpotenzierung 
MDI mild cognitive impairment

MAP1/MAP2 Mikrotubulus-assoziierte Proteine 1/2

MMST Mini-Mental-Status-Test

n

Number

NINCS-ADRDA The National Institute of Neurological and Communicative Disorders and Stroke and the Alzheimer's Disease and Related Disorders Association

PBS

phosphate buffered saline

PHF

paired helical filaments

PICALM

phosphatidylinositol binding clathrin assembly protein

PS

Presenilin

S.

Siehe

u.

und

vgl.

vergleiche

WHO

Weltgesundheitsorganisation 


\section{Einleitung}

\subsection{Die Alzheimer-Erkrankung}

Seit dem Beginn ihrer Erstbeschreibung durch Alois Alzheimer im Jahr 1901 ist die Demenz vom Alzheimer-Typ zu einer wachsenden Herausforderung für Gesellschaft und Gesundheitssystem der Industriestaaten geworden. Prognosen sagen voraus, dass sich die Anzahl der an Morbus Alzheimer erkrankten Menschen bis zum Jahr 2048 in den USA vervierfachen wird (Brookmeyer et al. 1998). Bis heute konnten zwar eine Vielzahl von Risikofaktoren ausgemacht und der Einfluss von Genmutationen gesichert werden, die Ursachen der Erkrankung konnten jedoch noch nicht vollends erschlossen werden. Neben wenigen symptomatischen Therapieansätzen gibt es bisher keine Möglichkeit der Heilung. In der Zukunft wird die Alzheimersche Erkrankung mehr und mehr eine erhebliche Belastung für die Gesellschaft, das Gesundheitssystem und insbesondere für die Erkrankten und deren Pflegenden darstellen.

\subsubsection{Erstbeschreibung}

Der deutsche Psychiater und Neuropathologe Alois Alzheimer beschrieb im Jahr 1901 den Fall der Auguste D. Sie wies deutliche Einschränkungen in ihrer kognitiven Leistungsfähigkeit auf und war mit einem Alter von 50 Jahren jung im Vergleich zu bisher bekannten Fällen von Demenz. Diese Tatsache war Anlass für Alzheimer, den Progress der Krankheit bei Auguste D. für 5 weitere Jahre bis zu ihrem Tode zu verfolgen. Während der post-mortalen Untersuchungen fiel Alois Alzheimer makroskopisch eine Hirnatrophie auf, während er auf mikroskopischer Ebene Fibrillenablagerungen in den Nervenzellen und extrazelluläre Ablagerungen im Hirnparenchym nachweisen konnte. Er beschrieb somit erstmals die der Erkrankung zugrundeliegende Pathologie. Die autoptisch gewonnenen histologischen Präparate stellten ein bis dahin unbekanntes neuropathologisches Korrelat der Erkrankung dar, das für die weitere Erforschung dieser Erkrankung wegweisend sein sollte. 


\subsubsection{Klinische Ausprägung}

Nach ICD-10 wird die Alzheimer-Erkrankung als eine "primär degenerative zerebrale Krankheit mit unbekannter Ätiologie und charakteristischen neuropathologischen und neurochemischen Merkmalen" definiert. Sie entwickelt sich langsam aber stetig über einen Zeitraum von mehreren Jahren, daher lässt sich der Beginn der Symptomatik rückblickend meist nicht erfassen. Typisch für die Alzheimer-Erkrankung ist die schleichende Entwicklung einer Demenz mit Verlust von kognitiven Fähigkeiten, besonders des Gedächtnisses und des Denkvermögens, aber auch Apathie und Wortfindungsstörungen treten früh auf (Haupt et al. 1992). Der für die AD ebenfalls typische langsam progrediente Verlauf ist eines der wichtigsten Merkmale zur Abgrenzung von anderen Demenzformen (Tang-Wai et al. 2005). Die AlzheimerErkrankung wird nach ICD-10 unterteilt in eine häufige Spätform mit Beginn nach dem 65. Lebensjahr (late onset Alzheimer's disease oder LOAD) und eine wesentlich seltenere Frühform mit Beginn vor dem 65. Lebensjahr (early onset Alzheimer's disease, $E O A D$ ), die in seltenen Fällen schon im vierten Lebensjahrzent diagnostiziert werden konnte (Filley et al. 2007). Die EOAD zeigt oft einen schnelleren Progress als die LOAD und damit eine stärkere Ausprägung der Symptome in jüngerem Alter, was sie wiederum schlechter abgrenzbar von anderen demeziellen Syndromen macht (Filley et al. 2007). Das klinische Bild der AD findet Ausdruck in Frühsymptomen, Symptomen im Verlauf und Spätsymptomen. Die Symptomatik gleicht zu Beginn der einer leichten kognitiven Störung. Es bestehen oftmals selektive Beeinträchtigungen der Gedächtnisfunktion, die sich testdiagnostisch objektivieren lassen, die jedoch meist ohne wesentliche Auswirkungen auf die alläglich Funktionsfähigkeit des Patienten bleiben (mild cognitive impairment; (Gauthier et al. 2006)). In den Initialphasen der Erkrankung zeigen sich die Gedächtnisbeeinträchtigungen vor allem bei kürzlich erworbenen Informationen, wobei das Speichern und der Abruf neuerer Informationen oft betroffen sind. Da die Defizite anfangs über eine längere Zeit geringfügig sein können und sie die Patienten im Alltag geringgradig behindern, nehmen die Patienten die kognitiven Einschränkungen häufig zunächst nicht wahr. Das Phänomen der fehlenden Krankheitseinsicht wird als Anosognosie bezeichnet (Tang-Wai et al. 2005). Neben den Einschränkungen der Gedächtnisleistung können auch Wortfindungsstörungen, Schwierigkeiten in Entscheidungsfindung und Planung von Alltäglichem, erschwerte Organisation von Finanzen und Orientierungsminderung, die sich z.B. beim Autofahren zeigt, frühzeitig im Krankheitsverlauf auftreten (Baudic et al. 2006). Stimmungsabnormitäten, allen voran Depressionen, können zu jedem Zeitpunkt der 
Erkrankung auftreten. Die Prävalenz einer Major Depression bei Alzheimer- Erkrankten liegt zwischen 22 und 55 \% (Zubenko et al. 2003). Im Verlauf können Persönlichkeitsveränderung und Verhaltenstörung eintreten. Persönlichkeitsveränderungen wie beispielsweise Apathie mit Interessenverlust, später aber auch Agitation und Aggressivität, werden bei $75 \%$ der Patienten beobachtet. Im Rahmen von Verhaltensänderungen werden die Patienten zum Teil körperlich oder verbal ausfallend, wandern ziellos umher oder werden harninkontinent. Als Spätsymptome können psychotische Symptome wie Wahnvorstellungen oder visuelle und akustische Halluzinationen auftreten. Aber auch die Fehlidentifikation von Angehörigen und Einschränkungen motorischer Fähigkeiten kommen in einem späteren Stadium der Erkrankung vor. Der progrediente geistige Abbau hat immer stärker werdende Einschränkungen im Alltagsleben zur Folge bis hin zum Verlust gesellschaftlicher und individueller Maximen wie beruflicher, familiärer und gesellschaftlicher Integrität, Unabhängigkeit und Selbstbestimmung, was oftmals mit Gefühlen des Würdeverlustes verbunden ist. Für die verantwortlichen Pflegenden, vor allem zu Beginn der Erkrankung sind es häufig Angehörige, stellt dies eine große Belastung dar. Etwa die Hälfte aller Pflegenden entwickeln depressive Störungen, weshalb häufig psychotherapeutische Interventionen notwendig werden (Small et al. 1997). Nach Symptombeginn leben die Patienten meist noch 7-10 Jahre, wobei die ein Großteil der Patienten an Infektionen wie Pneumonien aufgrund der Bettlägrigkeit versterben (Tang-Wai et al. 2005). 


\subsubsection{Einordnung in den Formenkreis der Demenzen}

Die Weltgesundheitsorganisation WHO definiert in ihrem internationalen Klassifikationsmanual für Krankheiten von 2006 (ICD-10) die Demenz als ein Syndrom in der Folge einer meist chronischen, fortschreitenden Krankheit des Gehirns mit Störung vieler höherer kortikaler Funktionen, einschließlich Gedächtnis, Denken, Orientierung, Auffassung, Rechnen, Lernfähigkeit, Sprache und Urteilsvermögen.

Zur Definition gehören folgende Kriterien:

- Störungen des Gedächtnisses mit verminderter Aufnahme- und Wiedergabefähigkeit neuer Informationen und Verlust erlernter und vertrauter Inhalte

- Störungen des Denkvermögens

- Störungen der emotionalen Kontrolle, des Sozialverhaltens und der Motivation

- Das Bewusstsein ist nicht eingetrübt

Die Störungen müssen länger als 6 Monate bestehen und eine Einschränkung der alltagspraktischen Fähigkeiten nach sich ziehen (Mahlberg und Gutzmann 1995). Die Demenz muss aufgefasst werden als Symptomkomplex, der einer bestimmten Ursache oder Krankheit nicht zugeordnet werden kann (Tang-Wai et al. 2005).

Hieran wird die Schwierigkeit der klinischen Diagnosestellung ersichtlich, die sich auch an der Vielzahl der Differentialdiagnosen verdeutlicht.

Zur Einordnung der Alzheimer-Erkrankung in den Formenkreis der Demenzen gibt es mehrere Modelle. So orientiert sich eine Trennung der Demenzen in kortikale, subkortikale und frontale Demenzen an dem anatomischen Ort des Gehirns, an dem die Pathophysiologie der Erkrankung stattfindet (Lauter 1988). In ihren Leitlinien für Diagnostik und Therapie unterteilt die Deutsche Gesellschaft für Neurologie die Demenzen ihrer Genese nach in degenerative und vaskuläre Demenzen (Diener et al. 2008). Die Weltgesundheitsorganisation WHO differenziert anhand des ICD-10-Codes F00-F03 zwischen Demenz vom Alzheimer Typ und vaskulärer Demenz, welches die zwei häufigsten Demenzformen darstellen (s. Kapitel 1.1.4) und als primäre Demenzen von sekundären Demenzformen, als Folge anderer Grunderkrankungen, abgegrenzt werden. Die dem Syndrom Demenz zugrunde liegenden Erkrankungen lassen sich in diese Modelle einordnen und stellen die für die Diagnose der Alzheimer-Erkrankung in Betracht zu ziehenden Differentialdiagnosen dar, wie Tabelle 1 verdeutlicht: 


\begin{tabular}{|c|c|c|}
\hline \multirow{3}{*}{$\begin{array}{l}\text { Zuordnung } \\
\text { nach } \\
\text { Schädigungs- } \\
\text { ort }\end{array}$} & kortikal & M. Alzheimer \\
\hline & subkortikal & $\begin{array}{l}\text { Demenz bei Morbus } \\
\text { Parkinson, Alkoholdemenz, } \\
\text { Demenz bei } \\
\text { Normaldruckhydrozephalus }\end{array}$ \\
\hline & frontal & $\begin{array}{l}\text { Morbus Pick } \\
\text { (frontotemporale Demenz) }\end{array}$ \\
\hline \multirow[t]{2}{*}{ DGN } & degenerativ & $\begin{array}{l}\text { M. Alzheimer, Lewy- } \\
\text { Body-Demenz, fronto- } \\
\text { temporale Demenz, } \\
\text { Parkinson-Demenz }\end{array}$ \\
\hline & vaskulär & $\begin{array}{l}\text { subkortikale vaskuläre } \\
\text { Demenz, Multiinfarktdemenz }\end{array}$ \\
\hline \multirow[t]{3}{*}{ ICD-10 } & $\begin{array}{l}\text { Typ Alzheimer } \\
\text { (F00) }\end{array}$ & $\begin{array}{l}\text { M. Alzheimer, } \\
\text { Mischdemenzen }\end{array}$ \\
\hline & $\begin{array}{l}\text { vaskuläre } \\
\text { Demenz (F01) }\end{array}$ & $\begin{array}{l}\text { subkortikale vaskuläre } \\
\text { Demenz, Multiinfarktdemenz }\end{array}$ \\
\hline & $\begin{array}{l}\text { sekundäre } \\
\text { Demenz (F02) }\end{array}$ & $\begin{array}{l}\text { M. Pick, CJD, M. Huntington, } \\
\text { M. Parkinson, HIV-Infektion, } \\
\text { Hypothyreose, } \\
\text { Hyperkalzämie, Multiple } \\
\text { Sklerose, VitB12-Mangel }\end{array}$ \\
\hline
\end{tabular}

Tabelle 1: Einteilungsformen der Demenzen

Um die von einem an Demenz erkrankten Patienten dargebotene Symptomatik der richtigen Erkrankung zuordnen zu können, werden die Differentialdiagnosen in die Diagnosefindung einbezogen. Die näheren Differentialdiagnosen sind in Tabelle 2 aufgeführt. Daneben existieren noch eine Reihe an Erkrankungen außerhalb des primär psychiatrischen oder neurologischen Formenkreises, die ebenfalls ein Demenzsyndrom hervorrufen können, z.B. Endokrinopathien, Vitaminmangelkrankheiten, Intoxikationen, Elektrolytstörungen (S3-Leitlinien Demenzen der Deutschen Gesellschaft für Neurologie (DGN 2009)). Die Diagnosestellung einer Demenzerkrankung fällt meist nicht leicht, da die Krankheitsbilder häufig die Kriterien mehrerer Erkrankungen erfüllen und sich so als Mischformen präsentieren oder keiner Erkrankung eindeutig zuzuweisen sind. Die differentialdiagnostisch in Betracht zu ziehenden Erkrankungen haben jedoch jeweils bestimmte Symptome zu eigen, die sie leichter voneinander abgrenzbar machen (s. Tabelle 2). 


\begin{tabular}{|c|c|}
\hline Erkrankung & Symptome \\
\hline Morbus Alzheimer & $\begin{array}{l}\text { - schleichender Beginn } \\
\text { - langsames Fortschreiten } \\
\text { - Gedächtnis-, Aufmerksamkeits- } \\
\text { und Orientierungsstörung }\end{array}$ \\
\hline Vaskuläre Demenz & $\begin{array}{l}\text { - begleitende vaskuläre Ereignisse } \\
\text { (Herzinfarkt, Hirninfarkt, } \\
\text { Thromboembolien) } \\
\text { Arterosklerose, } \\
\text { - plötzlicher Eintritt der Demenz } \\
\text { Nach ischämischem Ereignis }\end{array}$ \\
\hline Frontotemporale Demenz & $\begin{array}{l}\text { - Persönlichkeits- und } \\
\text { Verhaltensveränderungen als } \\
\text { Initialsymptom } \\
\text { - progrediente Sprachstörung }\end{array}$ \\
\hline Lewy-Body-Demenz & $\begin{array}{l}\text { - Halluzinationen } \\
\text { - begleitende Parkinson- } \\
\text { Erkrankung }\end{array}$ \\
\hline $\begin{array}{l}\text { Creutzfeldt-Jakob-Erkrankung } \\
\text { (CJD) }\end{array}$ & $\begin{array}{l}\text { - rasche Progression der } \\
\text { Gedächtnisstörung über Wochen } \\
\text { bis Monate } \\
\text { - begleitende psychomotorische } \\
\text { Defizite }\end{array}$ \\
\hline Morbus Huntington & $\begin{array}{l}\text { - oft Beginn mit psycho- } \\
\text { pathologischen Symptomen } \\
\text { (psychotische und } \\
\text { kognititve Störungen) } \\
\text { - choreatische } \\
\text { Bewegungsstörungen }\end{array}$ \\
\hline
\end{tabular}

Tabelle 2: Symptomatik verschiedener Demenzformen (Masuhr und Neumann 2007)

Die neurodegenerativen Demenzerkrankungen (Alzheimer-Demenz, frontotemporale Demenz, Parkinson-Demenz, Lewy-Körperchen-Demenz) zeigen progressive Verläufe über mehrere Jahre, wobei die Dauer der Ekrankungsverläufe sehr variabel ist. Die genannten Erkrankungen lassen sich weder heilen noch existieren Therapien zur Beendigung der Progression. Daher führen alle im Verlauf zu einer weitreichenden Pflegebedürftigkeit, verbunden mit einer reduzierten Lebenserwartung. Bei vaskulären Demenzen hingegen sind stufenförmige Verläufe mit langen Phasen ohne Progredienz bzw. sogar Phasen leichter Besserung beschrieben (S3-Leitlinien Demenzen der DGN 2009). Das allgemeine Überleben nach dem Beginn der Demenz beträgt annäherungsweise fünf Jahre (Berr et al. 2007). 


\subsubsection{Epidemiologie}

Die Alzheimer-Erkrankung ist die sowohl in Bezug auf die Anzahl der bekannten Fälle (Prävalenz) als auch auf die Anzahl der jährlichen Neuerscheinungen (Inzidenz) die weitaus häufigste Demenzform.

Lobo und Mitarbeiter haben im Jahr 2000 aus einer Analyse von 6 europäischen Studien die Prävalenz von Demenzen und den Anteil der Alzheimer-Erkrankung an diesen bestimmt: Mit einem Anteil von 54\% aller Fälle von Demenz ist die AD die mit Abstand häufigste Demenzform vor der vaskulären Demenz mit 16\%.

Bei einer Prävalenz aller Demenzen von 0,8\% in der Gruppe der 65- bis 69-Jährigen und 28,5\% im Alter von 90 und mehr Jahren lässt sich die Gesamtprävalenz der Demenz vom Alzheimer-Typ auf 0,6\% respektive 22,2\% berechnen (Lobo et al. 2000). Abbildung 1 verdeutlicht den bedeutenden Anteil der Alzheimer-Demenz an allen Demenzerkrankungen:

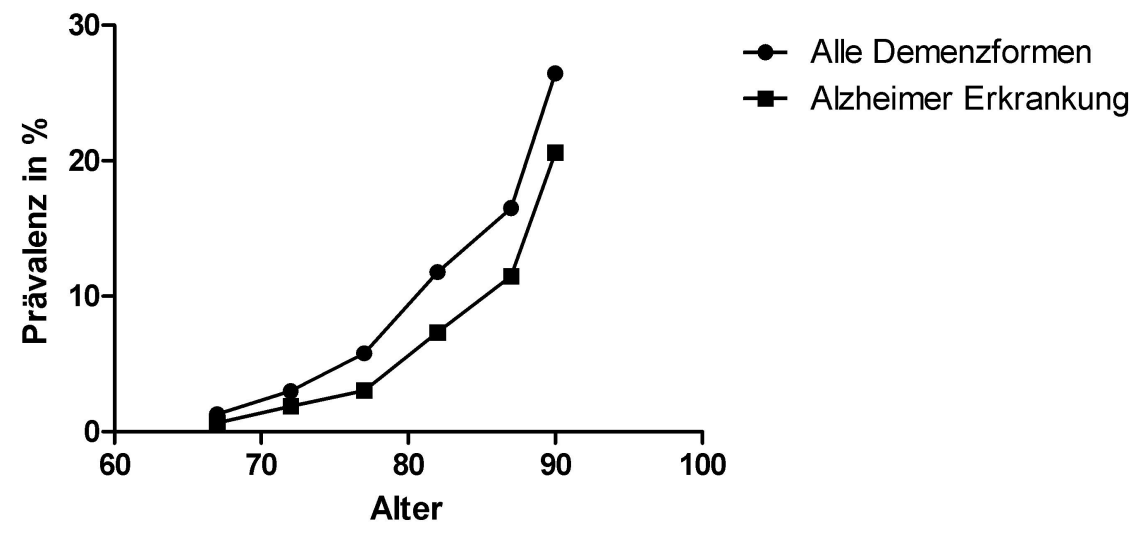

Abb. 1 : Prävalenz von Demenz-Erkrankungen nach Lobo (Lobo et al. 2000)

Jedes Jahr, so berechneten Fratiglioni und Kollegen, seien $60-70 \%$ der neuaufgetretenen Fälle von Demenz der Alzheimer-Erkrankung zuzuordnen (Fratiglioni et al. 2000). Diese hohe Inzidenz bestätige, dass die AD die häufigste dementielle Erkrankung in allen Altersklassen sei. Sowohl von der Alzheimer-Erkrankung als auch von der Gesamtheit der Demenzerkrankungen sind Frauen 1,2-1,5 mal häufiger betroffen als Männer (Tang-Wai et al. 2005). Insbesondere unter den über 80-Jährigen erkranken jedes Jahr mehr Frauen als Männer an der AD, wobei nach dem 84. Lebensjahr der Anstieg der Inzidenz unter Männern sistiert und unter Frauen weiter steigt (Fratiglioni et al. 2000). So ist es nicht verwunderlich, dass Frauen mit einem Anteil von $70 \%$ in Deutschland die größere Patientengruppe unter den an AD- Erkrankten darstellen (Bickel 2000). 
Wancata und Mitarbeiter berechneten 2003 auf Basis von mehreren epidemiologischen Metaanalysen eine europaweite Gesamtzahl von 7,1 Millionen Demenzerkrankten für das Jahr 2000. Bis zum Jahr 2050 werde in Europa die Zahl auf 16,2 Millionen steigen. Im Gegensatz zu dieser Entwicklung würden die Ressourcen, die nötig sind, um dieser Herausforderung entgegenzuwirken, immer knapper werden: Kamen im Jahr 2000 noch 69,4 Menschen im arbeitsfähigen Alter auf einen Demenzerkrankten, so würden es 2050 durch die Überalterung der Gesellschaft nur noch 21,1 Menschen sein. Folglich wird die durch Demenzerkrankungen bedingte finanzielle und emotionale Belastung insbesondere für den arbeitenden Teil der Bevölkerung zunehmend ansteigen (Wancata et al. 2003).

\subsubsection{Diagnostik}

Die Diagnose der Alzheimer-Erkrankung basiert zu größten Teilen auf dem Erkennen typischer Symptommuster des Patienten, das die Beurteilung kognitiver Fähigkeiten, des Verhaltens und der Verhaltensänderung in vergangener Zeit beinhaltet.

Zur Beurteilung der kognitiven Fähigkeiten des Patienten sind dem Arzt objektivierte Hilfsmittel gegeben: Der Mini-Mental-Status-Test (MMST) ist ein Screeningtest, der 9 Aufgabenkomplexe zur Prüfung zentraler kognitiver Funktionen enthält. Diese umfassen zeitliche und räumliche Orientierung, Merk- und Erinnerungsfähigkeit, Aufmerksamkeit, Rechnen, Lesen, Schreiben, Zeichen, Sprechen und Sprachverständnis. Die kognitive Leistungsfähigkeit des Patienten wird anhand eines 30 PunkteScores bewertet. Bei einem Score von $\leq 26$ liegt eine krankheitswertige Beeinträchtigung vor:

- MMST 20 bis 26 Punkte: leichte Alzheimer-Erkrankung

- MMST 10 bis 19 Punkte: moderate / mittelschwere Alzheimer-Erkrankung

- MMST weniger als 10 Punkte: schwere Alzheimer-Erkrankung (DGN 2009, Folstein et al. 1975)

Ein weiterer Screeningtest ist der Demenz-Detektionstest (DEMTECT), der mit fünf Fragen die kognitiven Bereiche Aufmerksamkeit, verbales Gedächtnis, Wortflüssigkeit und intellektuelle Flexibilität abdeckt. Es handelt sich hierbei um einen kurzen, leicht anwendbaren Test (8-10 Minuten), dessen Höchstpunktzahl unabhängig ist von Alter und Bildungsgrad des Patienten. Der Test wird zur Unterscheidung herangezogen, ob die kognitive Leistung altersentsprechend ist (13-18 Punkte), eine leichte kognitive Beeinträchtigung (mild cognitive impairment, 9-12 Punkte) oder eine Demenz (8 
Punkte oder weniger) vorliegt (Kalbe et al. 2004). Eine Verhaltensänderung des Patienten kann nur anhand einer Fremdanamnese von Familienangehörigen oder Personen mit langjähriger intensiver Beziehung zum Patienten festgestellt werden. Eine neurologische wie auch eine internistische körperliche und laborchemische Untersuchung ermöglicht eine Abgrenzung zu den Differentialdiagnosen und kann Mischformen der Demenzen aufdecken. McKhann und Kollegen veröffentlichten 1984 den Konsens einer Arbeitsgruppe (NINCS-ADRDA) zur Einigung über eine klinische Basis für die Diagnose der Alzheimer-Erkrankung. Anhand klinischer und histologischer Kriterien wurde die Wahrscheinlichkeit einer bestehenden AD unterteilt in mögliche, wahrscheinliche und gesicherte Alzheimer-Erkrankung:

NINCS-ADRDA-Einteilung in:

1. mögliche (atypisches klinisches Bild ohne alternative Diagnose und ohne histolog.

Sicherung)

2. wahrscheinliche (typisches klinisches Bild ohne histolog. Sicherung)

3. gesicherte AD (klinische und histolog. Diagnose anhand postmortalem Präparat) (McKhann et al. 1984)

\subsection{Risikofaktoren für die Entstehung einer $A D$}

Die Alzheimer-Erkrankung ist eine multifaktorielle Erkrankung, die in Zusammenhang mit einer Reihe von Risikofaktoren gebracht werden konnte. Es existiert eine Vielzahl individueller, umweltbedingter und genetischer Risikofaktoren, von denen jedoch kein Einzelner allein für die Entstehung der Erkrankung verantwortlich zu sein scheint. Bislang konnten lediglich Assoziationen zwischen Risikofaktoren und Erkrankungswahrscheinlichkeit nachgewiesen werden. Anhand von Familienstudien, die ein erhöhtes Erkrankungsrisiko für Verwandte ersten Grades von Alzheimer-Erkrankten gegenüber der Normalbevölkerung gezeigt haben, (Breitner et al. 1988, Lautenschlager et al. 1996), konnte eine starke genetische Komponente für die Erkrankung verantwortlich gemacht werden. Zwillingsstudien wiederum haben gezeigt, dass das Erkrankungsrisiko für einen eineiigen Zwilling, dessen Geschwisterzwilling an der AD erkrankt ist, weniger als $100 \%$ beträgt (Raiha et al. 1996). Diese Tatsache legt den Schluss nahe, dass nicht nur genetische Faktoren eine Rolle in der Entwicklung der Erkrankung spielen, sondern auch Einflüsse aus der Umwelt. 


\subsubsection{Individuelle Risikofaktoren}

\subsubsection{Alter}

Als erster und wichtigster Risikofaktor für die Entwicklung einer Alzheimer-Erkrankung wird das Alter angesehen. Die aus epidemiologischen Studien bekannten Zahlen vorliegender Fälle und sich jährlich neu ereignender Fälle von AD haben eine hohe Aussagekraft in Bezug auf das exponentiell zum Alter steigende Erkrankungsrisiko für eine $A D$. Wie bereits eingangs beschrieben, leiden $0,6 \%$ aller 60 - bis 65 -jährigen an einer Demenz vom Alzheimer-Typ, unter den über 90-Jährigen sind es 22,2\% (Siehe Kapitel 1.1.4 Epidemiologie). Auch wenn der Risikofaktor Alter aufgrund der Tatsache, dass er weder therapierbar, noch durch Prävention zu verhindern ist, vernachlässigbar erscheint, so ist er doch von Bedeutung für das Verständnis der Pathogenese (siehe Kapitel 1.3 Pathogenese).

\subsubsection{Lebensstil und kardiovaskuläres Risiko}

Es existiert eine signifikante Assoziation zwischen kardiovaskulären Risikofaktoren wie arterieller Hypertonie, Diabetes mellitus, Hyperlipidämie, Hyperhomocysteinämie und Rauchen und dem Risiko für die Alzheimer-Erkrankung (Luchsinger et al. 2005, Seshadri et al. 2002). Stattgehabte zerebrovaskuläre Ereignisse wie Hirninfarkte verstärken das kognitive Defizit bei bereits vorliegender Alzheimer-Pathohistologie (Snowdon et al. 1997). Unausgewogene, fettreiche Ernährung, Bewegungsmangel, Adipositas und Rauchen fördern die Entstehung von vaskulären Erkrankungen und können als eigenständige Risikofaktoren mit der Entwicklung einer $A D$ assoziiert werden (Cataldo et al. 2010, Fillit et al. 2008)

Ein niedriger Bildungsstand vor allem bei Männern (Launer et al. 1999) und kleinere soziale Netzwerke bei Frauen (Crooks et al. 2008) erweisen sich als soziale Risikofaktoren. Assoziiert mit der AD ist auch das Auftreten einer Depression bis zu mehreren Jahren vor Beginn der AD-Symptomatik (Green et al. 2003)

Erniedrigte Serumkonzentrationen von Folsäure und Vitamin B12 wirken erkrankungsfördernd, dagegen scheint eine vermehrte Einnahme von nicht-steroidalen Antirheumatika eher protektiv zu wirken (Clarke et al. 1998, Stewart et al. 1997). Einige Studien lassen regelmäßige körperliche Bewegung als einen wichtigen protektiven Faktor vermuten, welcher eine wichtige Komponente präventiver Strategien darstellen könnte (Lindsay et al. 2002). 


\subsubsection{Geschlecht}

Anhand mehrerer Prävalenzstudien, die die Verteilung der AD in der Gesellschaft unterschiedlicher Länder untersucht haben, konnte festgestellt werden, dass Frauen häufiger von der Erkrankung betroffen sind als Männer (Corso et al. 1992, Folstein et al. 1991, Kiyohara et al. 1994). Inwiefern das Geschlecht tatsächlich Einfluss auf die Entstehung der AD hat, wird kontrovers diskutiert und ist auch in dieser Arbeit ein zentraler Gegenstand.

Ein Grund für die höhere Prävalenz der $A D$ unter Frauen wird in der höheren Lebenserwartung des weiblichen Geschlechts gesehen: So erreichten mehr Frauen als Männer das Alter mit dem größten Erkrankungsrisiko. Dies könnte ein Grund dafür sein, dass in der Altersklasse mit der höchsten Prävalenz der AD (>90 Jahre) in der Mehrheit Frauen von der Erkrankung betroffen sind (Hebert et al. 2001).

Um das Erkrankungsrisiko in Bezug auf das Geschlecht beurteilen zu können, betrachtete man in Studien und Metaanalysen die Inzidenz der AD. Sowohl ein fehlender (Hebert et al.) als auch ein vorhandener Unterschied (Gao et al. 1998, Henderson 2006, Launer et al. 1999) in der Inzidenz der AD bei Frauen und Männern konnte gefunden werden. Die erhöhte Inzidenz der AD unter Frauen im hohen Alter könnte darauf zurückzuführen sein, dass Männer sich häufiger den oben genannten Risikofaktoren, wie z.B. dem Rauchen, aussetzten und daher früher als Frauen an der $A D$ erkrankten. In diesem Fall tauchten in Inzidenzstudien weniger Männer in hohen Altersgruppen als neuerkrankt auf (Fratiglioni et al. 2000).

Ein wichtiger Fokus aktueller Untersuchungen liegt auf der Beeinflussung des Gedächtnisses durch die weiblichen Geschlechtshormone:

Eine große US-amerikanische Kohortenstudie zeigte eine verminderte Inzidenz der AD für postmenopausale Frauen, die sich einer Hormonersatztherapie (HET) unterzogen hatten, verglichen mit Frauen ohne HET (Zandi et al. 2002). Auch anhand anderer Beobachtungsstudien ließ sich dieser Zusammenhang bestätigen, was die Vermutung nahelegte, dass die menopausal sinkendenden Östrogenspiegel zum kognitiven Defizit beitragen und durch Substitution revidiert werden könnten (Kawas et al. 1997, Paganini-Hill und Henderson 1996, Tang et al. 1996). Die gegensätzliche Evidenz lieferte eine große doppelblinde, randomisierte und kontrollierte klinische Studie, indem sie ein explizit erhöhtes Erkrankungsrisiko der AD für Frauen mit HET aufzeigte (Shumaker et al. 2003). Aus dieser Diskrepanz entwickelte sich die Theorie des "kritischen Fensters", die die HET mit Beginn zum ungefähren Zeitpunkt der Menopause als protektiv und einen späteren Beginn der HET als erkrankungsfördernd 
designierte (Wharton et al. 2009, Whitmer et al. 2011). Die Erkenntnis einer Hormonsubstitution als potenziellem Präventivum der AD wird unterstützt durch die Bedeutung der weiblichen Geschlechtshormone für die kognitive Leistungsfähigkeit: Die Gedächtnisfähigkeit von Frauen variiert im Einklang mit den hormonellen Schwankungen während des Menstruationszyklus (Phillips und Sherwin 1992). Sie nimmt nach natürlicher und künstlich herbeigeführter Menopause, z.B. durch chirurgische Ovariektomie oder Anwendung von GnRH-Analoga, ab (Berman et al. 1997) und durch darauf folgende Hormonsubstitution wieder zu (Jacobs et al. 1998, Sherwin 1988). Pathohistologisch konnte eine fördernde Wirkung von Östrogen auf die Dendritendichte von Neuronen und die Neurogenese in Hirnarealen mit wichtiger Bedeutung für die Kognition beobachtet werden (Tanapat et al. 1999, Woolley und McEwen 1992). So wird eine neuroprotektive Wirkung der weiblichen Geschlechtshormone, insbesondere Östrogen, im Allgemeinen und im Speziellen vor dem Hintergrund der AD angenommen. Der im Rahmen der Menopause natürlich einsetzende Östrogenmangel könnte daher das weibliche Geschlecht verwundbarer für die Pathogenese der AD machen.

Geschlechtsspezifische Unterschiede im Auftreten einer AD konnten nicht nur bei Menschen beobachtet werden, sondern ebenfalls in einer Reihe von Tierstudien. Beispielsweise zeigte eine Studie mit einem bestimmten transgenen Mausmodell (Tg2576), dass weibliche Mäuse die für Alzheimer typische Neuropathologie signifikant häufiger zeigten als männliche Mäuse gleichen Alters (Callahan et al. 2001). Ein möglicher Zusammenhang zwischen dem Auftreten einer AD und dem Östrogenhaushalt konnte u.a. auch in einer Studie nachgewiesen werden, in der weibliche Mäuse nach einer Ovariektomie ein erhöhtes Risiko aufwiesen Alzheimer ähnliche neuropathologische Veränderungen $\mathrm{zu}$ entwickeln als gesunde Kontrolltiere (Petanceska et al. 2000).

Zusammenfassend lassen sich sowohl in Menschen als auch in Tieren geschlechtsspezifische Unterschiede finden, die einen Zusammenhang mit den weiblichen Hormonen und der Entwicklung einer AD nahelegen. 


\subsubsection{Genetische Risikofaktoren}

\subsubsection{ApoE}

Im Jahr 1993 fanden Corder et al. heraus, dass es einen signifikanten Zusammenhang gibt zwischen der Entwicklung der Spätform der Alzheimer-Erkrankung (LOAD) und dem Vorliegen des epsilon4-Allels des ApoE-Gens, das für das Protein ApoLipoprotein E, einem Transportprotein des Fettstoffwechsels, kodiert (Corder et al. 1993). Das epsilon4-Allel ist eines von drei Allelen (neben epsilon2 und epsilon3) des ApoE-Gens, das dem Chromosom 19 zugeordnet wird. Menschen, die dieses Allel in ihrem Genom tragen, haben ein zweifach erhöhtes Risiko, eine AD zu entwickeln. In homozygoter Form führt diese Genvariante in $90 \%$ der Fälle zu einer AD im Alter von 80 Jahren (Strittmatter und Roses 1996).

Es konnten fördernde Effekte des ApoE-e4 auf die pathophysiologischen Kernprozesse der AD nachgewiesen werden: ApoE-e4 fördert die AB-Ablagerung (Reiman et al. 2009), forciert die Phosphorylierung von Tau (Holtzman et al. 2000) und beeinflusst die Aggregationseigenschaften, die molekulare Konformation und die Toxizität von $A \beta$, einem Hauptsubstrat der pathophysiologischen Prozesse der AD (Bales et al. 1999, Castano et al. 1995, Ma et al. 1994).

Das Allel e2 des ApoE-Gens hingegen scheint eine protektive Wirkung in Bezug auf die Entwicklung einer AD zu haben (Corder et al. 1994).

\subsubsection{Down-Syndrom}

Bereits seit über 80 Jahren ist eine Korrelation zwischen der AD und der Trisomie 21, auch bezeichnet als Down-Syndrom, bekannt (Struwe 1929). Beim Down-Syndrom handelt es sich um eine autosomale Chromosomenaberration, bei der das Chromosom 21 in dreifacher Ausführung vorliegt. Da das APP-Gen, dessen Produkt das Vorläuferprotein des Amyloids ist, auf dem Chromosom 21 lokalisiert ist und wesentlich an der Entstehung einer AD beteiligt ist, liegt es bei dem Down-Syndrom in dreifacher statt, wie normal, in zweifacher Ausführung vor. Es besteht also eine genetische Prädisposition für die vermehrte Ablagerung von Amyloid und damit für die AD-typische histopathologische Entwicklung (Buselmaier und Tariverdian 2007). Histopathologische Untersuchungen haben schon früh gezeigt, dass typische Läsionen der $A D$ auch vermehrt in Hirnschnitten von Menschen mit Down-Syndrom zu finden sind (Jervis 1948). Bereits im Alter von 40 Jahren weisen Erwachsene mit einer Trisomie 21 eine typische Neuropathologie, ausreichend für die Diagnose einer AD, auf (Lott und Head 
2005). Das durchschnittliche Alter beim Einsetzen einer klinischen Demenz liegt bei 55 Jahren (Schupf und Sergievsky 2002).

\subsubsection{Weitere Genassoziationen}

Durch in jüngster Zeit durchgeführte genomweite Assoziationsanalysen (genome-wide association analyses, GWA), die die Gesamtheit aller Gene vieler AlzheimerErkrankten auf eine mögliche statistisch signifikante Assoziation mit der Erkrankung überprüfen, sind neben ApoE weitere Gene gefunden worden, deren Allelausprägungen einen Einfluß auf die Entstehung einer $A D$ zu haben scheinen. Hierzu zählen beispielsweise das Clusterin (Clu)-Gen, das die Konformation und Aggregation von $A \beta$ beeinflusst, und das Picalm-Gen (PICALM, phosphatidylinositol binding clathrin assembly protein), das über Optimierung von Endozytosewegen zur Aufrechterhaltung der Synapsenfunktion beiträgt (Harold et al. 2009). Liegen bestimmte Allelausprägungen dieser Gene vor, besteht ein erhöhtes Risiko für den Träger, eine $A D$ zu entwickeln. Schon über 600 mit der $A D$ assoziierte Gene sind in das Blickfeld der Forschung gerückt (http://www.alzgene.org/ 14.04.2011).

\subsubsection{Mutationen}

Es sind mehrere genetische Mutationen bekannt, die mit der Frühform der AD (EOAD) assoziiert werden konnten und die in familiärer Häufung zu beobachten sind.

Durch Austausch einzelner Basen im Gen für das Amyloid-Precursor-Protein (APP), dem Vorläuferprotein des Hauptbestandteils der Alzheimer-Plaques, entstehen Missense-Mutationen, die dazu führen, dass in das exprimierte Protein falsche Aminosäuren eingebaut werden. Diese Änderung der APP-Struktur bewirkt, dass durch Spaltung des APP vermehrt $A \beta 40$ und $A \beta 42$, in der Mehrzahl der Fälle jedoch nur $A \beta 42$, übermäßig produziert werden. $A \beta 40$ und $A \beta 42$ sind Proteine, die wesentlich zur Entstehung der typischen Neuropathologie der Alzheimer-Erkrankung beitragen. Die London-, Swedish- und Florida-Mutationen (benannt nach ihrem Entdeckungsort; (Eckman et al. 1997, Goate et al. 1991, Mullan et al. 1992) stellen solche MissenseMutationen dar und folgen einem autosomal-dominanten Erbgang (vgl. Kapitel 2.1). Seltener sind autosomal-rezessive Erbgänge (Di Fede et al. 2009). Es konnten ebenfalls Duplikationen von ganzen Abschnitten des APP-Gens gefunden werden, die durch Erhöhung der Aß-Produktion zur EOAD führen (Rovelet-Lecrux et al. 2006).

Laut der Alzheimer Disease \& Frontotemporal Dementia Mutation Database (http://www.molgen.ua.ac.be/ADMutations 03.11.2013) konnten 33 Mutationen im APP-Gen mit der AD assoziiert werden. Weitere Mutationen, die das Auftreten von EOAD fördern, sind in den Presenilin-Genen PS1 und PS2 (Presenilin 1 und 2) zu 
finden (Rogaev et al. 1995, Sherrington et al. 1995). Die Presenilin-Proteine sind Teil des $\mathrm{y}$-Sekretase-Komplexes, der an der Spaltung des APP beteiligt ist (De Strooper 2003). Missense-Mutationen in PS1 und PS2 führen zu einer Erhöhung von ausschließlich $A \beta 42$ und damit zu einem besonders frühen und schnellen Einsetzen der Erkrankung (Duff et al. 1996, Scheuner et al. 1996, Xia et al. 1997). Den 13 bekannten Mutationen im PS2-Gen stehen 185 Mutationen im PS1-Gen gegenüber (http://www.molgen.ua.ac.be/ADMutations 03.11.2013). Dies macht die PS1Mutationen zur häufigsten Ursache für die familiäre EOAD. Insgesamt sind $13 \%$ aller Fälle von EOAD auf autosomal-dominante Mutationen in den drei Genen APP, PS1 oder PS2 zurückzuführen, was $0,5 \%$ aller Fälle der AD entspricht. Mutationen in PS1 zeigen sich am häufigsten verantwortlich, vor Mutationen in APP, gefolgt von PS2 (Campion et al. 1999).

\subsection{3 Ätiologie in der Zusammenfassung}

Die Alzheimer-Erkrankung ist eine multifaktorielle Erkrankung und kann trotz Vorliegen genetischer, umweltbedingter oder lebensstilassoziierter Risikofaktoren in ihrer Ausprägung interindividuell stark variieren.

Trotz dieser scheinbaren ätiologischen Unregelmässigkeit geht man davon aus, dass 1-2\% aller Fälle durch autosomal-dominante Vererbung von Genmutationen verursacht werden, daher eine familiäre Häufung aufweisen und sich als rapide progredienter Early-Onset-Typ der AD manifestieren. Über die Hälfte dieser Fälle geht auf Mutationen in den APP-, PS1- und PS2-Genen zurück. Die restlichen 98\% der Fälle von $A D$ finden ihre Ursache in einem Potpourri aus Lebensstil, Bildung, sozialem Umfeld und genetischer Prädisposition.

Der Zusammenhang eines erhöhten Erkrankungsrisikos der Late-Onset-AD mit dem ApoE-e4-Allel gilt als gesichert. Zunehmend werden weitere Genassoziationen gefunden und die Wirkung von exogenen und endogenen Einflüssen wie der des Östrogens auf die Pathogenese der AD nachgewiesen. 


\subsection{Pathogenese}

Alois Alzheimer beschrieb anhand der histologischen Präparate des Gehirns von Auguste D. das Vorhandensein von "senilen Plaques" in der Großhirnrinde, eines der drei wesentlichen Merkmale der Demenz vom Alzheimer-Typ. Auch heute noch stehen diese Plaques im Fokus der Demenzforschung. Neben den extrazellulären Plaques gelten mikropathologisch das Vorhandensein von intrazellulären Neurofibrillen und makropathologisch die Atrophie der Großhirnrinde als Folge von Neuronenverlust als typisch für die Erkrankung.

\subsubsection{Vom APP über $\beta$-Amyloid zu den Plaques}

Im Folgenden soll dargestellt werden, wie es zu der Entstehung der Plaques im Gehirn von Alzheimer-Erkrankten kommt. Die Darstellung der Pathophysiologie der Erkrankung beginnt bei der Beschreibung des Hauptbestandteils der Plaques, dem $\beta$ Amyloid-Protein, und seinem Vorläuferprotein Amyloid-Precursor-Protein (APP). Die Entstehung, Aggregation und Wirkung auf Nervenzellen von $\beta$-Amyloid gilt als ein zentraler Pathomechanismus der Alzheimerschen Erkrankung (Hardy und Selkoe 2002).

\subsubsection{Das Amyloid-Precursor-Protein}

Das Amyloid-Precursor-Protein (APP) ist ein integrales Membranprotein vieler Gewebearten des menschlichen Körpers. Die Dichte des Proteins ist besonders hoch in Nervenzellen des zentralen Nervensystems. Seine genaue Funktion ist bisher noch nicht bekannt, jedoch wird dem Protein eine Rolle in der Entstehung von Neuronen und Synapsen sowohl während der Entwicklung des Gehirns (Hung et al. 1992) als auch während Heilungsprozessen nach Schädel-Hirn-Traumata (Van den Heuvel et al. 1999) zugeordnet. Zwischen der Expression des Proteins und der Synaptogeneserate konnte eine positive Korrelation nachgewiesen werden (Moya et al. 1994). Des Weiteren tragen Spaltprodukte des APP zur neuronalen Erregbarkeit und synaptischer Plastizität bei und wirken auf diese Weise neuroprotektiv (Mattson 1997). Die Tatsache, dass das hoch konservierte Protein ebenfalls in anderen Säugetierarten und in Fliegen der Drosophila-Gattung nachgewiesen werden konnte, legt den Schluss nahe, dass es von größerer Bedeutung für Lebewesen sein könnte. Die aktuelle 
Forschung untersucht auch die Bedeutung des APP als Zellrezeptor in der Krebsentstehung, und zeigt, dass der Einfluss des Proteins sich nicht auf das Feld der neurodegenerativen Erkrankungen beschränkt (Venkataramani et al. 2010).

Neben der beschriebenen neuroprotektiven Funktion des APP wird ein neurotoxisches Potenzial von Spaltprodukten des Proteins diskutiert, das zur Einleitung der Apoptose, des programmierten Zelltods, führt (Bertrand et al. 2001).

Das Gen, das APP kodiert, liegt auf Chromosom 21. Daher lassen sich, wie bereits weiter oben beschrieben, bei Patienten mit Down-Syndrom, bei denen eine Trisomie des Chromosoms 21 vorliegt, erhöhte Abeta-Konzentrationen als Ausdruck der vermehrten Expression der drei Kopien des APP-Gens finden.

\subsubsection{Vom APP zum Amyloid}

Die Entstehung des Amyloids aus seinem Vorläuferprotein APP ist Gegenstand intensiver Untersuchungen, da die Möglichkeit, durch Eingriff in den Entstehungsweg des Amyloids das Auftreten oder die Progression der AD verhindern zu können, in Betracht gezogen wird.

Das APP wird in zwei alternativen Wegen, an denen drei Proteasen beteiligt sind, prozessiert (s. Abbildung 2): Der erste und nicht-amyloidogene Weg erfolgt im ersten Schritt durch die a-Sekretase, die an der extrazellulären Domäne des APP angreift und es in ein nach extrazellulär sezerniertes Protein APPs- $\alpha$ und ein weiterhin membranständiges Protein C83 mit intrazellulärer Komponente teilt. Im zweiten Schritt wird das C83 im Bereich der Zellmembran durch die $y$-Sekretase in ein intrazellulär verbleibendes Protein AICD (APP intracellular domain) und ein nach extrazellulär entlassenes Protein P3 geteilt.

Der zweite und amyloidogene Weg ähnelt dem ersten mit dem Unterschied, dass der erste Schritt von der $\beta$-Sekretase durchgeführt wird, die das APP in ein sezerniertes APPs- $\beta$ und ein membranständiges $C 99$ teilt. Im zweiten Schritt wirkt auch hier die $\gamma^{-}$ Sekretase durch Teilung des C99 in das intrazellulär verbleibende AICD und das extrazelluläre $\beta$-Amyloid $(A \beta)$. Wie maßgeblich die $\beta$-Sekretase oder auch BACE, wie

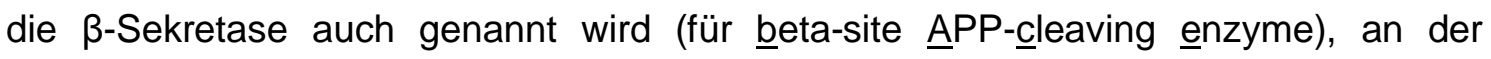
Entstehung von $\beta$-Amyloid als Essenz der $A D$ beteiligt ist, zeigen Studien mit Mausmodellen der Alzheimer-Erkrankung, denen das Gen für die $\beta$-Sekretase fehlt. Diese Knockout-Mäuse weisen keine Ansammlungen von $\beta$-Amyloid im Gehirn auf und zeigen ebenfalls keine Verhaltensänderungen, die auf einen Gedächtnisverlust hinweisen können (Luo et al. 2001, Ohno et al. 2004). 
Auf zwei konkurrierenden Wegen entstehen so Produkte mit unterschiedlicher physiologischer oder pathogener Wirkung. Während man sich über die physiologische Wirkung oder einen eventuellen neuroprotektiven Effekt der weiteren Produkte noch nicht im Klaren ist, gilt die Pathogenität des $\beta$-Amyloids im Rahmen der $A D$ als gesichert (Glenner und Wong 1984).

Da die $\beta$ - und $\alpha$-Sekretase um das APP konkurrieren, bewirkt ein Ausschalten der $\beta$ Sekretase z.B. mittels kompetitiver Hemmung oder genetischer Modifikation zu einem vermehrten Durchlaufen des nicht-amyloidogenen Prozessierungswegs und so zu verminderter Amyloidproduktion (Luo et al. 2001, Ohno et al. 2004, Postina 2012).

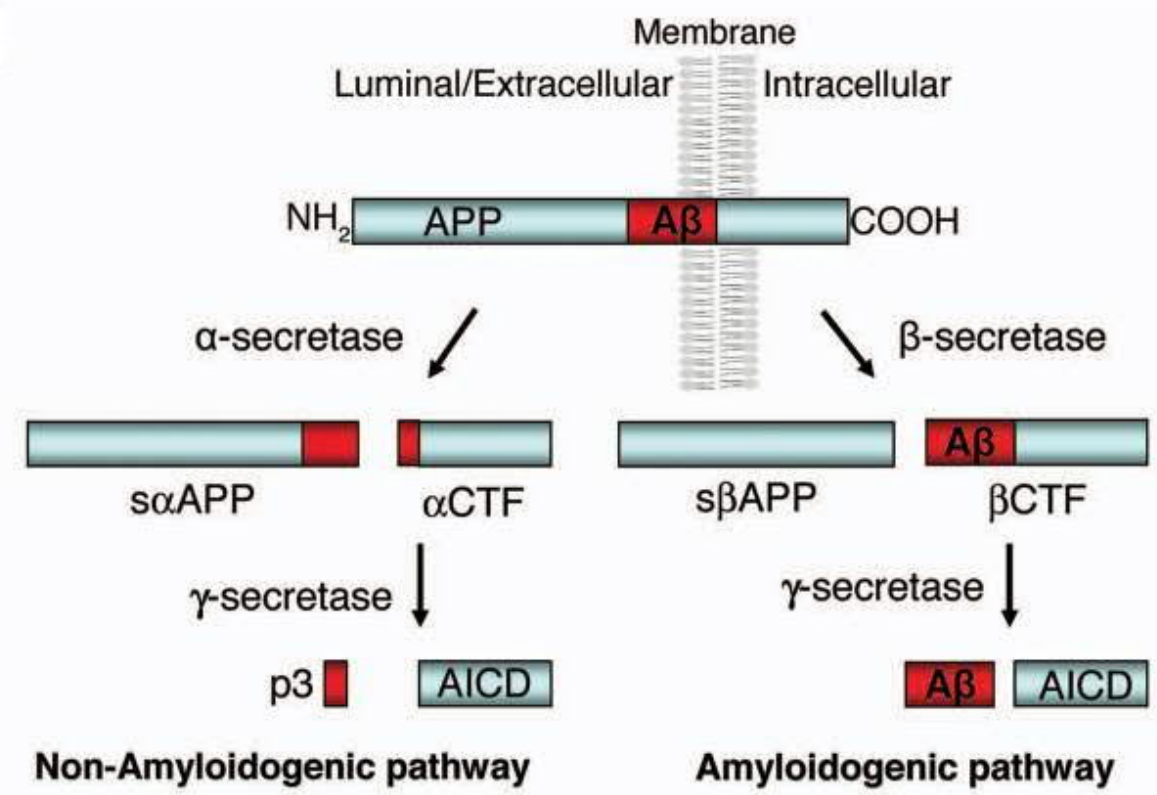

Abb. 2: Schematische Darstellung der APP-Prozessierung. Im non-amyloidogenen Weg (in der Abbildung links) erzeugt die Spaltung durch die a-Sekretase lösliches APPa (saAPP) und ein membranverankertes C-terminales Fragment (aCTF), welches weiter gespalten wird in ein 3 $k D a$ Fragment (p3) und eine intrazelluläre C-terminale APP Domäne (AICD). Im amyloidogenen Weg (in der Abbildung rechts) erzeugt die Spaltung durch die $\beta$-Sekretase $s \beta A P P$ und $\beta C T F$. Letzteres wird durch die $\gamma$-Sekretase in $\beta$-amyloid $(A \beta)$ und AICD gespalten (Khalifa et al. 2010). Mit freundlicher Genehmigung von Landes Bioscience.

\subsection{4 $\beta$-Amyloid $(A \beta)$}

Die Prozessierung des APP durch die $\beta$-Sekretase findet an einer spezifischen Stelle in der Aminosäuresequenz des APP statt. Jedoch entstehen durch ungenaue Spaltung des APP durch die $\gamma$-Sekretase $\beta$-Amyloidpeptide von unterschiedlicher Länge im Bereich von 38 bis 42 Aminosäuren (Vassar et al. 2009). 
In extrazellulären Amyloidablagerungen finden sich hauptsächlich Peptide mit einer Länge von 40 (Aß40) und 42 (Aß42) Aminosäuren (Roher et al. 1993). Das physiologische Verhältnis von $A \beta 40$ zu A $\beta 42$ im gesunden Gehirn beträgt ca. 10:1. In Gehirnen von Alzheimer-Erkrankten ist die Konzentration von $A \beta 42$ wesentlich erhöht. Bei familiären Formen der AD, bei denen Amyloidablagerung und Symptomatik früher beginnen als bei sporadischen Formen (Vergleiche 1.1 .2 und 1.2.2.4), ist das Verhältnis erheblich zu Gunsten von $A \beta 42$ verschoben (Bitan et al. 2003).

$A \beta$ existiert in löslichen und unlöslichen Formen: Zu den löslichen Formen zählen unter anderem $A \beta$-Monomere, kleine $A \beta$-Oligomere (Dimere, Trimere), diffusionsfähige $A \beta$ Oligomere, die als Liganden an Rezeptoren wirken ( $\underline{A} \beta$-derived diffusible ligands oder ADDLs), und aus mehreren Oligomeren zusammengesetzte ca. $5 \mathrm{~nm}$ große Protofibrillen. Zu den unlöslichen Formen gehören die ca. $10 \mathrm{~nm}$ großen Aß-Fibrillen, die Hauptbestandteil der neuritischen Plaques sind (s.u.). Die Fibrillen können aus einer Zusammenlagerung mehrerer Protofibrillen oder durch die Anlagerung von Oligomeren an Protofibrillen entstehen (Walsh und Selkoe 2007).

\subsubsection{Neurotoxizität von $A \beta 42$}

Eine viel vertretene und reichlich belegte Hypothese über den Zusammenhang zwischen vermehrter $A \beta$-Ansammlung und Verlust kognitiver Fähigkeiten besagt, dass $A \beta$ neurotoxische Eigenschaften besitzt. $A \beta$ wirkt sowohl in vitro (Pike et al. 1991) als auch in vivo (Meyer-Luehmann et al. 2008) toxisch auf Nervenzellen. Das alleinige Vorliegen von $A \beta$ reicht für eine toxische Wirkung nicht aus. Vielmehr muss $A \beta$ bestimmte Strukturen bilden, die neurotoxisch sind, da einerseits die Schwere der Symptomatik der AD nicht mit der A $\beta$-Last korreliert (Terry et al. 1991) und andererseits auch reichlich $A \beta$ in gesunden Gehirnen zu finden ist (Haass et al. 1992).

Bestimmten strukturellen Formen von $A \beta$ konnten unterschiedliche Effekte auf Nervenzellen zugeordnet werden: So besteht schon in der frühen Phase der Einwirkung von $A \beta$ auf Neuronen ein unmittelbarer Einfluss von ADDLs (Lambert et al. 1998) und Protofibrillen (Hartley et al. 1999) auf die neuronale Signaltransduktion, was nahelegt, dass eine Störung des neuronalen Zellstoffwechsels bereits vor zellulären Strukturschäden auftritt. Eine Signaltransduktionsstörung durch $A \beta$-Oligomere lässt sich auch in Neuronen des Hippocampus in Form einer verminderten Langzeitpotenzierung (LTP) nachweisen (Walsh et al. 2002). Eine verminderte hippocampale Langzeitpotenzierung hat neben der herabgesetzten Fähigkeit, neue Informationen 
aufzunehmen, auch den Verlust bereits gelernter Informationen zur Folge (Pastalkova et al. 2006).

Da die LTP das elektrophysiologische Korrelat der Funktionsfähigkeit (oder auch Plastizität) von Synapsen darstellt, wird durch oben genannten Nachweis ein durch $A \beta$ hervorgerufener Funktionsverlust der Synapsen denkbar. Tatsächlich kann schon frühzeitig im Verlauf der AD die Abnahme der Dichte von Synapsen nachgewiesen und in signifikanten Zusammenhang mit der kognitiven Einschränkung gebracht werden (Davies et al. 1987, DeKosky und Scheff 1990). Experimentell ließ sich der Synapsenverlust durch immunoreaktive Nachweise des Rückgangs des präsynaptischen Markers Synaptophysin belegen (Masliah et al. 1991). Der Synapsenverlust gilt noch vor dem Neuronenverlust als stärkstes Korrelat der ADSymptomatik, da der eigentliche Nervenzellverlust erst später im Verlauf der Erkrankung eintritt (Terry et al. 1991).

In den letzten Jahren verdichteten sich die Hinweise darauf, dass lösliche A $\beta$-Formen die primäre toxische Form des Amyloids sind (Lambert et al. 1998). Lue und Kollegen konnten einen Zusammenhang zwischen der Menge von löslichen Aß-Oligomeren und dem Grad der synaptischen Dysfunktion nachweisen (Lue et al. 1999). Durch die Erkenntnis Lesnes und Mitarbeiter, dass die Konzentration löslicher Aß-Oligomere und der Abbau der kognitiven Funktion signifikant miteinander korrelieren (Lesne et al. 2006), schließt sich der Kreis zwischen löslichem Aß, Synapsendysfunktion und Gedächtnisverlust.

Noch ungeklärt ist die Frage, ob intrazelluläres oder extrazelluläres $A \beta$ verantwortlich für den Synapsenverlust ist. Einerseits wird ein deaktivierender Effekt von extrazellulärem $A \beta$ auf Synapsen über synaptische Rezeptoren diskutiert (Shankar et al. 2007). Hierbei handelt es sich um die oben beschriebene Abnahme der Langzeitpotenzierung von Synapsen. Andererseits konnte in Studien mit Mausmodellen eine intrazelluläre Anreicherung von $A \beta$ mit Synapsen- und Neuronenverlust in Verbindung gebracht werden (Breyhan et al. 2009, Christensen et al. 2008). Für den durch intrazelluläres $A \beta$ ausgelösten Neuronenverlust werden verschiedene Mechanismen verantwortlich gemacht: So bildet $A \beta$ intrazellulär in Interaktion mit Lipiden der Zellmembran reaktive Sauerstoff- und Stickstoffradikale, die die Mitochondrien der Nervenzelle schädigen. Die mitochondriale Schädigung durch Sauerstoffradikale oder auch durch direkte hemmende Wirkung von $A \beta$ auf die Atmungskette führt zur Apoptose, dem programmierten Zelltod, unter anderem vermittelt durch Caspasen und das Tumorsupressorgen p53 (Gervais et al. 1999, Zhang et al. 2002). Durch Bindung und Reduzierung reaktiver Metallionen wie Kupfer 
kann $A \beta$ ebenfalls Sauerstoffradikale bilden und so zu weiterem oxidativem Stress führen (Bush 2013).

Auch ein verstärkter Kalziumeinstrom in die Nervenzelle durch direkte Aktivierung von vorhandenen lonenkanälen durch $A \beta$ oder Formierung von $A \beta$-Oligomeren zu neuen membranständigen lonenkanälen (Bezprozvanny und Mattson 2008) kann durch Exzitotoxizität oder Apoptose zum Zelltod führen. Neuere Untersuchungen haben ergeben, dass die Endozytose von extrazellulären Aß42-Oligomeren einen wichtigen Mechanismus, der zur intrazellulären toxischen Wirksamkeit von $A \beta$ führt, darstellt (Yu et al. 2010).

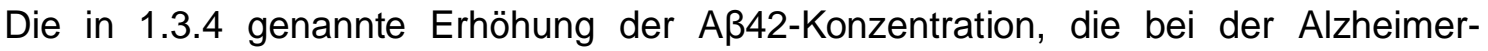
Erkrankung nachweisbar ist, spricht dafür, dass $A \beta 42$ im Vergleich zu $A \beta 40$ die stärker treibende Kraft der pathologischen Vorgänge ist. Bestätigt wird diese Vermutung durch die Tatsache, dass speziell $A \beta 42$ störende Einflüsse auf Synapsen und toxische Einflüsse auf Nervenzellen hat (Butterfield 2002, Glabe 2008, LaFerla et al. 1995, Parameshwaran et al. 2007). Die Klärung der Fragen, wie Löslichkeit, Wirkungsort und Struktur von $A \beta$ im Zusammenhang mit Synapsen- und Nervenzellverlust stehen, ist neben den pathologischen Mechanismen ein zentraler Punkt der Alzheimer-Forschung.

\subsubsection{Plaques}

Alois Alzheimer beschrieb Plaques als histologisches Phänomen im Präparat des Gehirns von Auguste D. und bezeichnete sie als histopathologisches Korrelat der Demenzsymptomatik. Heute herrscht die Einsicht, dass Plaques auch im gesunden Gehirn vorkommen, sich dann allerdings in ihrer Struktur von der, der zur AD führenden Plaques, unterscheiden. Aus diesem Grund unterscheidet man zwischen zwei Formen von Plaques: neuritische und diffuse Plaques. Die neuritischen Plaques kommen im Gehirn von AD-Patienten, vorrangig im Hippocampus und dem Assoziationskortex, vor. Sie stellen ein hartes Kriterium zur definitiven Diagnose der $A D$ dar. Sternenförmig angeordnete $A \beta 40$ - und $A \beta 42-$ Fibrillen bilden den Kern einer Plaque. Außerdem sind im Kern aktivierte Mikrogliazellen und dystrophe Neuriten von geschädigten Neuronen nachweisbar. Im Randbereich der Plaque befinden sich reaktive Astrozyten und ebenfalls dystrophe Neuriten. Der Durchmesser einer Plaque variiert zwischen 10 und $120 \mu \mathrm{m}$ und auch die Dichte des Amyloidkerns ist von Plaque zu Plaque unterschiedlich (Selkoe 2001).

Diffuse Plaques sind Amyloidablagerungen mit einem weniger dichten, amorph erscheinenden Amyloidkern ohne A $\beta$-Fibrillen. Im Gegensatz zu den aus $A \beta 40$ und 
A $\beta 42$ gemischten neuritischen Plaques bestehen die diffusen Plaques vorwiegend aus $\mathrm{A} \beta 42$, haben wenig bis keine dystrophen Neuriten eingeschlossen und weisen nur eine gering ausgeprägte bis keine reaktive Astrozytose auf (Yamaguchi et al. 1988). Diffuse Plaques werden als Zeichen des physiologischen Alterns verstanden, die keine Umgebungsreaktion hervorrufen, und sind sowohl in Hirnschnitten von AD-Patienten als auch von nicht dementen Patienten zu finden (Joachim et al. 1989). Da jedoch Zwischenformen existieren, die Eigenschaften von diffusen und neuritischen Plaques aufweisen, ist die Bestimmung, ab welchem Stadium eine Plaque schon Ausdruck der AD oder noch des Alterns ist, schwierig (Dickson 1997).

Die Theorie, dass sich neuritische Plaques aus diffusen Plaques entwickeln (Iwatsubo et al. 1995, Tagliavini et al. 1988), hat bis heute Bestand. Und auch die Erkenntnis, dass bei AD-Patienten in Hirnregionen, deren Beeinträchtigung verantwortlich für die Symptomatik der AD ist (limbischer und Assoziationskortex) diffuse Plaques neben neuritischen Plaques vorkommen, bei Gesunden jedoch nur diffuse Plaques, unterstützt diese Theorie (Selkoe 2001).

Die Frage nach der Rolle der Plaques im pathologischen Geschehen ist bislang nicht vollends geklärt. Im Einklang mit der Hypothese, dass lösliche A $\beta$-Oligomere das toxische Substrat der Erkrankung darstellen könnten, könnten die langfristig entstandenen $A \beta$-Plaques als Reservoir für bioaktive Oligomere dienen (Haass und Selkoe 2007). Abbildungen 3A, 3C und 3D zeigen beispielhaft das histologische Erscheinungsbild von Plaques.

\subsubsection{Neurofibrillen}

Neben den Amyloidplaques stellen Neurofibrillen ein weiteres Merkmal der AlzheimerErkrankung dar. Neurofibrillen sind intrazelluläre Konglomerate von Tau, einem Protein, dessen Funktion in der Formierung und Stabilisierung von neuronalen Mikrotubuli liegt. Daher ist dieses Protein an der Aufrechterhaltung des axonalen Transports in Nervenzellen beteiligt. Die Bindungsaffinität von Tau zum Mikrotubulus wird reguliert über Phosphorylierung und Dephosphorylierung durch Kinasen respektive Phosphatasen. Mit steigendem Phosphorylierungsgrad des Tau sinkt sowohl seine Affinität zum Mikrotubulus als auch seine Löslichkeit (lqbal et al. 2005, Lindwall und Cole 1984).

In Gehirnen mit Alzheimer-Pathologie findet man im Vergleich zum Gesunden über die Norm phosphoryliertes (hyperphosphoryliertes) Tau. Aufgrund seiner geringen Löslichkeit aggregiert es zu helikalen filamentösen Strukturen, die sich paarweise 
zusammenlagern und daher als paired helical filaments (PHF) bezeichnet werden. Mehrere dieser ca. $10 \mathrm{~nm}$ großen PHF bilden die vorrangig in Zellkernnähe vorkommenden Neurofibrillen (Selkoe 2001).

Die Hyperphosphorylierung des Tau hat die funktionelle Inaktivierung des Proteins zur Folge. Durch Dephosphorylierung lässt sich seine Funktionalität in vitro wiederherstellen (Wang et al. 1995). Die Hyperphosphorylierung des Tau gilt daher als wichtiger Punkt der Tau-assoziierten Pathogenität (Alonso et al. 1994, Grundke-lqbal et al. 1986 b). Zwar kann die fehlende Stabilisierung der Mikrotubuli nach Inaktivierung von Tau durch andere mikrotubulus-assoziierte Proteine (MAP1/MAP2) übernommen werden, jedoch werden diese Proteine durch das hyperphosphorylierte Tau ebenfalls inaktiviert, wodurch es zum endgültigen Verlust der Mikrotubulusstabilität kommt. Über die dadurch bedingte Einschränkung des axonalen Transports verliert die Nervenzelle die Fähigkeit zur Versorgung ihrer Synapsen und degeneriert, was messbare kognitive Einschränkungen zur Folge hat (Santacruz et al. 2005). Dieses toxische Potenzial des hyperphosphorylierten Tau geht, ähnlich wie beim $\beta$-Amyloid, nicht von den großen unlöslichen PHFs und Neurofibrillen, sondern von noch leichter löslichen, intermediären Tau-Kongregaten aus (Khlistunova et al. 2006). Den Neurofibrillen wird gar ein protektiver Effekt eingeräumt, da sie einen Aggregationspunkt für hyperphosphoryliertes Tau darstellen und dadurch dessen destabilisierende Wirkung auf Mikrotubuli abschwächen (Lee et al. 2005).

Die Ursachen für die AD-assoziierte Hyperphosphorylierung von Tau werden einerseits in einer gestörten Aktivität von Kinasen und Phosphatasen vermutet. Die konsekutive Aktivierung der Kinase Cdk5 durch abnorme Proteolyse seiner regulatorischen Untereinheit führt zu verstärkten Phosphorylierung von Tau (Patrick et al. 1999). Die bei der $A D$ beobachtete reduzierte Aktivität der Phosphatase PP-2A führt zur verminderten Dephosphorylierung von Tau (Gong et al. 1995).

Andererseits könnte durch $\beta$-Amyloid ausgelöster oxidativer Stress zu Fehlfunktionen von Zellorganellen wie dem endoplasmatischen Retikulum führen, so dass Fehler beim Falten von Tau entstehen, die wiederum den Abbau von Tau erschweren und es anfällig für verstärkte Phosphorylierung machen. Da $\beta$-Amyloid das Gleichgewicht von Kalzium in Nervenzellen verschiebt, ist eine kalziuminduzierte Aktivitätsänderung von Kinasen und Phosphatasen ebenfalls denkbar (Selkoe 2001).

Ein Konsens über den Zusammenhang zwischen den zwei Merkmalen $\beta$-Amyloid und Tau, die die AD charakterisieren, besteht bislang noch nicht. Die Hyperphosphorylierung von Tau in Nervenzellen ist kein rein pathologisches Phänomen, sondern auch während der Entwicklung des Gehirns und nach Narkose oder Hypothermie zu beobachten und so eventuell als protektive Reaktion der Nervenzelle zu verstehen 
(Planel et al. 2007, Run et al. 2009, Schmitt et al. 1977). Daher ist es vorstellbar, dass die Hyperphosphorylierung von Tau eine Reaktion der Nervenzelle auf die toxische Einwirkung von $\beta$-Amyloid ist und so die $\beta$-Amyloidaggregation der Neurofibrillenbildung vorausgeht (Vgl. Kapitel 1.3.8).

Kritikpunkte ergeben sich aufgrund der Tatsachen, dass 1.) während des normalen Alterns sich reichlich $\beta$-Amyloid und keine Neurofibrillen ansammeln,

2.) unterschiedliche histopathologische AD-Formen existieren, zwischen denen das Verhältnis von Plaques zu Neurofibrillen variiert, und 3.) andere neurodegenerative Demenzerkrankungen wie Morbus Pick, Kortikobasale Degeneration und Progressive Supranukleäre Blickparese gleiche Tau-Pathologie bei fehlenden $\beta$-Amyloidablagerungen aufweisen (Run et al. 2009). Die Bedeutung der Tau-Pathologie für die Entwicklung der Erkrankung wird auch daran deutlich, dass die Last an Neurofibrillen gut mit dem kognitiven Defizit korreliert und der Verdacht auf AD sogar durch Bestimmung von phosphoryliertem Tau aus dem Liquor bei Patienten mit kognitiven Defiziten erhärtet werden kann (Mattsson et al. 2009). Abbildungen 3B, 3C und 3E zeigen beispielhaft das histologische Erscheinungsbild von Neurofibrillen.

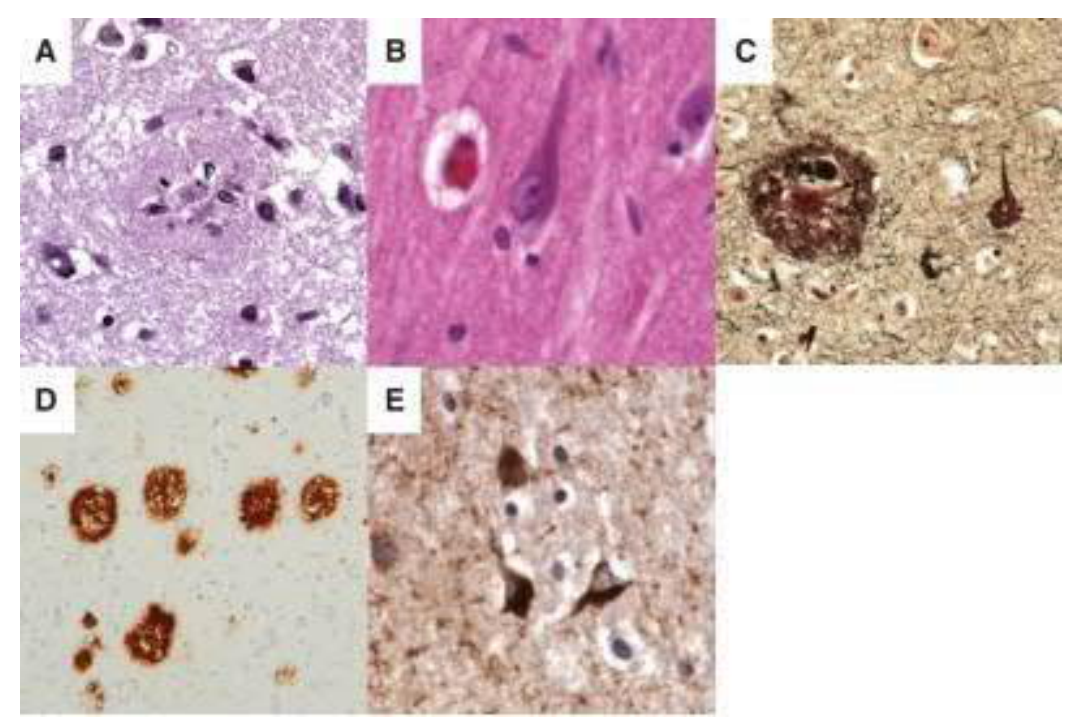

Abb. 3: Histopathologische Merkmale der Alzheimer-Erkrankung.

A: Plaque in HE-Färbung

B: Neurofibrillen in einer hippocampalen Pyramidenzelle, in HE-Färbung

C: Silberfärbung zeigt Plaque und Neurofibrillen

$D$ : Immunhistochemische Darstellung von $A \beta$ in Plaques

E: Immunhistochemische Darstellung von Neurofibrillen

Modifiziert nach Serrano-Pozo (Serrano-Pozo et al. 2011)

Mit freundlicher Genehmigung von Cold Spring Harbor Laboratory Press. 


\subsubsection{Neuronenverlust}

Die in den vorangegangenen Kapiteln dargestellten pathophysiologischen Prozesse der AD führen zu einem Verlust von Nervenzellen, der sich makroskopisch als Gehirnatrophie darstellen kann. Der Grad der Atrophie kann interindividuell deutlich unterschiedlich ausfallen und zwischen makroskopisch unsichtbarer Atrophie und deutlichem Parenchymschwund liegen (s. Abbildung 4). Die so genannte äußere Atrophie der Hirnrinde wird erkennbar an der Verschmälerung der Gyri und Erweiterung der Sulci, die am deutlichsten am medialen Temporallappen, in dem der Hippocampus liegt, zu erkennen ist. Anhand der Erweiterung der Liquorräume wird die zu beobachtende innere Gehirnatrophie deutlich (Wallesch und Förstl 2005). Ein starker Verlust von Neuronen in bestimmten Hirnarealen mit kognitiven Funktionen ist bereits in frühen Krankheitsstadien der AD histopathologisch nachweisbar (Gomez-Isla et al. 1996). Mittels Magnetresonanztomographie kann auch in vivo ein Volumenverlust dieser Hirnareale festgestellt werden. So sind in diesem Bildgebungsverfahren Hippocampus, Gyrus Hippocampalis und temporaler Neokortex sowie entorhinaler Kortex, der die Verbindungsstruktur zwischen Hippocampus und den Assoziationszentren des Neokortex darstellt, bei AD-Patienten im Vergleich zu gesunden Patienten signifikant in ihrem Volumen vermindert (Bobinski

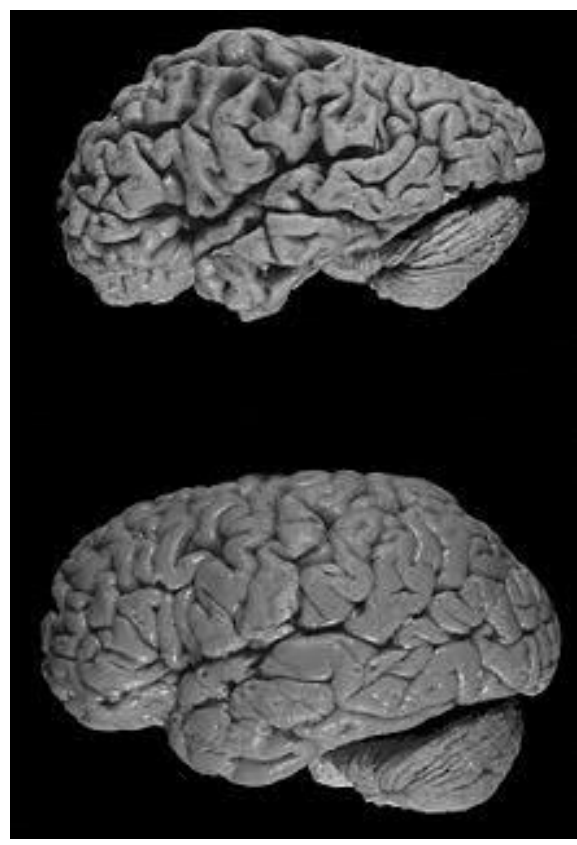

Abb. 4: Hirnatrophie. Oben: Gehirn eines Alzheimer-Patienten. Unten: Gehirn eines gesunden Menschen. http://commons.wikimedia.org/wiki/ File:AD_versus_CO.jpg.

(03.11.2013) et al. 1999, Detoledo-Morrell et al. 1997). Lange Zeit wurde angenommen, dass die physiologische Hirnalterung zwangsläufig von einem Neuronenverlust im Neokortex und Hippocampus begleitet wird. Studien zeigen jedoch, dass der Untergang von Neuronen während des normalen Alterungsprozesses limitiert ist und daher als Ursache der altersbedingten Beeinträchtigung der neokortikalen und hippocampalen Funktionen nicht wahrscheinlich erscheint (Morrison und Hof 1997). 


\subsubsection{Acetylcholinmangel}

Der Nucleus basalis Meynert, gelegen im basalen Vorderhirn, ist einer der wichtigsten Acetylcholin produzierenden Kerne. Efferenzen ziehen vom Nucleus basalis u.a. in den Hippocampus und zur Amygdala im Temporallappen sowie in den Neokortex und sind einbezogen in kognitive Funktionen wie Gedächtnisbildung, Aufmerksamkeit und Wahrnehmung (Gratwicke et al. 2013, Kitt et al. 1987). Ein Verlust an cholinergen Neuronen in der Region den Nucleus basalis bei Patientin mit AD wurde bereits in den frühen $80 \mathrm{er}$ Jahren beschrieben. Eine Degeneration und damit einen Zelluntergang findet man bei $70-75 \%$ der cholinergen Zellen des Nucleus basalis in AD-Patienten (Arendt et al. 1983, Whitehouse et al. 1982). Passend dazu konnte eine gesteigerte Expression von APP in den Neuronen des Nucleus basalis nachgewiesen werden, welche mit Progression der Erkrankung zunimmt. Gleichzeitig kommt es in den Zellen zu einer vermehrten Bildung von Neurofibrillen (Murphy et al. 1992).

Der aus dem Zellverlust resultierende Acetylcholinmangel führt $z u$ einer Beeinträchtigung der oben genannten Funktionen. Das cholinerge System wird daher als therapeutischer Ansatzpunkt genutzt. Acetylcholinesterasehemmer binden reversibel an die Acetylcholinesterase, das für die hydrolytische Spaltung von Acetylcholin zu Cholin und Acetat verantwortliche Enzym. Durch die Bindung kommt es zu einer Inaktivierung des Enzyms und somit zu einem verringerten Abbau von Acetylcholin im synaptischen Spalt. Donepezil, Galantamin und Rivastigmin sind die wichtigsten Vertreter dieser Medikamentengruppe und kommen vor allem bei milden bis moderaten Formen der AD zum Einsatz (Winslow et al. 2011).

\subsubsection{Atrophie von Hippocampus und Thalamus}

Der Hippocampus ist eine für die Gedächtniskonsolidierung wichtige Struktur im Temporallappen. Histologisch wird er in den Gyrus dentatus und ins Ammonshorn (Cornu Ammonis, CA) unterteilt (s. Abbildung 5). Letzteres wiederum besteht aus vier Untereinheiten: CA1, CA2, CA3 und CA4 (Taupin 2007). 


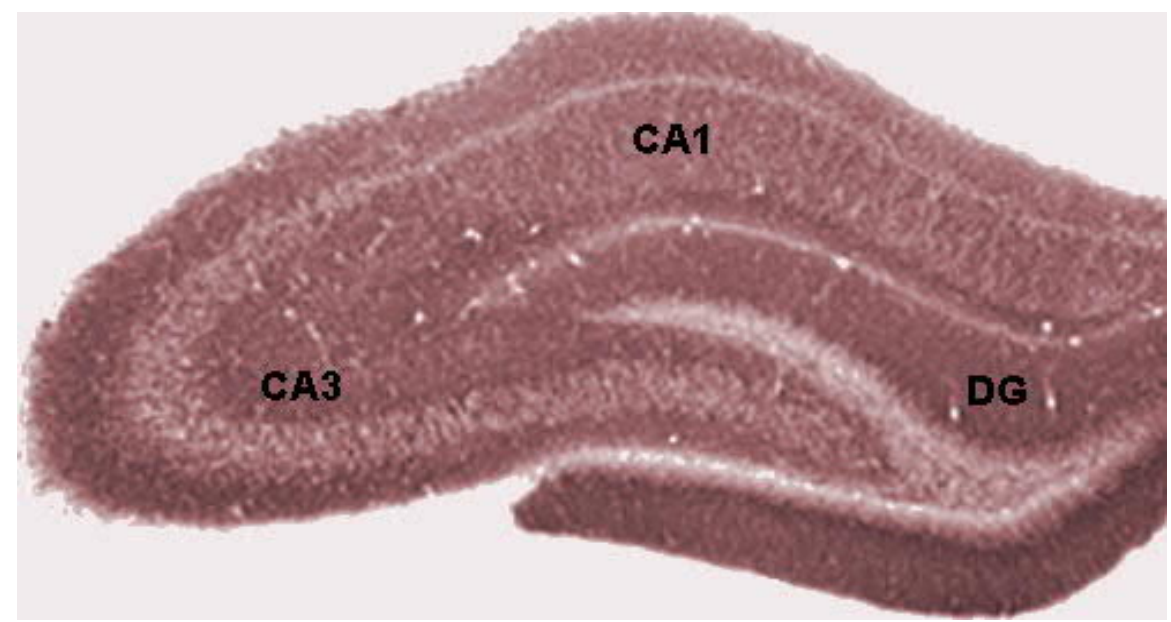

Abb. 5: Histologischer Schnitt des Hippocampus. DG: Gyrus dentatus. CA1: Unterregion 1 des Corpus ammonis (CA), CA3: Unterregion 3 des Corpus ammonis. http://commons.wikimedia.org/wiki/File:HippocampalRegions.jpg (03.11.2013)

Kernspintomographisch konnte ein verringertes Volumen des Hippocampus bei Patienten mit $\mathrm{MCl}$ und Alzheimer nachgewiesen werden, so dass man heutzutage davon ausgeht, dass diese Gehirnstruktur eine der Regionen ist, die besonders früh im Verlauf der Erkrankung betroffen zu sein scheint. Dabei hat bei Patienten mit $\mathrm{MCl}$ die hippocampale Atrophie die stärkste Vorhersagekraft für eine Progression der Erkrankung in eine AD (Henneman et al. 2009).

Ein signifikante Abnahme der Neuronendichte im Hippocampus bei AlzheimerPatienten ist besonders prominent in der dem Subiculum anliegenden, hippocampalen Region CA1 (Padurariu et al. 2012).

Nicht nur die Großhirnrinde und der Hippocampus sind bei Patientin mit einer AD von der Atrophie betroffen. Neuere Studien zeigen, dass auch tiefer liegende graue Substanz von der Atrophie betroffen sein kann. In MRT-Studien wurden bei Patienten mit einer $A D$ signifikant reduzierte Volumina des Thalamus, verglichen zur Kontrollgruppe, nachgewiesen. Des Weiteren konnte gezeigt werden, dass das Ausmaß des verringerten Thalamusvolumens linear korrelierte mit der Einschränkung der kognitiven Leistungsfähigkeit (de Jong et al. 2008). Der Thalamus ist u.a. entscheidend an der Generierung von Aufmerksamkeit beteiligt und wichtig für ein funktionierendes deklaratives Gedächtnis (Newman 1995, Van der Werf et al. 2000). In der vorliegenden Arbeit wurde der Schwerpunkt auf die CA1-Region des Hippocampus und den Thalamus gelegt. 


\subsubsection{Die $\beta$-Amyloid-Kaskaden-Hypothese und ihre Modifizierung}

Ein anschauliches Konzept zur Verbildlichung der A $\beta$-Pathologie liefert die von Hardy und Allsop erarbeitete Kaskaden-Hypothese (s. Abbildung 6). Sie verkettet den durch Mutationen oder äußere Einwirkungen veränderten APP-Metabolismus über die A $\beta$ Ablagerung mit der Plaque- und Neurofibrillenbildung, die durch die neuronale Schädigung die Demenz-symptomatik hervorruft (Hardy und Allsop 1991).

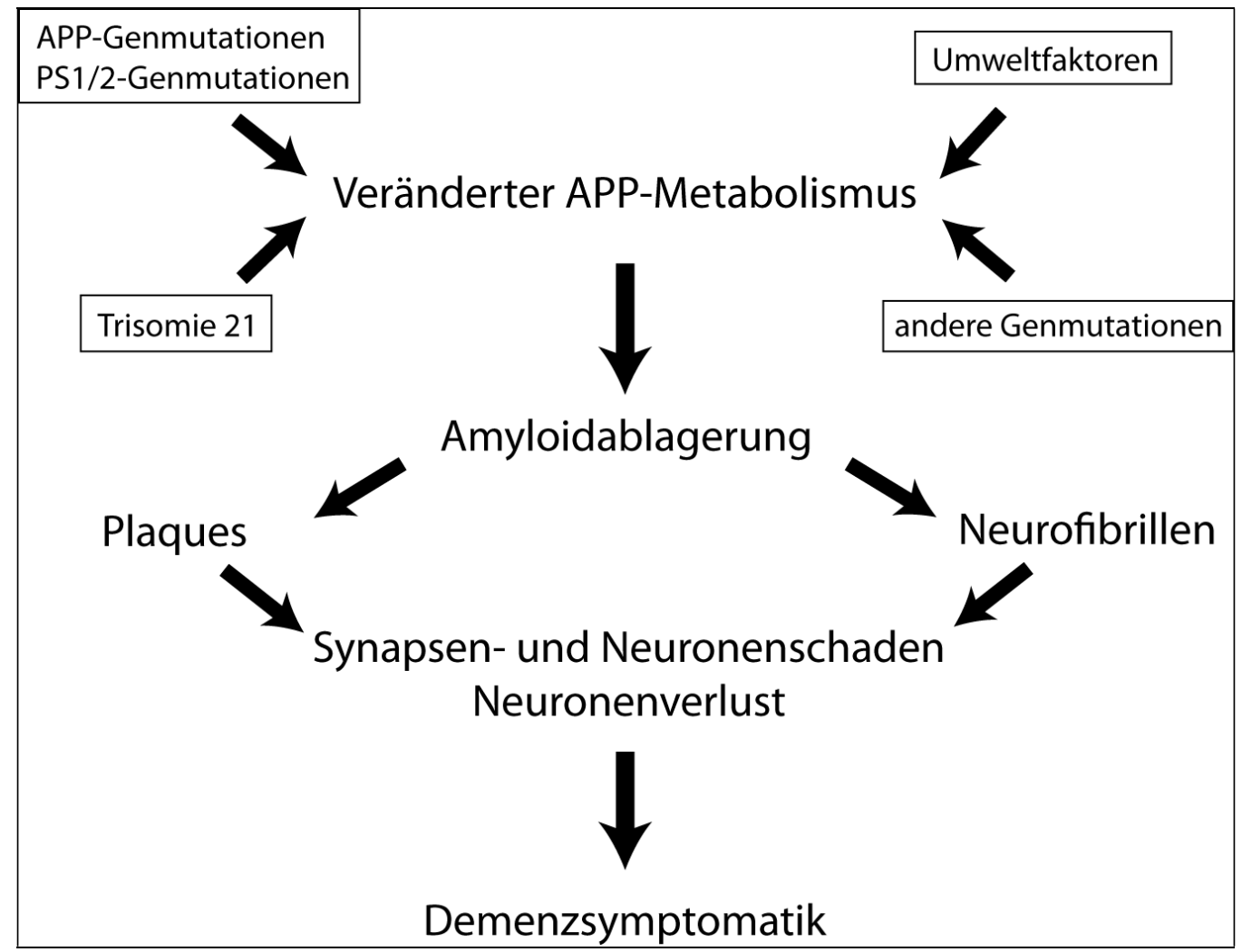

Abb. 6: Die $\beta$-Amyloid-Kaskaden-Hypothese modifiziert nach Hardy und Allsop (Hardy und Allsop 1991).

Diese Kaskaden-Hypothese lässt sich durch die Erweiterung mit jüngeren Erkenntnissen so modifizieren, dass die unter Kapitel 1.3.5 beschriebene intrazelluläre neurotoxische Wirkung von $A \beta$ in die Hypothese einfließt. Wirths und Kollegen taten dies, um die Hypothese mit jüngeren Erkenntnissen zu erweitern und den Einfluss des intraneuronalen $A \beta$ auf die Pathogenese zu unterstreichen (Wirths et al. 2004).

Folgende Erkenntnisse integrieren Wirths und Kollegen in die Kaskaden-Hypothese von Hardy und Allsop:

$A \beta$ wird bereits intrazellulär abgelagert, bevor es sezerniert wird (Masters et al. 1985). Auch sind intrazelluläre $A \beta$-Ablagerungen noch vor der Entstehung von Neurofibrillen nachweisbar (Fernandez-Vizarra et al. 2004). Im Verhältnis zu Aß40 lässt sich in 
Nervenzellkulturen intrazellulär mehr A 342 nachweisen als extrazellulär (Turner et al. 1996). Außerdem ist die Konzentration von Aß42 im AD-Mausmodell deutlich erhöht (Takeda et al. 2004). Da in vivo die intrazelluläre Aß42-Erhöhung einen verstärkten Neuronenverlust nach sich zieht (LaFerla et al. 1995), liegt die also Vermutung nahe, dass eine verstärkte Neurotoxizität von der bei der $A D$ vorliegenden intrazellulären $A \beta 42-E r h o ̈ h u n g$ ausgeht. Das intrazelluläre $A \beta$ wird also als Substrat des pathophysiologischen Prozesses definiert.

Den extrazellulären Plaques wird die Funktion eines Reservoirs für extrazelluläres $A \beta$, das in die Nervenzellen wiederaufgenommen werden kann, zugeschrieben (Wirths et al. 2004). Abbildung 7 stellt die modifizierte Amyloid-Kaskaden-Hypothese dar.

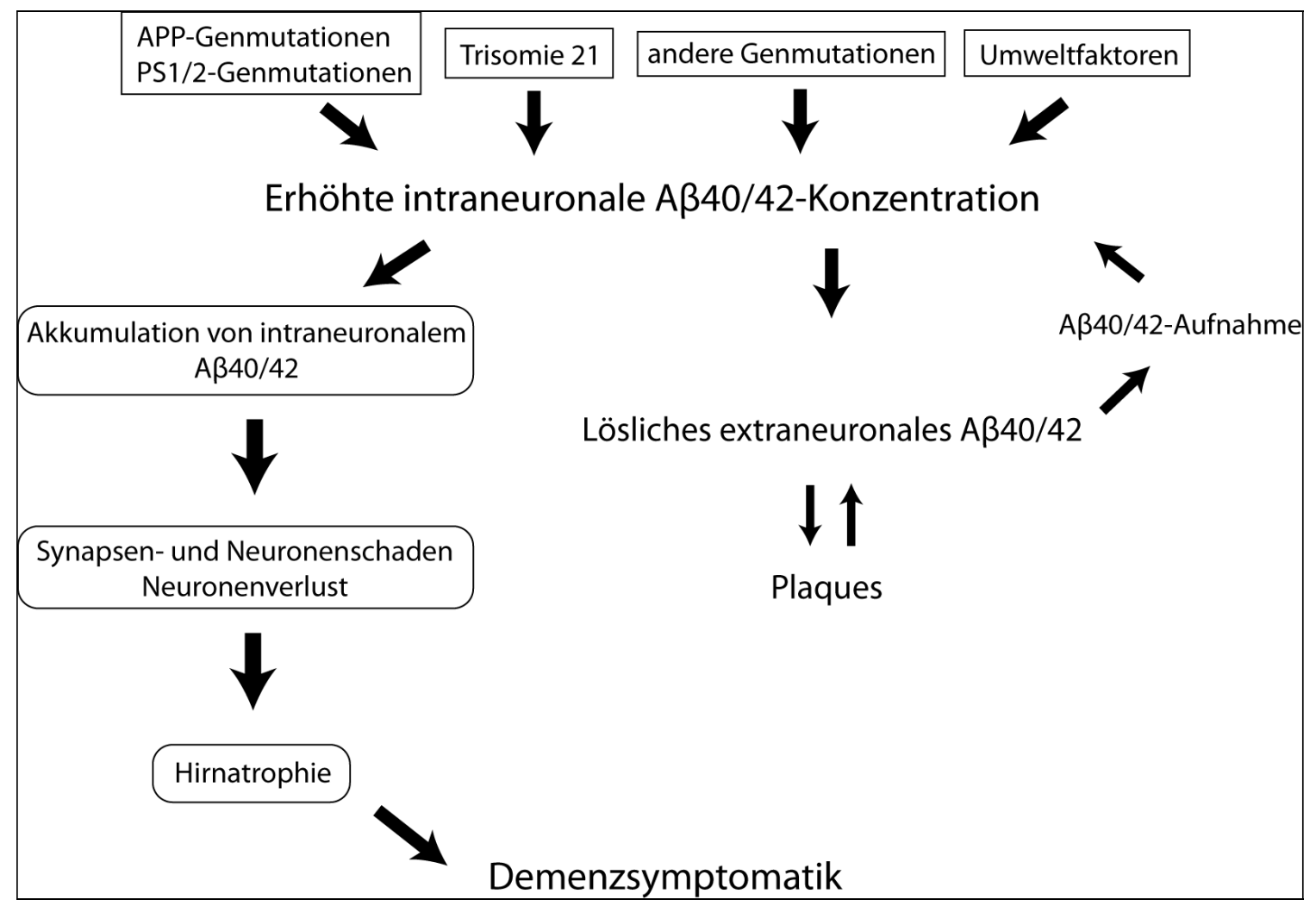

Abb. 7: Die modifizierte $\beta$-Amyloid-Kaskaden-Hypothese nach Wirths (Wirths et al. 2004).

\subsubsection{Inflammatorische und immunologische Reaktionen}

Die Vielschichtigkeit der Alzheimerpathologie wird besonders deutlich durch Studien, die neben oben genannten Faktoren auch immunologische und inflammatorische Prozesse beteiligt sehen. Wie weiter oben beschrieben, hat die Ablagerung von $A \beta$ im Hirngewebe eine toxische Wirkung zur Folge. Diese ruft eine inflammatorische 
Reaktion auf mehreren Ebenen hervor: So konnte eine Aktivierung der Mikroglia und Astrozyten als Zeichen der zellvermittelten Immunabwehr nachgewiesen werden (Luber-Narod und Rogers 1988, Sofroniew und Vinters 2010). Auch molekulare Mediatoren in Form des Komplementsystems sind an der Entzündungsreaktion beteiligt. $\beta$-Amyloid, ist in der Lage, über eine Bindung an eine spezifische Domäne des ersten Komplementfaktors $\mathrm{C} 1$ den klassischen Komplementweg zu aktivieren, wodurch es zur Bildung des Membranangriffskomplex kommt und zu einer Zerstörung der umliegenden Neuronen (Jiang et al. 1994, McGeer et al. 1989, Rogers et al. 1992). Letztlich bleibt unklar, inwiefern diese Prozesse als Reaktion oder als Auslöser der Pathologie anzusehen sind.

\subsection{Zielsetzung und Arbeitshypothese}

Das Ziel dieser Arbeit ist es, anhand eines Mausmodells der Alzheimer-Erkrankung, das genetisch so modifiziert wurde, dass die pathophysiologischen Prozesse der AD beschleunigt und verstärkt ablaufen, einen Einfluss von Geschlecht und genetischem Hintergrund auf die Ausprägung der Erkrankung auf histopathologischer Ebene nachzuweisen und diesen Nachweis anhand zweier für Kognition und Regulation wichtiger Hirnregionen, Hippocampus und Thalamus, zu führen.

Das 5xFAD-Mausmodell trägt fünf Mutationen, die als mitverantwortlich für die Entwicklung der familiären Alzheimer-Erkrankung gesehen werden und zeigt eine rasche Entwicklung der AD-typischen $\beta$-Amyloidablagerungen im Mausgehirn. Es wurde von Oakley und Kollegen auf Grundlage vorbestehender Mausmodelle entwickelt, die weniger Mutationen enthielten und einen langsameren Progress der Histopathologie aufwiesen. Anhand des 5xFAD-Mausmodells soll ein von Oakley et al. nachgewiesener Einfluss des Geschlechtes auf die $\beta$-Amyloidbelastung mittels Plaqueloadbestimmung verifiziert werden. Zudem soll durch stereologische Neuronenzählung ein Neuronenverlust, wie er für die AD typisch ist, objektiviert werden. Die gewonnenen Erkenntnisse werden ebenfalls in Bezug zu zwei genetischen Hintergründen der Mäuse gesetzt. 


\section{Material und Methoden}

\subsection{Das transgene Mausmodell 5xFAD}

Zur Untersuchung der AD können verschiedene Mausmodelle genutzt werden, die unterschiedliche Mutationen bzw. Kombinationen verschiedener Mutationen aufweisen. In dieser Arbeit wurde das von Oakley und Kollegen beschriebene Mausmodell 5xFAD verwendet. Dieses Mausmodell zeichnet sich durch eine schnelle und massive Anreicherung von $A \beta 42$ in bereits jungem Lebensalter der Tiere aus. Ein additiver Effekt der insgesamt fünf Mutationen, drei davon im APP-Gen und zwei im PS1-Gen, wird hierfür verantwortlich gemacht (Oakley et al. 2006). Da die Tiere ebenfalls bereits in jungem Alter Verhaltensänderungen zeigen, die der Symptomatik der AD entsprechen, eignen sie sich gut als Modell für die Alzheimerpathologie.

Das Mausmodell 5xFAD zeigt eine Überexpression der aus 695 Aminosäuren bestehenden APP-Isoform. Zu den drei APP-Mutationen gehören die schwedische (K670N/M671L)-, die Florida (I716V)- und die London (V717I)-Mutation, die Mutationen im PS1-Gen sind die M146L- und L286V-Mutationen (s. Abbildung 8A).

In dieser Arbeit wurde die Mauslinie Tg6799 zum Vergleich genommen, da sie die höchste Expression an APP hat (s. Abbildung 8B). Die schwedische Mutation erhöht die Produktion des gesamten $A \beta$, die Florida- und London- sowie die beiden PS1Mutationen (M146L und L286V) führen dagegen zu einer spezifischen Zunahme des A 4 42-Amyloids. Vor beide Transgene ist der neuronenspezifische Mauspromotor Thy1 gesetzt, um eine Überexpression zu forcieren (Moechars et al. 1996, Oakley et al. 2006, Selkoe 2001, Sisodia et al. 1999). 


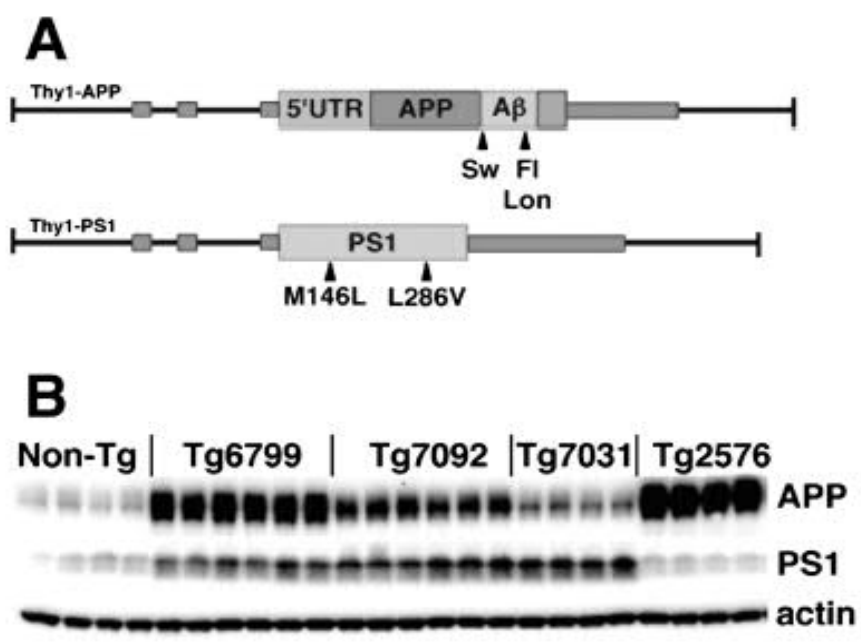

Abb. 8: A: Schematische Darstellung des APP-Gens mit Swedish- (sw), Florida- (FI), London-Mutation (Lon) und des PS1-Gens. B: Immunoblot-Analyse der APP- und PS1-Expression der Tg6799-, Tg7092-, Tg7031-Linien des 5xFAD-Mausmodells sowie der Tg2576-Linie (Swedish-Mutation) und einer Non-transgenen-Linie (Non-Tg). Aktin als Positivkontrolle (Oakley et al 2006). Mit freundlicher Genehmigung von Society for Neuroscience.

Eine der drei transgenen 5xFAD-Mauslinien ist in dieser Arbeit auf dem hemizygoten B6/SJL-F1-Hybrid-Hintergrund und zwei weitere 5xFAD-Mauslinien sind auf dem genetischen B6-Hintergrund gezüchtet (bestellt von Taconic Farms, Germantown, NY). Oakley und Kollegen haben bei dem transgenen Mausmodell auf dem Hintergrund B6/SJL eine massive Akkumulation von $A \beta 42$ beginnend schon im jungen Alter von anderthalb Monaten gefunden und eine deutlich höhere A $342-$ als $A \beta 40$-Produktion. Diesen Ergebnissen folgend, fanden sich bereits im Alter von zwei Monaten die ersten Amyloid-Plaques, also kurz nach dem ersten Nachweis von Aß42-Peptid. Auch intraneuronale $A \beta$-Ablagerungen manifestierten sich bevor sich Amyloid-Plaques gebildet haben, womit die Hypothese unterstützt wird, dass intraneuronale $A \beta-$ Ablagerungen zum Zelluntergang und Plaqueformation führen (inside-out process). Im Alter von vier Monaten äußern die Mäuse im hippocampusabhängigen räumlichen Arbeitsgedächtnis im Vergleich zu einer gesunden Population Defizite (sogenanntes $Y$ Maze = Y-Labyrinth). Ebenso haben die Mäuse im Morris-Water-Maze (MorrisWasserlabyrinth) Defizite im Alter von vier bis fünf Monaten im Bereich Gedächtnis und Konditionierung demonstriert (Oakley et al. 2006). 


\subsection{Mäusepopulationen}

Es wurden insgesamt 14 Mäuse mit je sechs Monaten stereologisch untersucht, wovon 13 der Bestimmung der $A \beta$-Belastung zur Verfügung standen. Alle Tiere trugen die 5xFAD-Mutationen, jedoch unterschieden sie sich in Geschlecht und/oder genetischem Hintergrund. Die Tiere wurden in drei Gruppen aufgeteilt: je eine weibliche und männliche Gruppe des B6-Hintergrundes und eine männliche des B6/SJLHintergrundes. Die getroffene Auswahl der Mäusepopulationen ermöglichte es, im 5xFAD-Mausmodell einen Einfluss von Geschlecht und genetischem Hintergrund auf die Ergebnisse der stereologischen Untersuchung und der $A \beta$-Belastungsbestimmung zu prüfen.

Die Handhabung aller untersuchten Tiere geschah gemäß den deutschen Richtlinien für Tierschutz. Die Ermittlung des transgenen Status der Mäuse erfolgte mittels PCR aus einer Ohrbiopsie.

\subsection{Perfusion der Mäuse}

Nach Betäubung mittels eines Narkotikums wurden die Mäuse transkardial mit ca. 5-10 $\mathrm{ml}$ eiskaltem 0,01 M PBS (phosphate buffered saline) perfundiert. Über dieselbe Kanüle wurde 5-10 ml 4\%iges Paraformaldehyd, in PBS gelöst, eingeleitet, bis die Maus fixiert war. Der Kopf wurde dann in der atlanto-axialen Verbindung mit einem Schnitt abgetrennt. Nach Öffnung des Schädels in anteriorer Richtung und behutsamer Öffnung der Schädeldecke wurde das Gehirn entnommen. Daraufhin wurden die Hirnhälften entlang der Mittellinie voneinander getrennt. Jede linke Gehirnhälfte wurde anschließend zwei Stunden bei $4{ }^{\circ} \mathrm{C}$ in Paraformaldehyd inkubiert und daraufhin über Nacht bei $4{ }^{\circ} \mathrm{C}$ in einer 30\%igen Saccharoselösung gelagert. Am folgenden Tag wurden die linken Gehirnhälften bis zur weiteren Verwendung bei $-80^{\circ} \mathrm{C}$ eingefroren. Jede rechte Gehirnhälfte wurde sofort nach Entnahme auf Trockeneis eingefroren und bei $-80^{\circ} \mathrm{C}$ gelagert.

\subsection{Anfertigung der histologischen Schnitte}

Mindestens 24 Stunden vor der weiteren Bearbeitung wurde die jeweils bei $-80{ }^{\circ} \mathrm{C}$ eingefrorene linke Gehirnhälfte bei $-20^{\circ} \mathrm{C}$ gelagert. Um eine Standfläche zu schaffen, wurde das Kleinhirn in koronarer Ebene abgetrennt. Zum Schneiden wurde die 
Gehirnhälfte mit der so entstandenen Schnittfläche auf den auf $-20{ }^{\circ} \mathrm{C}$ vorgekühlten Schneideblock des Kryostats (Microtom-Kryostat MICROM HM550) gestellt. Dort wurde das Gehirn mit einem Gewebekleber fixiert (Tissue-Tek® O.C.T. TM Compound SAKURA Finetek Europe B.V.) und mit selbigem pyramidenförmig umhüllt. Schnitte mit einer Dicke von $30 \mu \mathrm{m}$ bei einem Schnittwinkel von $12^{\circ}$ wurden angefertigt und als 10er Serien erzeugt. Jeder Schnitt wurde der Reihe nach in einem von zehn Gefäßen (Straight-Side Wide-Mouth Jar PC, Size 15ml, Nalge Nunc International) untergebracht, so dass in jedem Gefäß Gehirnschnitte mit einem Abstand von $300 \mu \mathrm{m}$ gesammelt wurden. Danach wurden alle Gefäße bei $-80^{\circ} \mathrm{C}$ gelagert.

\subsection{Cresylviolett-Färbung (Nissl-Färbung)}

Die free-floating Methode wurde genutzt, um mit eiskaltem PBS die Gefäße zu spülen. Dazu wurde pro Maus immer das gleiche Gefäß ausgewählt. Auf elektrostatischen Objektträgern (SuperfrostPlus, $25 \times 75 \times 1,0 \mathrm{~mm}$, Menzel $\mathrm{GmbH}$ \& Co KG, Braunschweig) wurden die Schnitte sortiert. Es folgte eine zweistündige Trocknungsphase bei Raumtemperaturen. Im Anschluss erfolgte die Färbung der Schnitte entsprechend der nachstehenden Färbeanleitung mit Cresylviolett.

\section{Färbeanleitung:}

\section{1) Puffer:}

1A (Stocklösung): $1 \mathrm{M}$ Natriumacetat (136,08 g Na-Acetat-Trihydrat in 1 Liter Milli-Q) 1B (Arbeitslösung): $40 \mathrm{ml} 1 \mathrm{M}$ Natriumacetat $(1 \mathrm{~A})+9,6 \mathrm{ml}$ konzentrierte Essigsäure, auffüllen auf 1 Liter mit Milli-Q.

\section{2) Färbelösung (am Vortag herstellen):}

$0,1 \mathrm{~g}$ Cresylviolett in 1 Liter der Lösung 1B lösen

30 min rühren

über Nacht stehen lassen

kurz vor Gebrauch filtern

\section{3) Entfettungslösung:}

3A (Stocklösung): 2 \%ige Triton X-100 (980 ml Milli-Q + 20 ml Triton X-100) ungefähr 1 Stunde rühren (lange haltbar)

3B (Arbeitslösung): 2,5 ml 3A + $50 \mathrm{ml}$ Milli-Q $+150 \mathrm{ml} 100 \%$ Ethanol 


\section{Färbeprotokoll:}

1.) $2 \times 10$ min in $1 \mathrm{~B}$ (2 verschiedene Küvetten)

2.) $20 \mathrm{~min}$ in $3 \mathrm{~B}$

3.) $2 \times 10$ min in $1 \mathrm{~B}$ (2 verschieden Küvetten)

4.) $2 \times 8$ min in 2 (2 verschiedene Küvetten)

5.) $3 \times 1 \mathrm{~min}$ in 1B (3 verschiedene Küvetten)

6.) $3 \mathrm{~min}$ in $100 \%$ Ethanol

7.) $1 \times 10 \mathrm{~min}$ in Isopropanol (=2-Propanol)

8.) $2 \times 5$ min in Xylol

9.) mit Corbit-Balsam einschließen und über Nacht trocknen lassen

\subsection{Stereologische Untersuchung}

Für die stereologische Untersuchung wurden die, wie in Kapitel 2.4 und 2.5 beschrieben, mit Cresylviolett angefärbten $30 \mu \mathrm{m}$ dicken histologischen Schnitte verwendet. Innerhalb der Schnitte wurden die Flächen des CA1-Hippocampus und des Thalamus anhand des Mäusebildatlas von Paxinos und Franklin bestimmt. Für den CA1-Hippocampus wurde die Region von $-1,22 \mathrm{~mm}$ bis $-3,80 \mathrm{~mm}$ und für den Thalamus die Region von $-0,94 \mathrm{~mm}$ bis $-2,54 \mathrm{~mm}$ relativ zur Bregma-Linie festgelegt (s. Abbildung 9) (Paxinos et al. 2001). 


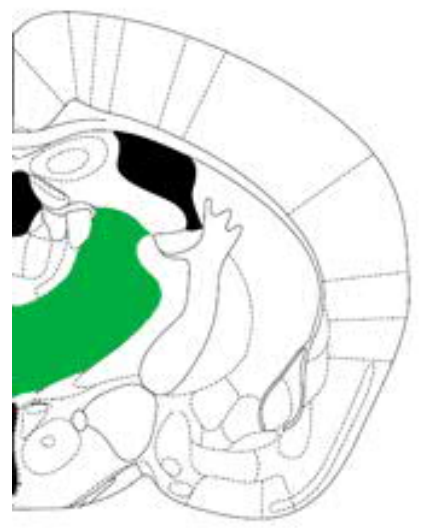

A

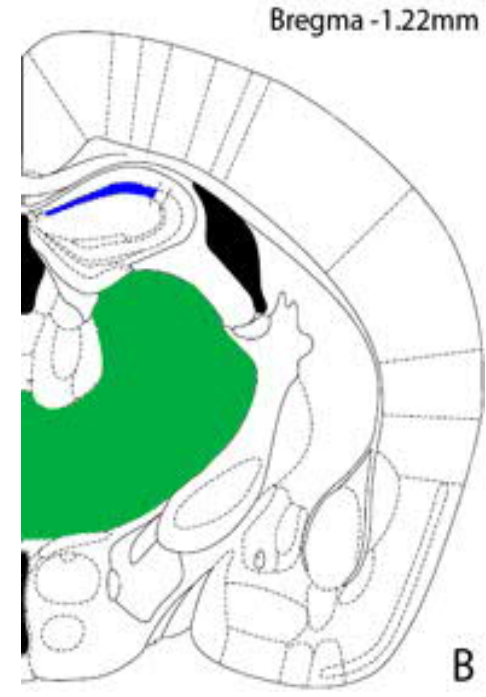

Bregma $-2.54 \mathrm{~mm}$

Bregma $-3.80 \mathrm{~mm}$
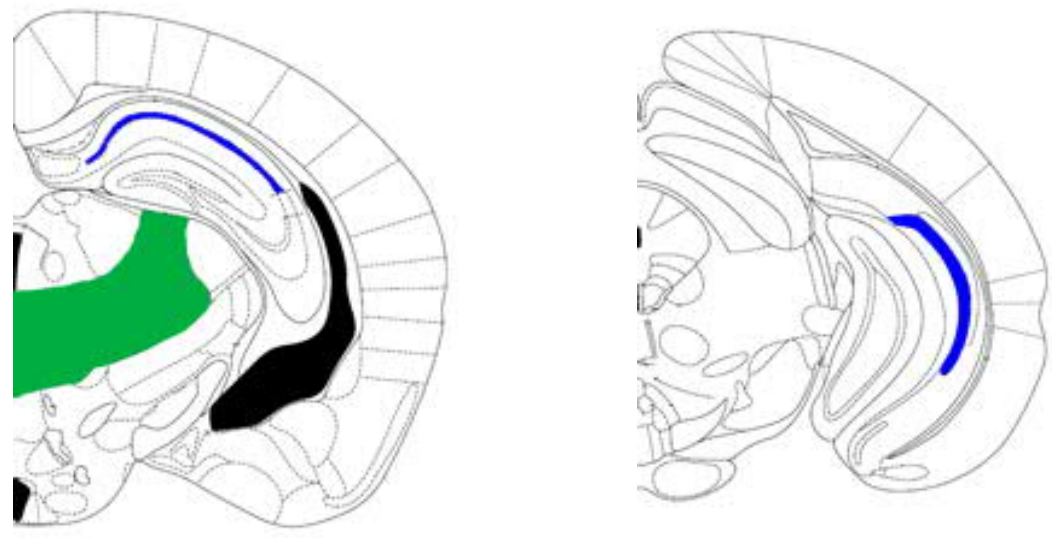

C

D

Abb. 9: Schematische Darstellung der untersuchten Hirnabschnitte: CA1-Hippocampus in blau, Thalamus in grün, Ventrikel in schwarz. Als Orientierung dient der Abstand zur Bregma-Linie in Millimetern. Beginn des Thalamusabschnittes bei Bregma $-0.94 m m(A)$, Ende bei Bregma -2.54mm (C). Beginn des CA1-Hippocampus-Abschnittes bei Bregma $1.22 \mathrm{~mm}(B)$, Ende bei Bregma -3,80mm (D) (Paxinos und Franklin 2001). Mit freundlicher Genehmigung von Elsevier.

Mithilfe des Mikroskops BX51 von Olympus und des Programms Stereoinvestigator 7 (Micro Brightfield) erfolgten die stereologischen Untersuchungen. Zur Ermittlung der Gesamtneuronenzahl und des Volumens jeder Maus wurde die design-basierte Stereologie benutzt. Zur Markierung der zu untersuchenden Regionen des Thalamus und des CA1-Hippocampus wurde eine zehnfache Vergrößerung gewählt, die Neuronen wurden mittels 100facher Vergrößerung ausgezählt. Da, wie bereits in

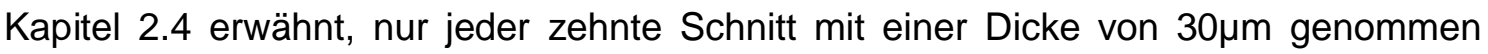
wurde, betrug der Abstand zwischen den einzelnen Stichproben $300 \mu \mathrm{m}$. Das Zählen 
der Neuronen erfolgte nach vorher festgelegten Zählregeln, die im nächsten Kapitel beschrieben sind.

Die eingestellten Parameter im Stereoinvestigator sind in Tabelle 3 aufgeführt:

\begin{tabular}{|c|c|c|}
\hline & CA1-Hippocampus & Thalamus \\
\hline $\begin{array}{l}\text { Counting Frame }(\mathrm{X}) \mathrm{x} \\
(\mathrm{Y})\end{array}$ & $16 \mu \mathrm{m}(\mathrm{X}) \times 16 \mu \mathrm{m}(\mathrm{Y})$ & $\begin{array}{c}40 \mu \mathrm{m}(\mathrm{X}) \times 40 \\
\mu \mathrm{m}(\mathrm{Y})\end{array}$ \\
\hline $\begin{array}{l}\text { Counting Frame Area } \\
(X Y)\end{array}$ & $256 \mu \mathrm{m}$ & $1600 \mu \mathrm{m}$ \\
\hline Disector Height (Z) & $8 \mu \mathrm{m}$ & $6 \mu \mathrm{m}$ \\
\hline Disector Volume (XYZ) & $2048 \mu \mathrm{m}^{3}$ & $9600 \mu \mathrm{m}^{3}$ \\
\hline Sampling Grid (X) & $90 \mu \mathrm{m}$ & $260 \mu \mathrm{m}$ \\
\hline Sampling Grid (Y) & $90 \mu \mathrm{m}$ & $250 \mu \mathrm{m}$ \\
\hline $\begin{array}{l}\text { Sampling Grid Area } \\
(\mathrm{XY})\end{array}$ & $8100 \mu \mathrm{m}^{2}$ & $65000 \mu \mathrm{m}^{2}$ \\
\hline $\begin{array}{l}\text { Distance from section } \\
\text { top to } 3 D \text { counting frame }\end{array}$ & $2,00 \mu \mathrm{m}$ & $2,00 \mu \mathrm{m}$ \\
\hline Section thickness & $30,00 \mu \mathrm{m}$ & $30,00 \mu \mathrm{m}$ \\
\hline Grid Rotation & 0,00 Degrees & 0,00 Degrees \\
\hline Section Periodicity & 10 & 10 \\
\hline Focus method & Manual focus & manual focus \\
\hline $\begin{array}{l}\text { Refocus to top of } \\
\text { section }\end{array}$ & at each grid site & at each grid site \\
\hline $\begin{array}{l}\text { Measure section } \\
\text { thickness }\end{array}$ & at every 10 th grid site & $\begin{array}{c}\text { at every } 10^{\text {th }} \text { grid } \\
\text { site }\end{array}$ \\
\hline Desired sampling sites & 1 & 1 \\
\hline
\end{tabular}

Tabelle 3: Parametereinstellung zur stereologischen Neuronenzählung. 


\subsubsection{Design-basierte Stereologie}

Die design-basierte Stereologie (design-based stereology) ist eine geeignete Methode zur Bestimmung von morphologischen ZNS-Charakteristika, wie z.B. Volumina, Gefäßlängen, Zellzahl sowie der durchschnittlichen Dicke von Zellen und Zellarchitektur. Auf diese Weise trägt die Methode zur Quantifizierung unterschiedlicher ZNS-spezifischer Fragestellungen bei. Die durch die design-basierte Stereologie gewonnenen Ergebnisse stehen repräsentativ für die gesamte untersuchte Hirnregion und sind unabhängig von der Objektform, der Lage oder der räumlichen Verteilung. Der Vorteil dieser Methode liegt in der Minimierung systematischer Fehler. Das Systematic Random Sampling ist das grundlegende Prinzip der stereologischen Analyse. Dabei handelt es sich um eine systematische Stichprobenerhebung, bei der die Stichproben aus Schnitten mit einem definierten Abstand zueinander erhoben werden. Die Methode der design-basierte Stereologie wurde in einem Review von Schmitz und Hof zusammengefasst (Schmitz und Hof 2005). Die Schnitte, die in dieser Arbeit verwendet wurden, hatten einen Abstand von $300 \mu \mathrm{m}$ zueinander. Das Programm wählt auf den Schnitten entsprechend den Voreinstellungen bestimmte Bereiche, sogenannte counting frames (Zählrahmen), aus, die ausgezählt werden. Die counting frames haben den gleichen Abstand zueinander und sind gleichmäßig auf den Schnitt verteilt. Anhand der errechneten Daten können das Volumen und die Gesamtneuronenzahl für das untersuchte Gehirn bestimmt werden.

Mittels eines Rasters werden die counting frames auf den vorher vom Benutzer festgelegten Bereich des Gehirnschnittes projiziert. Der Zählrahmen besitzt eine X-, Yund Z-Koordinate, der nun entstandene Würfel sechs Seiten. Da Zellfragmente beim Schneiden hängen bleiben können und die Würfel nicht direkt nebeneinander liegen, müssen vorher Zählregeln (counting rules) festgelegt werden, um die Neuronen auszuzählen. Diese Zählregeln definieren genau wann eine Zelle mitgezählt werden darf und wann nicht. Auf diese Weise wird eine Mehrfachzählung von Zellen vermieden. Das Programm würde eine zu hohe Gesamtneuronenzahl für das Gehirn bestimmen, wenn Zellen, die direkt auf einer Linie liegen, auf allen Seiten mitgezählt werden würden. 
Die Zählregeln lauten wie folgt:

1. Nur Nucleoli von Neuronen, die sich innerhalb des Zählrahmens oder an der unteren Grenze des Zählrahmens scharf stellen lassen bzw. diese berühren, werden gezählt. Nicht mitgezählt werden Nucleoli, die sich oberhalb der oberen Grenze scharf stellen lassen bzw. diese berühren.

2. Nucleoli, die im Zählrahmen ausschließende Grenzen (excluding lines) berühren, dürfen nicht mitgezählt werden. Berühren sie jedoch Einschlussgrenzen (including lines) werden sie mitgezählt.

Nachdem alle Neuronen ausgewählt worden sind, folgt der nächste Zählrahmen, bis alle Zählrahmen eines Schnittes und letztlich alle Schnitte einer Maus ausgezählt wurden. Anhand von nachfolgend aufgeführten Formeln, lassen sich die Gesamtneuronenzahl und die Volumina errechnen.

2.6.2 Berechnung der Neuronenzahlen von CA1-Hippocampus und Thalamus

Die Neuronenzahl errechnet sich gemäß der optical fractionator method (West et al. 1991): $\mathbf{N}=$ total markers counted $x$ asf $\mathbf{x}$ ssf $\mathbf{x}$ tsf

asf $=$ sampling grid area $(X Y) /$ counting frame area $(X Y) \rightarrow 175000 \mu \mathrm{m}^{2} / 729 \mu \mathrm{m}^{2} \mathbf{s s f}$ $=10$ (jeder zehnte Schnitt) $\mathbf{t s f}=$ number weighted mean section thickness $/$ disector height $(Z) \rightarrow$ jeweilige aktuelle Schnittdicke in $\mu \mathrm{m} / 6 \mu \mathrm{m}$ total markers counted: ermittelte Neuronenzahl in den Zählrahmen $\mathbf{N}=$ Gesamtneuronenzahl des jeweiligen Areals (CA1-Hippocampus oder Thalamus) einer Hemisphäre. 
2.6.3 Berechnung der Volumina von CA1-Hippocampus und Thalamus

Das Volumen von CA1-Hippocampus und Thalamus wurde mittels der Formel Cavalieri 's Estimator of Morphometric Volume berechnet (Rosen und Harry 1990):

$$
\mathrm{V}_{\mathrm{C}}=\mathrm{d}\left(\sum_{i=1}^{\mathrm{n}}\left(y_{i}\right)\right)-(\mathrm{t}) y_{\max }
$$

$\mathrm{d}=$ Abstand zwischen den analysierten Schnitten $=300 \mu \mathrm{m}$

$\mathrm{y}_{\mathrm{i}}=$ Fläche von Schnitt $\mathrm{i}\left[\mu \mathrm{m}^{2}\right]$

$\mathrm{t}=$ jeweilige Schnittdicke $[\mu \mathrm{m}]$

$\mathrm{y}_{\max }=$ größte gemessene Fläche $\left[\mu \mathrm{m}^{2}\right]$

\subsection{Herstellung von histologischen Schnitten für den Plaqueload und die immunhistochemische Färbung}

Die in Paraffin eingebetteten rechten Hemisphären wurden, wie in Kapitel 2.3 beschrieben, gleich nach der Entnahme auf Trockeneis eingefroren und bei $-80{ }^{\circ} \mathrm{C}$ gelagert. Aus diesen erfolgte die Erzeugung der Schnitte für den Plaqueload. Mittels des Microm HM 335 E wurden die Schnitte mit einem Schnittwinkel von $6^{\circ}$ und einer Dicke von $4 \mu \mathrm{m}$ hergestellt und anschließend auf Objektträger gezogen (SuperfrostPlus, $25 \times 75 \times 1,0 \mathrm{~mm}$, Menzel GmbH \& Co KG, Braunschweig). Über Nacht wurden die Schnitte der 5xFAD-Mäuse bei $37^{\circ} \mathrm{C}$ inkubiert und anschließend mit dem Antikörper 4G8 (Covance), der gegen die Aminosäuren 17-24 des $\beta$-Amyloids gerichtet ist in einer Konzentration von 1:10.000, den N-terminalen Antikörper $A \beta[N]$ (IBL, Hamburg, Germany) in einer Konzentration von 1:500 und dem Antikörper 23850 gegen humanes APP (Gerd Multhaup) in einer Konzentration von 1:500 nach dem Färbeprotokoll im Anhang behandelt (siehe Tabelle im Kap. 6. Anhang Seite 72-73). Zum Visualisieren wurde 3,3-Diaminobenzidin (DAB) genutzt, welches eine bräunliche Färbung hervorruft. Zur Schaffung eines Kontrastes wurde mit Hämatoxylin gegengefärbt. 
2.7.1 Bestimmung des Plaqueload (quantitative $A \beta$-Bestimmung) und intraneuronale $A \beta$ Aggregation

Mittels eines Olympus BX-51 Mikroskops mit einer Olympus DP-50 Kamera wurden Photos von CA1-Hippocampus und Thalamus in vierfacher Vergrößerung gemacht, anhand derer der Plaqueload bestimmt wurde. Die Umwandlung der Bilder in 8-bit schwarzweiß erfolgte mithilfe der Software ImageJ (Version 1.40g, NIH, USA). Die Bilder wurden durch den Einsatz eines Schwarzweiß-Schwellenwertes, wodurch hauptsächlich Plaques und möglichst wenig Hintergrundrauschen angezeigt wurden, ausgewertet. Anschließend wurde der prozentuale Anteil der Anfärbung durch die Antikörper ausgewertet und verglichen.

In Tabelle 4 erfolgt eine Auflistung der verwendeten Mäuse und AntikörperVerdünnungsverhältnisse:

\begin{tabular}{|c|c|c|}
\hline & $4 G 8$ & ABN \\
\hline 5xFAD-B6, weiblich & $1: 500$ & $1: 10000$ \\
\hline $\begin{array}{c}\text { 5xFAD-B6, } \\
\text { männlich }\end{array}$ & $1: 500$ & $1: 10000$ \\
\hline $\begin{array}{c}\text { 5xFAD-B6/SJL, } \\
\text { männlich }\end{array}$ & $1: 500$ & $1: 10000$ \\
\hline
\end{tabular}

Tabelle 4: Auflistung der verwendeten Mauslinien mit jeweiligem Antikörper.

\subsection{Statistik}

Mithilfe der Graph Pad Prism-Software Version 4.03 für Windows (GraphPad Software, San Diego, CA, USA) wurde die statistische Auswertung durchgeführt. Der Plaqueload sowie die stereologischen Untersuchungen erfolgten mittels t-Test. Alle Ergebnisse werden als Mittelwerte \pm Standardabweichung $\zeta$ angeben. Die Signifikanzniveaus der T-tests werden definiert als: ${ }^{* *}=p<0,01 ;{ }^{*}=p<0,05$. 


\section{Ergebnisse}

\subsection{Stereologische Untersuchung}

Anhand einer Design-basierten-Studie wurden vier weibliche und vier männliche Mäuse der 5xFAD-B6-Linie und sechs männliche Mäuse der 5xFAD-B6/SJL-Linie, alle im Alter von sechs Monaten, auf die Gesamtneuronenzahl im Thalamus und Hippocampus untersucht. Weiterhin wurden die Volumina der untersuchten Hirnregionen bestimmt.

\subsubsection{Gesamtneuronenzahl}

\subsubsection{Gesamtneuronenzahl im Hippocampus}

Für die vier weiblichen und vier männlichen Mäuse der 5xFAD-B6-Linie, je sechs Monate alt, zeigten sich im Hippocampus folgende Ergebnisse (s. Tabelle 5):

\begin{tabular}{|c|c|c|} 
& $\begin{array}{c}\text { 5xFAD-B6, weiblich } \\
(\boldsymbol{n}=4)\end{array}$ & $\begin{array}{c}\text { 5xFAD-B6, männlich } \\
(\boldsymbol{n}=4)\end{array}$ \\
\hline Neuronenzahl & 270.769 & 233.144 \\
Hippocampus & 273.304 & 249.803 \\
(CA1) & 259.690 & 201.919 \\
& 141.489 & 236.308 \\
\hline Mittelwert & 236.313 & 230.293 \\
\hline
\end{tabular}

Tabelle 5: Gesamtneuronenzahl des CA1-Hippocampus von je vier weiblichen und männlichen 5xFAD-B6-Mäusen. 
Die Auswertung der sechs männlichen, sechs Monate alten 5xFAD-B6/SJL-Mäuse ergab folgendes (s. Tabelle 6):

\begin{tabular}{|c|c|}
\hline & \\
\hline Seuronenzahl & 178.362 \\
Hippocampus & 201.768 \\
(CA1) & 228.018 \\
& 164.583 \\
& 264.543 \\
& 207.610 \\
\hline Mittelwert & 207.481 \\
\hline
\end{tabular}

Tabelle 6: Gesamtneuronenzahl des CA1-Hippocampus von sechs

männlichen 5xFAD-B6/SJL-Mäusen.

Für die weiblichen 5xFAD-B6-Mäuse ergibt sich eine durchschnittliche Neuronenzahl von 236.313 mit einem Standardfehler von $\sigma(\theta)= \pm 31746$ und für die männlichen 5xFAD-B6-Mäuse eine durchschnittliche Neuronenzahl von 230.293 mit einem Standardfehler von $\sigma(\theta)= \pm 10124$. Die Ergebnisse zeigen keinen signifikanten Unterschied bei $p<0,05$.

Die Auswertung der männlichen 5xFAD-B6/SJL-Mäuse ergibt eine durchschnittliche Neuronenzahl von 207.481 mit einem Standardfehler von $\sigma(\theta)= \pm 14604$. Ein signifikanter Unterschied zu den männlichen 5xFAD-B6-Mäusen zeigt sich bei $p<0,05$ nicht. 


\subsubsection{Gesamtneuronenzahl im Thalamus}

Die Ergebnisse für den Thalamus der vier weiblichen und männlichen 5xFAD-B6Mäuse präsentieren sich wie folgt (s. Tabelle 7):

\begin{tabular}{|c|c|c|}
\hline & $\begin{array}{c}5 \times F A D-B 6, \text { weiblich } \\
\qquad(n=4)\end{array}$ & $\begin{array}{c}\text { 5xFAD-B6, männlich } \\
\qquad(n=4)\end{array}$ \\
\hline $\begin{array}{c}\text { Neuronenzahl } \\
\text { Thalamus }\end{array}$ & $\begin{array}{l}914.489 \\
833.198 \\
589.130 \\
583.213\end{array}$ & $\begin{array}{l}674.375 \\
573.490 \\
568.791 \\
355.063\end{array}$ \\
\hline Mittelwert & 730.008 & 542.930 \\
\hline
\end{tabular}

Tabelle 7: Gesamtneuronenzahl des Thalamus von je vier weiblichen und männlichen 5xFAD-B6-Mäusen.

Die Auswertung des Thalamus der sechs männlichen, sechs Monate alten 5xFADB6/SJL-Mäuse brachte folgendes Ergebnis (s. Tabelle 8):

\begin{tabular}{|c|c|}
\hline & 5xFAD-B6/SJL, männlich $(\boldsymbol{n}=6)$ \\
\hline Neuronenzahl & 507.020 \\
& 540.272 \\
& 465.793 \\
& 783.778 \\
& 651.835 \\
& 664.645 \\
\hline Mittelwert & 602.224 \\
\hline
\end{tabular}

Mäusen. 
Im Thalamus der weiblichen 5xFAD-B6-Mäuse konnte eine durchschnittliche Neuronenzahl von 730.008 mit einem Standardfehler von $\sigma(\theta)= \pm 84694$ festgestellt werden. Die männlichen 5xFAD-B6-Mäuse zeigen mit 542.930 Neuronen und einem Standardfehler von $\sigma(\theta)= \pm 67190$ eine geringere durchschnittliche Neuronenzahl im Thalamus. Der Unterschied ist bei $p<0.05$ nicht signifikant.

Die männlichen 5xFAD-B6/SJL-Mäuse wiesen im Thalamus eine durchschnittliche Neuronenzahl von 602.224 mit einem Standardfehler von $\sigma(\theta)= \pm 48592$ auf. Es gibt keinen signifikanten Unterschied zu den männlichen Mäusen der 5xFAD-B6-Reihe.

\subsubsection{Gesamtvolumina}

Aus der stereologischen Untersuchung von Hippocampus und Thalamus der vier weiblichen und vier männlichen 5xFAD-B6-Mäuse und der sechs 5xFAD-B6/SJLMäuse konnte anhand der unter 2.6.3 beschriebenen Formel (Cavalieri's Estimator of Morphometric Volume) das Volumen der entsprechenden Hirnregionen bestimmt werden.

\subsubsection{Gesamtvolumina im CA1-Hippocampus}

Für die CA1-Region des Hippocampus der vier weiblichen und vier männlichen 5xFADB6-Mäuse (6 Monate) wurden folgende Volumina bestimmt (s. Tabelle 9):

\begin{tabular}{|c|c|c|} 
& $\begin{array}{r}\text { 5xFAD-B6, } \\
\text { weiblich }(\boldsymbol{n}=4)\end{array}$ & $\begin{array}{c}\text { 5xFAD-B6, männlich } \\
(\boldsymbol{n}=4)\end{array}$ \\
\hline Gesamtvolumen & 0,535 & 0,535 \\
CA1 & 0,539 & 0,464 \\
(in $\mathrm{mm}^{3}$ ) & 0,578 & 0,494 \\
& 0,317 & 0,559 \\
\hline Mittelwert & 0,492 & 0,513 \\
\hline
\end{tabular}

Tabelle 9: Gesamtvolumen des CA1-Hippocampus von je vier weiblichen und männlichen 5xFAD-B6-Mäusen. 
Die Auswertung der Volumenbestimmung der CA1-Region des Hippocampus bei den sechs männlichen 5xFAD-B6/SJL-Mäusen zeigte dieses Ergebnis (s. Tabelle 10):

\begin{tabular}{|c|c|}
\hline & 5xFAD-B6/SJL, männlich ( $\mathbf{n}=6)$ \\
\hline Gesamtvolumen & 0,367 \\
CA1 & 0,465 \\
(in $\mathrm{mm}^{3}$ ) & 0,381 \\
& 0,414 \\
& 0,515 \\
& 0,420 \\
\hline Mittelwert & 0,427 \\
\hline Tabelle 10: Gesamtvolumen des CA1-Hippocampus von sechs männlichen 5xFAD- \\
\hline
\end{tabular}

Der Mittelwert des CA1-Volumens der weiblichen 5xFAD-B6-Mäuse beträgt 0,492 mm und hat einen Standardfehler von $\sigma(\theta)= \pm 0,059$. Das CA1-Volumen der männlichen 5xFAD-B6-Mäuse beträgt $0,514 \mathrm{~mm}^{3}$ mit einem Standardfehler von $\sigma(\theta)= \pm 0,021$ $\mathrm{mm}^{3}$. Zwischen den weiblichen und männlichen Mäusen der 5xFAD-B6-Linie gibt es bei $p<0,05$ keinen signifikanten Unterschied.

Die männlichen Mäuse der 5xFAD-B6/SJL-Linie weisen ein mittleres CA1-Volumen von $0,427 \mathrm{~mm}^{3}$ bei einem Standardfehler von $\sigma(\theta)= \pm 0,022 \mathrm{~mm}^{3}$ auf. Es ergibt sich ein signifikanter Unterschied zwischen den männlichen Mäusen der 5xFAD-B6- und der 5xFAD-B6/SJL-Linie mit einem P-Wert von 0,0296 bei $p<0,05$. 


\subsubsection{Gesamtvolumina des Thalamus}

Für die Gesamtvolumina des Thalamus der vier weiblichen und vier männlichen 5xFAD-B6-Mäuse ergeben sich folgende Werte (s. Tabelle 11):

\begin{tabular}{|c|c|c|} 
& $\begin{array}{r}\text { 5xFAD-B6, } \\
\text { weiblich }(\boldsymbol{n}=4)\end{array}$ & $\begin{array}{c}\text { 5xFAD-B6, männlich } \\
(\boldsymbol{n}=4)\end{array}$ \\
\hline Gesamtvolumen & 4,612 & 5,124 \\
Thalamus & 5,124 & 3,979 \\
${\text { (in } \mathrm{mm}^{3} \text { ) }}^{5,145}$ & 3,239 \\
& 4,847 & 3,914 \\
\hline Mittelwert & 4,932 & 4,064 \\
\hline
\end{tabular}

Tabelle 11: Gesamtvolumen des Thalamus bei je vier weiblichen und männlichen 5xFAD-B6-Mäusen.

Die sechs männlichen Mäuse der 5xFAD-B6/SJL-Reihe weisen im Thalamus die folgenden Gesamtvolumenwerte auf (s. Tabelle 12):

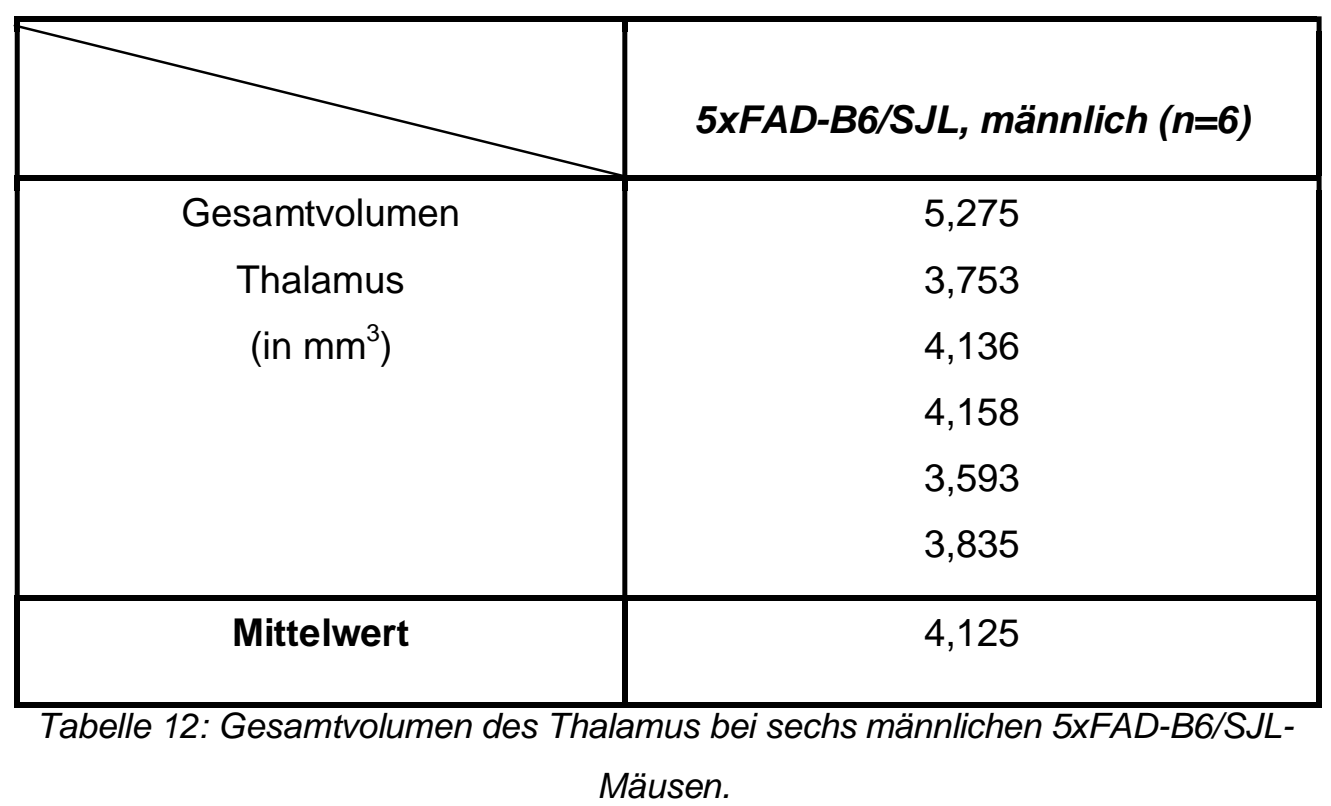

Die Volumenbestimmung des Thalamus ergab für die weiblichen Mäuse der 5xFADB6-Linie ein mittleres Volumen von $4,932 \mathrm{~mm}^{3}$ mit einem Standardfehler von $\sigma(\theta)= \pm$ $0,126 \mathrm{~mm}^{3}$. Die männlichen Mäuse derselben Linie wiesen ein mittleres Thalamusvolumen von $4,064 \mathrm{~mm}^{3}$ mit einem Standardfehler von $\sigma(\theta)= \pm 0,391 \mathrm{~mm}^{3}$ auf. Mit 
einem P-Wert von 0,08 ergibt sich jedoch keine Signifikanz $(p<0,05)$ zu den weiblichen Mäusen der 5xFAD-B6-Linie.

Die männlichen Mäuse der 5xFAD-B6/SJL-Linie zeigen ein mittleres Thalamusvolumen von 4,125 $\mathrm{mm}^{3}$ mit einem Standardfehler von $\sigma(\theta)= \pm 0,247 \mathrm{~mm}^{3}$. Zu den männlichen 5xFAD-B6-Mäusen besteht kein signifikanter Unterschied im Thalamusvolumen.

\subsubsection{Die Stereologiedaten im Vergleich}

Im Folgenden werden die aus dem Stereologieverfahren gewonnenen und in Kapitel 3.1.1 und 3.1.2 dargestellten Daten graphisch miteinander verglichen und die Mittelwerte der zu vergleichenden Gruppen zueinander in Relation gebracht.

Zwischen den weiblichen und männlichen Mäusen der 5xFAD-B6-Reihe ist im CA1Hippocampus ein sehr geringer Unterschied von $3 \%$ in der Neuronenzahl zu Gunsten der weiblichen Mäuse zu finden (s. Abbildung 10). Im Thalamus ist der Unterschied mit 34\% wesentlich ausgeprägter, unterschreitet jedoch mit einem P-Wert von 0,134 nicht die Signifikanzschwelle von $\mathrm{p}<0,05$ (s. Abbildung 11).

Der Vergleich zwischen den genetischen Hintergründen zeigt, dass die männlichen Mäuse der 5xFAD-B6 Reihe im CA1-Hippocampus 11\% mehr Neuronen, im Thalamus jedoch $11 \%$ weniger Neuronen aufweisen als die männlichen 5xFAD-B6/SJL-Mäuse. Die Unterschiede sind jedoch nicht signifikant bei $p=0,286$ für $C A 1$ und 0,483 für Thalamus.

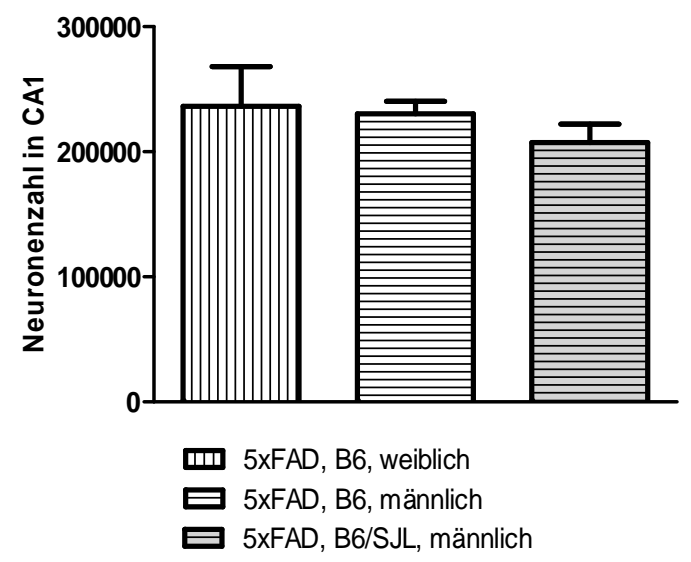

Abb. 10: Vergleich der Neuronenzahlen im CA1Hippocampus von weiblichen und männlichen Mäusen mit 5xFAD-B6-Hintergrund und männlichen Mäusen mit 5xFAD-B6/SJLHintergrund (je sechs Monate alt).

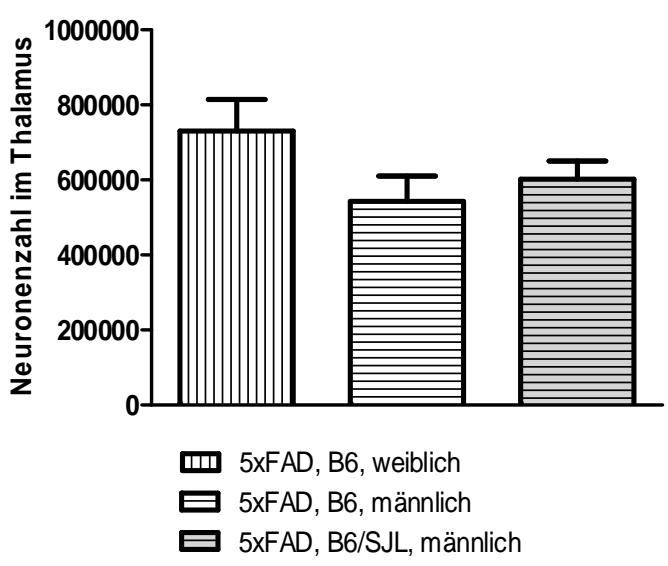

Abb. 11: Vergleich der Neuronenzahlen im Thalamus von weiblichen und männlichen Mäusen mit 5xFAD-B6-Hintergrund und männlichen Mäusen mit 5xFAD-B6/SJLHintergrund (je sechs Monate alt). 
Die weiblichen 5xFAD-B6-Mäuse haben ein 4\% kleineres CA1-Volumen als die männlichen Mäuse derselben Reihe (s. Abbildung 12). Der Unterschied im Thalamusvolumen beträgt $21 \%$, jedoch weisen hier die weiblichen Mäuse das größere Volumen auf. Eine Signifikanz liegt mit $P=0,08$ bei einem Signifikanzniveau von $\mathrm{p}<0,05$ knapp nicht vor (s. Abbildung 13).

Die männlichen 5xFAD-B6-Mäuse haben ein um 20\% größeres CA1-Volumen als die männlichen Mäuse der 5xFAD-B6/SJL-Reihe. Dieser Unterschied ist mit einem P-Wert von 0,03 signifikant $(p<0,05)$ (s. Abbildung 12). Das Thalamusvolumen der männlichen 5xFAD-B6-Mäuse ist 1,5\% geringer als das der männlichen 5xFAD-B6/SJL-Mäuse.

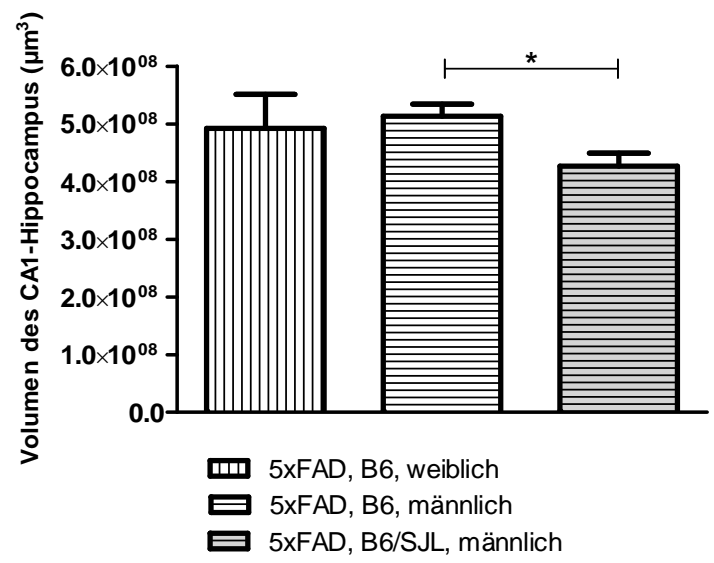

Abb. 12: Vergleich des Volumens des CA1Hippocampus von weiblichen und männlichen Mäusen mit 5xFAD-B6-Hintergrund und männlichen Mäusen mit 5xFAD-B6/SJLHintergrund (je sechs Monate alt). ${ }^{*}=p<0,05$.

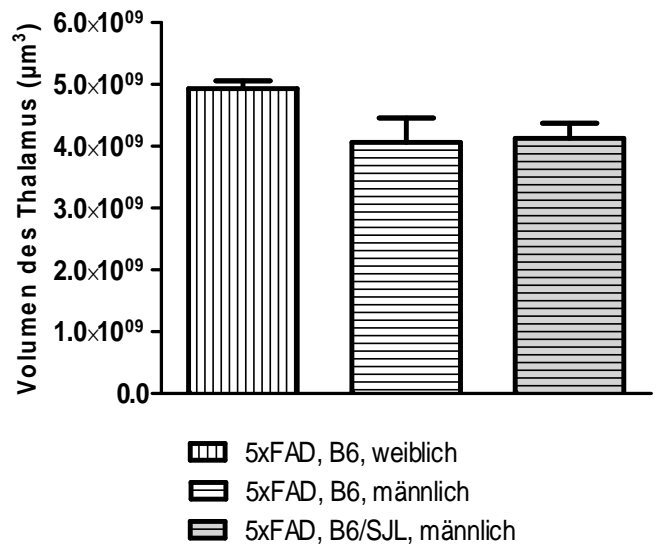

Abb. 13: Vergleich des Volumens des Thalamus von weiblichen und männlichen Mäusen mit 5xFAD-B6-Hintergrund und männlichen Mäusen mit 5xFAD-B6/SJLHintergrund (je sechs Monate alt).

\subsection{Untersuchung der $A \beta$-Belastung (Plaqueload)}

Zur Bestimmung der A $\beta$-Belastung (sog. Plaqueload) der CA1-Region des Hippocampus und der des Thalamus ist wie in Kapitel 2.5.1 vorgegangen worden. Im Verlauf erfolgt die Auswertung quantitativ und qualitativ.

\subsubsection{Quantitative Auswertung des Plaqueloads}

Die Bestimmung des Flächenanteils von $\beta$-Amyloid / der $\beta$-Amyloidbelastung des CA1Hippocampus und Thalamus wurde wie in Kapitel 2.7 beschrieben anhand von $A \beta N$ und 4G8-Antikörpern quantifiziert. 


\subsubsection{CA1-Hippocampus}

\begin{tabular}{|c|c|c|c|}
\hline & $\begin{array}{c}\text { 5xFAD-B6, } \\
\text { weiblich } \\
(\boldsymbol{n = 4})\end{array}$ & $\begin{array}{c}\text { 5xFAD-B6, } \\
\text { männlich } \\
(\boldsymbol{n}=4)\end{array}$ & $\begin{array}{c}\text { 5xFAD- } \\
\text { B6/SJL, } \\
\text { männlich } \\
(\boldsymbol{n}=5)\end{array}$ \\
\hline FlächN- & 0,30 & 0,18 & 0,03 \\
in \% & 0,40 & 0,20 & 0,23 \\
& 0,45 & 0,24 & 0,30 \\
& 0,55 & 0,36 & 0,45 \\
& & & 0,47 \\
\hline Mittelwert & 0,43 & 0,25 & 0,3 \\
\hline
\end{tabular}

Tabelle 13: Anteil der durch AßN gefärbten Fläche an Gesamtfläche des CA1-Hippocampus von je vier weiblichen und männlichen Mäusen der 5xFAD-B6-Reihe und sechs männlichen Mäusen der 5xFAD-B6/SJL-Reihe.

\begin{tabular}{|c|c|c|c|}
\hline & $\begin{array}{c}5 x F A D-B 6, \\
\text { weiblich } \\
(\boldsymbol{n}=4)\end{array}$ & $\begin{array}{c}\text { 5xFAD-B6, } \\
\text { männlich } \\
(\boldsymbol{n}=4)\end{array}$ & $\begin{array}{c}\text { 5xFAD- } \\
\text { B6/SJL, } \\
\text { männlich } \\
(\boldsymbol{n}=5)\end{array}$ \\
\hline Flächenanteil & 0,63 & 0,28 & 0,32 \\
in \% & 0,95 & 0,34 & 0,62 \\
& 1,00 & 0,60 & 1,05 \\
& 1,05 & 0,84 & 1,38 \\
& & & 1,60 \\
\hline Mittelwert & 0,91 & 0,52 & 0,99 \\
\hline
\end{tabular}

Tabelle 14: Anteil der durch 4G8 gefärbten Fläche an Gesamtfläche des CA1-Hippocampus von je vier weiblichen und männlichen Mäusen der 5xFAD-B6-Reihe und sechs männlichen Mäusen der 5xFAD-B6/SJL-Reihe.

Bei den weiblichen 5xFAD-B6-Mäusen färbt der AßN-Antikörper im CA1-Hippocampus einen mittleren Flächenanteil von $0,43 \%$ mit einem Standardfehler von $\sigma(\theta)= \pm$ 0,052\%. Die Anfärbung durch 4G8 beläuft sich auf 0,91\% mit einem Standardfehler von $\sigma(\theta)= \pm 0,095 \%$. Bei den männlichen Mäusen derselben Linie beträgt der mittlere Flächenanteil 0,25\% mit einem Standardfehler von $\sigma(\theta)= \pm 0,04 \%$. Der 4G8-Antikörper färbt hier $0,52 \%$ mit einem Standardfehler von $\sigma(\theta)= \pm 0,13 \%$ an. 
Die männlichen Mäuse der 5xFAD-B6/SJL-Linie weisen im CA1-Hippocampus bei

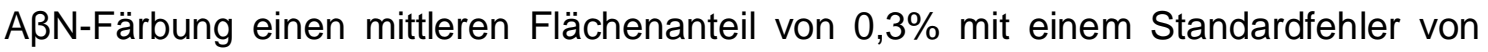
$\sigma(\theta)= \pm 0,08 \%$ auf. In der 4G8-Färbung beträgt der Flächenanteil des Antikörpers $0,99 \%$ mit einem Standardfehler von $\sigma(\theta)= \pm 0,23 \%$ (s. Tabelle 13 u. 14).

\subsubsection{Thalamus}

\begin{tabular}{|c|c|c|c|}
\hline & $\begin{array}{c}\text { 5xFAD-B6, } \\
\text { weiblich } \\
(n=4)\end{array}$ & $\begin{array}{c}\text { 5xFAD-B6, } \\
\text { männlich } \\
(n=4)\end{array}$ & $\begin{array}{c}\text { 5xFAD- } \\
\text { B6/SJL, } \\
\text { männlich } \\
\quad(n=5)\end{array}$ \\
\hline $\begin{array}{c}A \beta N- \\
\text { Flächenanteil } \\
\text { in \% }\end{array}$ & $\begin{array}{l}0,73 \\
0,84 \\
0,88 \\
1,33\end{array}$ & $\begin{array}{l}0,26 \\
0,26 \\
0,38 \\
0,70\end{array}$ & $\begin{array}{l}0,32 \\
0,62 \\
1,05 \\
1,38 \\
1,60\end{array}$ \\
\hline Mittelwert & 0,95 & 0,4 & 0,65 \\
\hline
\end{tabular}

Tabelle 15: Anteil der durch $A \beta N$ gefärbten Fläche an Gesamtfläche des Thalamus von je vier weiblichen und männlichen Mäusen der 5xFAD-B6-Reihe und sechs männlichen Mäusen der 5xFAD-B6/SJL-Reihe.

\begin{tabular}{|c|c|c|c|}
\hline & $\begin{array}{c}\text { 5xFAD-B6, } \\
\text { weiblich } \\
(\boldsymbol{n = 4})\end{array}$ & $\begin{array}{c}\text { 5xFAD-B6, } \\
\text { männlich } \\
(\boldsymbol{n}=4)\end{array}$ & $\begin{array}{c}\text { 5xFAD- } \\
\text { B6/SJL, } \\
\text { männlich } \\
(\boldsymbol{n}=5)\end{array}$ \\
\hline Flächenanteil & 1,75 & 0,84 & 0,20 \\
in \% & 1,95 & 0,94 & 1,53 \\
& 3,43 & 1,34 & 1,93 \\
& 1,60 & 1,60 & 2,03 \\
& & & 2,60 \\
\hline Mittelwert & 2,18 & 1,18 & 1,66 \\
\hline
\end{tabular}

Tabelle 16: Anteil der durch 4G8 gefärbten Fläche an Gesamtfläche des Thalamus von je vier weiblichen und männlichen Mäusen der 5xFAD-B6-Reihe und sechs männlichen Mäusen der 5xFAD-B6/SJL-Reihe. 
Die Färbung des Thalamus ergibt für die weiblichen 5xFAD-B6-Mäuse einen mittleren Flächenanteil des $A \beta N$-Antikörpers von $0,95 \%$ mit einem Standardfehler von $\sigma(\theta)= \pm$ 0,132\%. Der 4G8-Antikörper färbt im Mittel 2,18\% der Fläche mit einem Standardfehler von $\sigma(\theta)= \pm 0,422 \%$ an. Die männlichen Mäuse derselben Linie haben einen mittleren Flächenanteil durch $A \beta N$ von $0,4 \%$ mit einem Standardfehler von $\sigma(\theta)= \pm 0,104 \%$, und durch $4 G 8$ von $1,18 \%$ mit einem Standardfehler von $\sigma(\theta)= \pm 0,17 \%$.

Bei den männlichen Mäusen der 5xFAD-B6/SJL-Linie wird durch $A \beta N$ ein mittlerer Flächenanteil von $0,65 \%$ mit einem Standardfehler von $\sigma(\theta)= \pm 0,121 \%$ angefärbt. Der Mittelwert der 4G8-Färbung beträgt bei letzteren Tieren $1,66 \%$ mit einem Standardfehler von $\sigma(\theta)= \pm 0,403 \%$ (s. Tabelle 15 u. 16).

\subsubsection{Vergleich der Plaqueloaddaten}

Die in Kapitel 3.2.1.1 und 3.2.1.2 aufgeführten Daten werden im Folgenden graphisch dargestellt und miteinander verglichen.

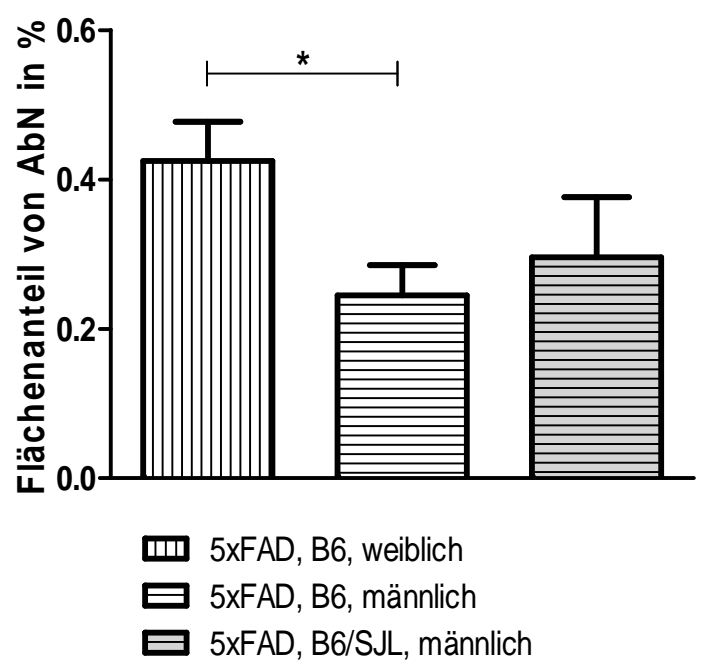

Abb. 14: Vergleich des Flächenanteils des $A \beta N$ Antikörpers an der Gesamtfläche des CA1Hippocampus von weiblichen und männlichen Mäusen mit 5xFAD-B6-Hintergrund und männlichen Mäusen mit 5xFAD-B6/SJLHintergrund (je sechs Monate alt) ${ }^{*}=p<0,05$.

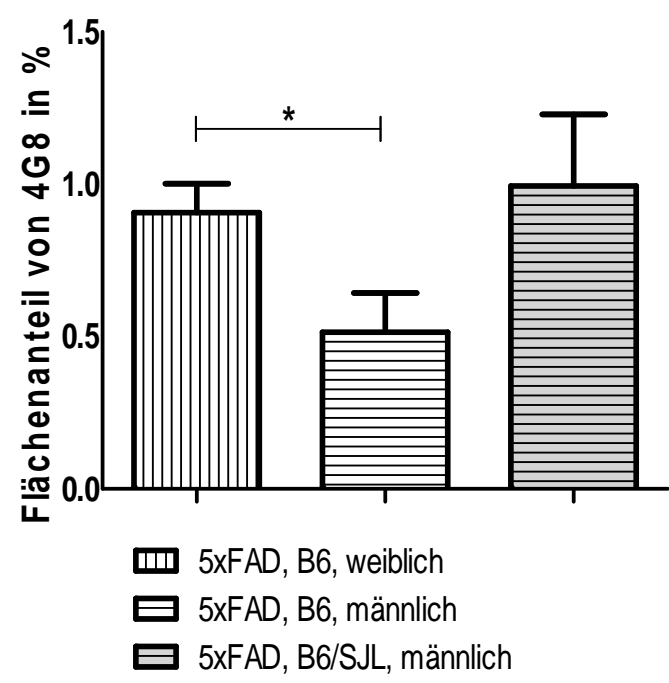

Abb. 15: Vergleich des Flächenanteils des 4G8-Antikörpers an der Gesamtfläche des CA1-Hippocampus von weiblichen und männlichen Mäusen mit 5xFAD-B6Hintergrund und männlichen Mäusen mit 5xFAD-B6/SJL-Hintergrund (je sechs Monate alt). ${ }^{*}=p<0,05$.

Der Vergleich der Flächenanteile der Antikörper an der Gesamtfläche der Hirnregionen zeigt, dass bei den weiblichen 5xFAD-B6-Mäusen sowohl bei $A \beta N$ - als auch bei 4G8- 
Färbung ein größerer Flächenanteil von den Antikörpern angefärbt wird als bei den männlichen Mäusen derselben Linie (72\% für $A \beta N$ und $75 \%$ für $4 \mathrm{G} 8$ )

$A \beta N$ färbt im Durchschnitt $72 \%$ mehr Fläche des CA1-Hippocampus bei weiblichen Mäusen als bei männlichen Mäusen der 5xFAD-B6-Linie an, bei 4G8-Färbung sind es $75 \%$. In beiden Fällen ist der Unterschied signifikant mit $P$-Werten von 0,034 für $A \beta N$ und 0,049 für 4G8 bei einem Signifikanzniveau von $p<0,05$ (s. Abbildung 14 u. 15).

Der CA1-Hippocampus der männlichen Mäuse der 5xFAD-B6/SJL-Linie wird zu 20\% stärker durch $A \beta N$ und $z u \quad 90 \%$ stärker durch 4G8 angefärbt als die gleichgeschlechtlichen Äquivalente der 5xFAD-B6-Linie. Es ergibt sich jedoch keine Signifikanz bei $P$-Werten von 0,618 für $A \beta N$ und 0,143 für $4 G 8$.

Im Durchschnitt der Geschlechter und Genotypen färbt 4G8 141\% mehr Fläche des CA1-Hippocampus an als $A B N$.

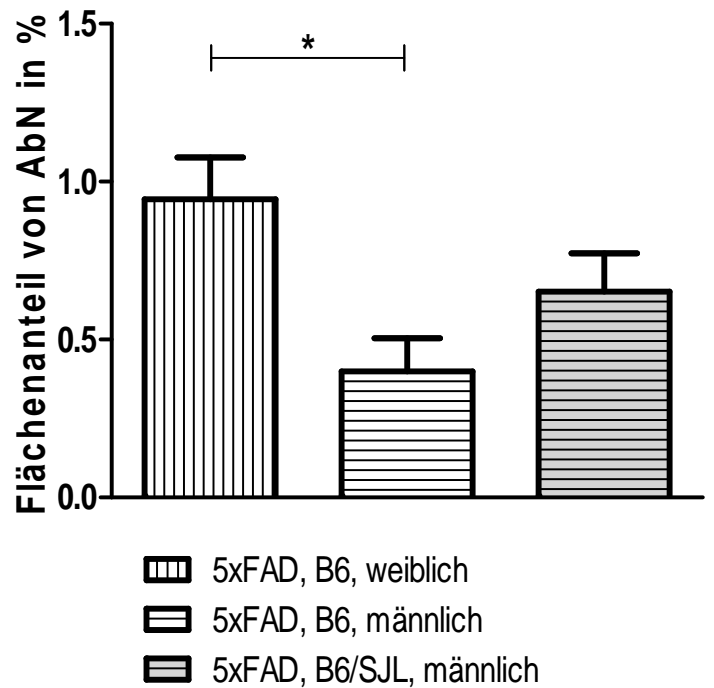

Abb. 16: Vergleich des Flächenanteils des $A \beta N$ Antikörpers an der Gesamtfläche des Thalamus von weiblichen und männlichen Mäusen mit 5xFAD-B6-Hintergrund und männlichen Mäusen mit 5xFAD-B6/SJL-Hintergrund (je sechs Monate alt ${ }^{*}=p<0,05$.

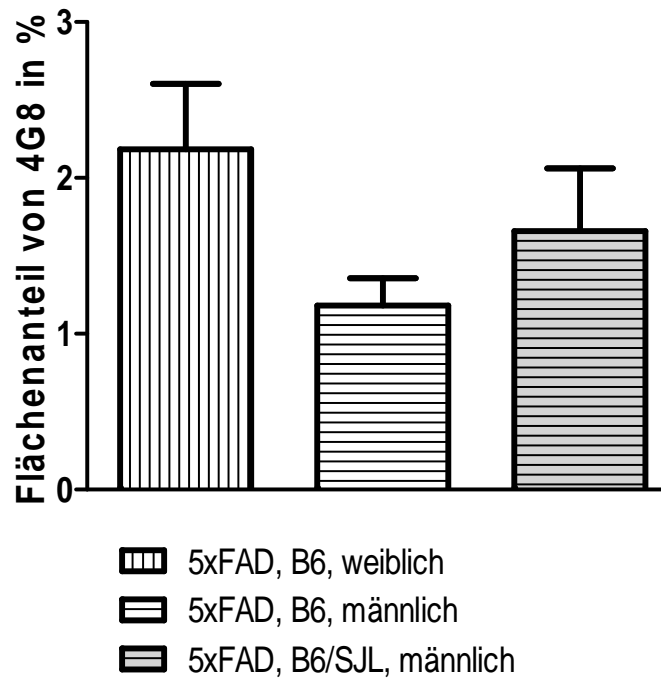

Abb. 17: Vergleich des Flächenanteils des 4G8-Antikörpers an der Gesamtfläche des Thalamus von weiblichen und männlichen Mäusen mit 5xFAD-B6-Hintergrund und männlichen Mäusen mit 5xFAD-B6/SJLHintergrund (je sechs Monate alt).

Ähnlich wie im CA1-Hippocampus wird der Thalamus der weiblichen 5xFAD-B6-Mäuse durch $A \beta N$ um $138 \%$ signifikant stärker angefärbt $(p=0,01$ bei $p<0,05)$ als der der männlichen Mäuse desselben Genotyps (s. Abbildung 16). Der mittlere Flächenanteil von 4G8 ist bei den Weibchen zwar ebenfalls um 85\% höher als bei den Männchen, jedoch unterschreitet der hierbei vorliegende P-Wert von 0,07 knapp die Signifikanzgrenze von $p<0,05$ nicht (s. Abbildung 17). 
Die männlichen Mäuse des 5xFAD-B6/SJL-Genotyps zeigen bei beiden Antikörpern eine erhöhte Färbetendenz im Vergleich zu den männlichen Mäusen des 5xFAD-B6Genotyps. AßN färbt 63\%, 4G8 41\% mehr Thalamusfläche bei den 5xFAD-B6/SJLMäusen als bei denen des 5xFAD-B6-Genotyps an. Es ergibt sich jedoch keine Signifikanz bei P-Werten von 0,170 für $A \beta N$ und 0,355 für 4G8. Im Durchschnitt der Geschlechter und Genotypen wird der Thalamus durch 4G8 zu 160\% mehr angefärbt als durch $A \beta N$. 


\subsubsection{Qualitative Auswertung des Plaqueloads}

Anhand der für die Bestimmung des Plaqueloads gewonnenen Bilder lassen sich Verteilungsmuster des $\beta$-Amyloids (dargestellt durch die Antikörper $A \beta[N]$ und 4G8) und des Vorläuferproteins APP (APP-Antikörper) in den zwei Linien B6 und B6/SJL des 5xFAD-Mausmodells bestimmen.

CA1-Hippocampus:

APP $4 G 8$ $\mathrm{A} \beta \mathrm{N}$

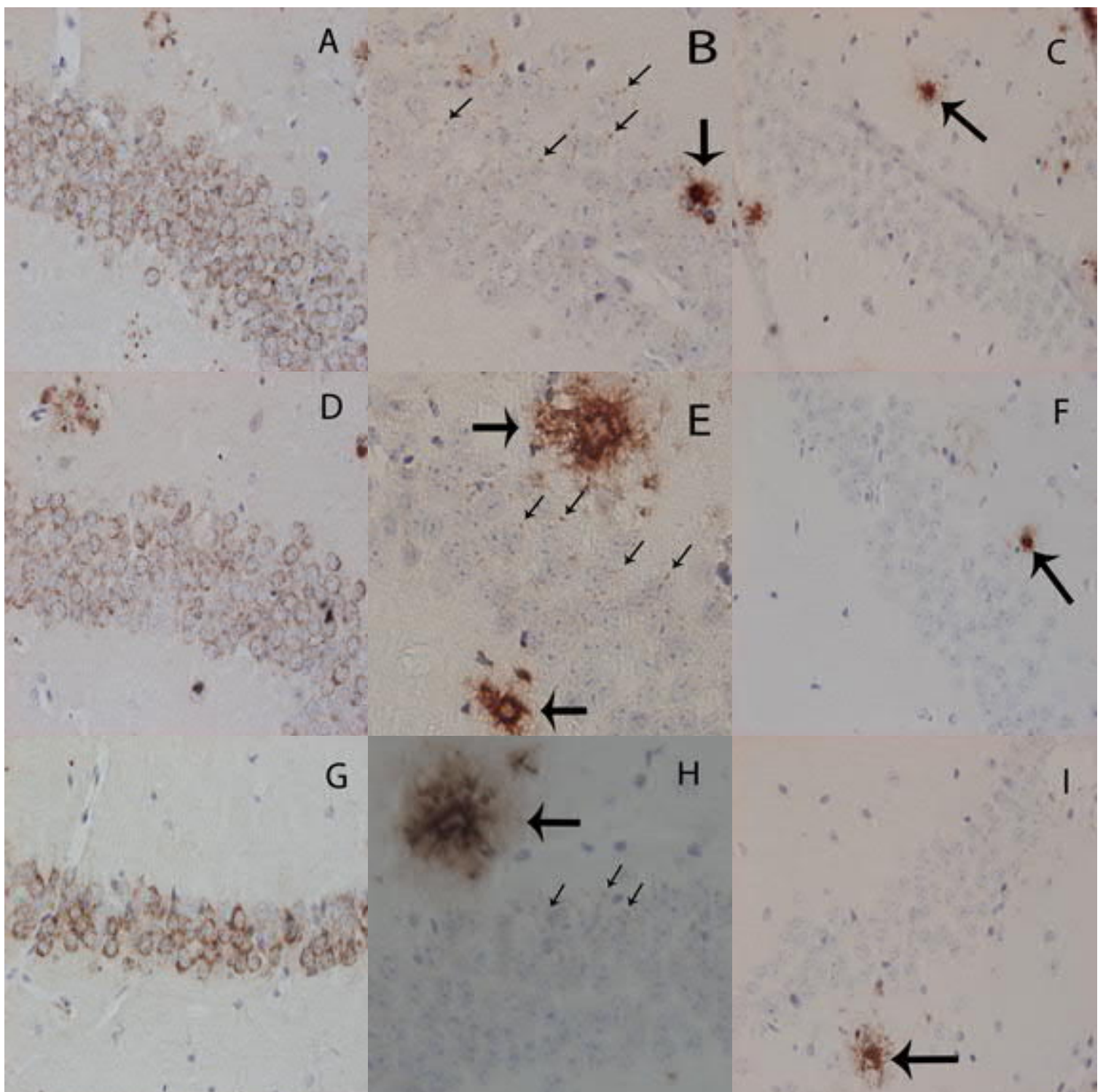

Abb. 18: Qualitative Darstellung der im CA1-Hippocampus gefundenen APP- und A Belastung (durch APP-, 4G8- und ABN-Antikörper) bei weiblichen B6-Mäusen $(A, B, C)$, männlichen B6-Mäusen ( $D, E, F)$ und männlichen B6/SJL-Mäusen $(G, H, I)$ des 5xFADMausmodells. Große Pfeile markieren extrazelluläre Plaques, kleine Pfeile intrazelluläres $A \beta$. APP- und ABN-Aufnahmen in 10x-Vergrößerung, 4G8-Aufnahmen in 20xVergrößerung. 
Thalamus:

APP $\quad 4 G 8 \quad A B N$

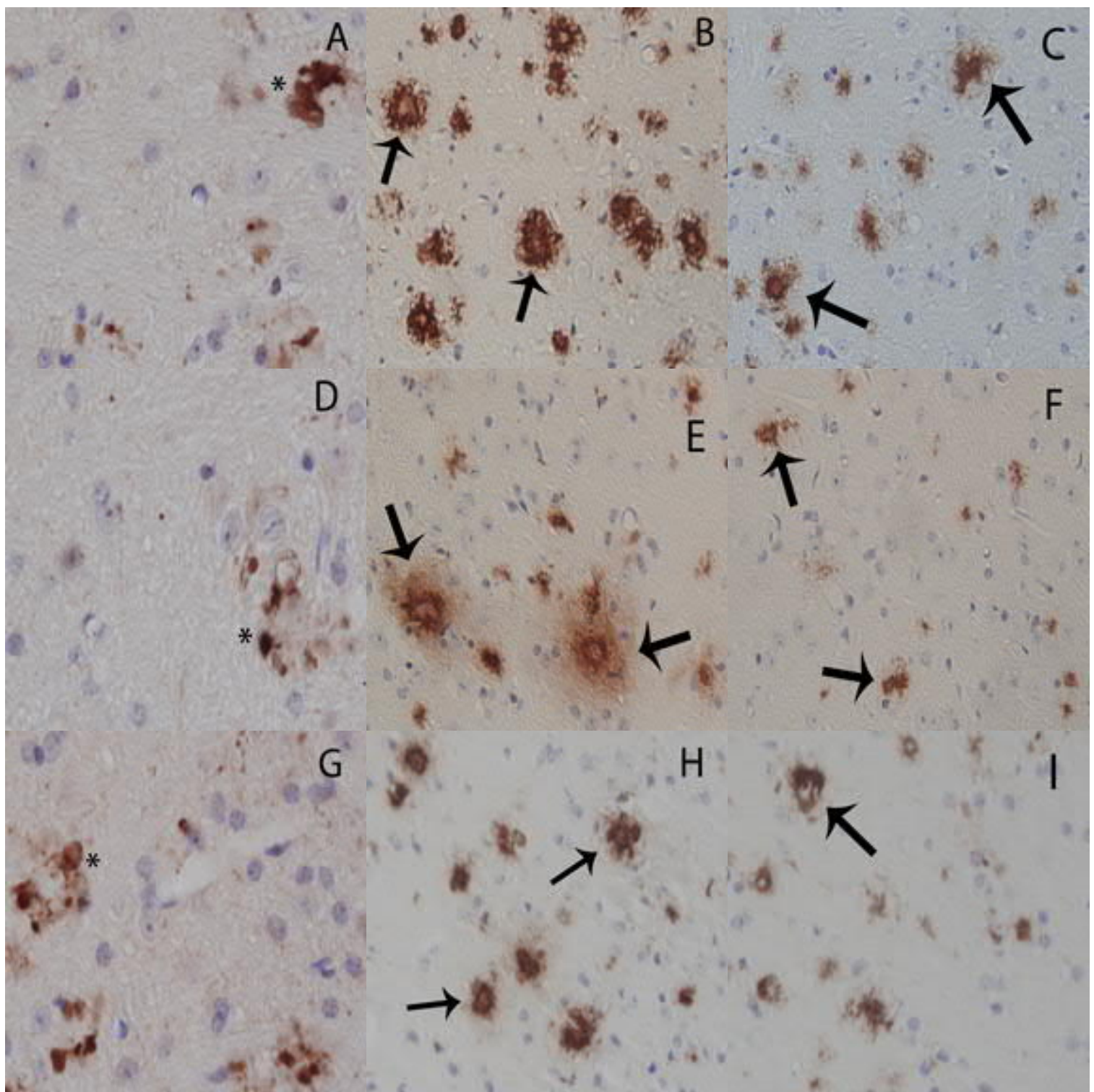

Abb. 19: Qualitative Darstellung der im Thalamus gefundenen APP- und $A \beta$-Belastung (durch APP-, 4G8- und ABN-Antikörper) bei weiblichen B6-Mäusen ( $A, B, C$ ), männlichen B6-Mäusen (D, E, F) und männlichen B6/SJL-Mäusen ( $G, H, I)$ des 5xFAD-Mausmodells. Pfeile markieren extrazelluläre Plaques, Sterne markieren extrazelluläre APPAnsammlungen in der Nähe von Plaques. APP-Aufnahmen in 20x-Vergrößerung, 4G8- und $A \beta N$ - Aufnahmen in 10x-Vergrößerung.

So befindet sich reichlich APP in der Plasmamembran und der Peripherie des Nervenzellsomas sowie in Plaqueperipherie des CA1-Hippocampus (s. Abbildungen 18A, 18D, 18G).

Eine deutlich geringere APP-Anfärbung zeigt sich hingegen in den Plasmamembranen der Thalamusneuronen. Hier erscheint jedoch eine APP-Akkumulation in Plaquenähe, 
die das APP aus dystrophen Neuronenresten repräsentiert (s. Abbildungen 19A, 19D, 19G).

Geringe intrazelluläre $A \beta$-Ablagerungen können lediglich durch 4G8-Anfärbung im CA1-Hippocampus dargestellt werden, hier zumeist punktuell im Bereich des Axonhügels (s. Abbildungen 18B, 18E, 18H).

Im Thalamus ist weder durch $A \beta N$ - noch durch 4G8-Färbung intrazelluläres $A \beta$ nachweisbar. Durch letztere Antikörper werden die Plaques in CA1-Hippocampus und Thalamus deutlich zielscheibenartig angefärbt mit zentraler Aufhellung (dystrophe Neuronenreste), starker Färbung ringförmig um das Zentrum im Bereich der stärksten Aß42-Akkumulation und deutlich abblassender Peripherie (Oakley et al. 2006, Selkoe 2001). 


\section{Diskussion}

Die Alzheimer-Demenz ist eine progrediente, degenerative Erkrankung kortikaler und subkortikaler Hirnstrukturen, die den Verlust für den Menschen äußerst wichtiger kognitiver Fähigkeiten bis hin zur vollständigen Pflegebedürftigkeit zur Folge haben kann.

Wie zuvor dargestellt, sind eine Vielzahl von Risikofaktoren, die die Entwicklung der Alzheimer-Erkrankung fördern, gefunden und in Zusammenhang gebracht worden. Hierunter hat die epidemiologische Beobachtung, dass Frauen ein erhöhtes Erkrankungsrisiko haben, erhebliche Forschungsangstrengungen nach sich gezogen.

Auch in dieser Arbeit, die die Pathohistologie zwischen den Geschlechtern in Bezug auf die $\beta$-Amyloidakkumulation in einem Mausmodell der familiären AlzheimerErkrankung mit raschem histopathologischem Progress betrachtet hat, konnte ein Geschlechtsunterschied feststellen werden.

\subsection{Erhöhter Plaqueload bei weiblichen Mäusen}

Durch das 5xFAD-Mausmodell wird anhand dieser Arbeit gezeigt, dass in Hirnarealen mit kognitiven und regulatorischen Funktionen der für die familiäre AlzheimerErkrankung (FAD) typische rapide histopathologische Progress bei weiblichen Individuen stärker ausgeprägt ist als bei männlichen. Im Alter von sechs Monaten zeigen die weiblichen Mäuse signifikant mehr Plaquebelastung im CA1-Hippocampus und im Thalamus als die männlichen Mäuse.

Dies bestätigt die von Oakley et al. nachgewiesene Suszeptibilität der weiblichen 5xFAD-Mäuse, die mit zunehmendem Alter stetig steigend eine höhere zerebrale $A \beta$ Konzentration als die männlichen Linienverwandten aufweisen.

Bestätigt wird diese Erkenntnis in Bezug auf das 5xFAD-Mausmodell durch eine Studie, die den Plaqueload im CA1-Hippocampus dieser Tiere unter Stressbedingungen untersucht (Devi et al. 2010): Hier findet sich ebenfalls eine höhere Konzentration von löslichem $A \beta 42$ und eine beschleunigte Plaqueformation bei weiblichen Tieren nach mehrtägiger Stressexposition.

In weiteren Arbeiten mit anderen AD-Mausmodellen konnte die Erkenntnis über einen verstärkten Plaqueload bei weiblichen Mäusen ebenfalls erhoben werden: Zunächst in 
einem Mausmodell mit lediglich einer Mutation, der Swedish-Mutation des APP, bei dem erst nach 15 Monaten eine signifikante Mehrbelastung mit $A \beta$ der weiblichen Mäuse nachzuweisen ist (Callahan et al. 2001). Es folgte die Betrachtung des APP/PS1-Modells, das zwei der fünf Mutationen des 5xFAD-Modells enthält und bereits nach 12 Monaten einen Unterschied zwischen den Geschlechtern feststellte (Wang et al. 2003). Hierauf wurde ein solcher Geschlechtsunterschied im 3xTgMausmodell nachgewiesen, das je eine APP-, PS1- und Tau-Mutation trägt (HirataFukae et al. 2008). Zudem konnten im Letztgenannten, einhergehend mit der stärkeren $A \beta$-Belastung, stärkere kognitive Defizite bei den weiblichen Mäusen festgestellt werden (Carroll et al. 2010).

Inwieweit die bereits nach sechs Monaten stärker ausgeprägte Histopathologie bei weiblichen Tieren des 5xFAD-Mausmodells mit einer stärkeren demenziellen Symptomatik im Vergleich zu den männlichen Tieren einhergeht, wäre durch kognitive Testungen zu untersuchen.

In Übereinstimmung mit den aus dem 5xFAD- und anderen Mausmodellen erhobenen Befunden kann auch beim Menschen eine bei weiblichen Individuen verstärkte $A \beta$ Pathologie definiert werden (Barnes et al. 2005).

Durch den Vergleich der Plaquebelastung der zwei Maushintergründe (B6 vs. B6/SJL) in der vorliegenden Arbeit kann eine Tendenz zu einer Mehrbelastung des SJLHintergrundes festgestellt werden. Da die Unterschiede jedoch nicht signifikant sind, kann ein Effekt des Hintergrundes auf die Plaqueentstehung nicht bestätigt werden. Zur weiteren Differenzierung müssten auch weibliche Tiere der zwei Hintergründe verglichen und Mäuse eines höheren Alters untersucht werden.

\subsection{Kein Unterschied in den Neuronenzahlen}

Die zweite wichtige Erkenntnis der vorliegenden Arbeit ist, dass es keine signifikanten Unterschiede in den Neuronenzahlen weder zwischen den Geschlechtern noch zwischen den unterschiedlichen Maushintergründen gibt.

Hier ist es aufgrund des jungen Alters der Tiere wahrscheinlich, dass zum Präparationszeitpunkt noch keine neurodegenerativen Prozesse eingetreten sind. Dies stimmt mit der Theorie überein, dass die Neurodegeneration erst im Verlauf nach intrazellulärer $A \beta$-Akkumulation, Plaquebildung und synaptischer Degeneration eintritt (Hardy und Allsop 1991). Auch in der vorliegenden Arbeit konnten unabhängig vom Geschlecht und Hintergrund nur geringe bis keine $A \beta$-Mengen in den untersuchten 
Hirnabschnitten nachgewiesen werden, so dass hierin der Grund für das Fehlen eines Unterschiedes in der Neuronenzahl gesehen werden kann. Dies stimmt überein mit den Ergebnissen von Christensen et al., die trotz ausgeprägter extrazellulärer Plaquebildung keinen Neuronenverlust im Thalamus nachweisen konnten (Christensen et al. 2008). In anderen Mausmodellen zeigt sich jedoch, dass es erst zu einem massiven Neuronenverlust kommt, sobald $A \beta$ intrazellulär akkumuliert - hier bereits ab einem Alter von sechs Monaten (Breyhan et al. 2009, Casas et al. 2004).

Oakley und Kollegen wiesen einen signifikanten Neuronenverlust im 5xFADMausmodell im Vergleich zum Wildtyp erst im Alter von 9 Monaten nach (Oakley et al. 2006). Jedoch konnte die Gruppe um Jawhar explizit im CA1-Hippocampus keinen Unterschied in der Neuronendichte zwischen Wildtyp und 5xFAD bis zum Alter von 12 Monaten feststellen (Jawhar et al. 2012).

Vermuten lässt sich, dass ein verstärkter Neuronenverlust also zunächst in anderen Gehirnarealen stattfindet. In letztgenannter Arbeit konnte ebenfalls festgestellt werden, dass es bei den 5xFAD-Mäusen ab 6 Monaten Lebensalter zu einer signifikanten Reduktion des räumlichen Arbeitsgedächtnisses kommt, das mit steigendem Alter zunimmt. Diese Beobachtung unterstützt die Theorie, dass die frühe Demenzsymptomatik durch synaptische Dysfunktionen und nicht durch einen manifesten Neuronenverlust eingeläutet wird.

Als Grund für den fehlenden Unterschied in der Neuronenzahl zwischen den Geschlechtern ist jedoch ein Zusammenhang mit der stereologischen Zählmethode nicht sicher auszuschließen: So könnte in der Nähe einer Plaque, die durch ihre Größe verdrängend auf umliegendes Nervengewebe wirkt, die Neuronendichte artifiziell erhöht sein und im Zählprozess zu falsch hohen Zählungen führen. Aufgrund der höheren Plaquebelastung bei weiblichen Tieren könnte es so zu vermehrt falsch hohen Zählungen kommen. Es benötigt andere Zählmethoden, um dies zu überprüfen.

Zusammenfassend lässt sich anhand der vorliegenden Arbeit die Hypothese der modifizierten $\beta$-Amyloid-Kaskade (Wirths et al. 2004) - dass nicht die extrazelluläre Plaquebelastung sondern vielmehr die intrazelluläre $A \beta$-Akkumulation $z u$ einem Neuronenverlust führt - bestätigen.

\subsection{Hirnvolumen in Abhängigkeit des genetischen Hintergrundes}

Es konnte ein Unterschied im Hirnvolumen des CA1-Hippocampus unter den männlichen Tieren zu Ungunsten der B6/SJL-Linie in der vorliegenden Arbeit 
festgestellt werden. Die (nicht signifikante) Beobachtung der geringeren Neuronenzahlen der B6/SJL-Tiere in dieser Arbeit könnte im Einklang damit stehen. Im Frontalkortex konnten die gleichen Ergebnisse bezüglich des Volumenverhältnisses zu Ungunsten der B6/SJL-Linie gemacht werden und mit einer signifikant verringerten Neuronenzahl korreliert werden (Kratz 2009).

Auch bei anderen neurodegenerativen Erkrankungen, wie z.B. der amyotrophen Lateralsklerose, können Unterschiede zwischen den Maushintergründen festgestellt werden: Mancuso und Kollegen fanden einen schnelleren Progress der Neuropathologie und eine verkürzte Lebenszeit der B6/SJL- gegenüber derjenigen der B6Mäuse (Mancuso et al. 2012).

Ebenfalls wurde bei der TG2576-Mauslinie, die die Swedish-Mutation beinhaltet und Grundlage für das 5xFAD-Modell ist, ein Einfluss des Hintergrundes auf die kognitive Leistung der Mäuse gefunden (Lassalle et al. 2008), worüber in der vorliegenden Arbeit jedoch keine Aussage getroffen werden kann.

$\mathrm{Zu}$ beachten ist, dass dem SJL-Mausstamm per se ein geringes Hirngewicht zu eigen ist und dies ebenfalls eine Ursache für das nachgewiesene geringere hippocampale CA1-Volumen, unabhängig von der Alzheimer-Histopathologie, sein könnte (http://www.informatics.jax.org/external/festing/mouse/docs/SJL.shtml 05.11.2013).

Der Hintergrund der Mauslinien scheint folglich ein wichtiger Faktor bei der Entwicklung der Neurodegeneration im Mausmodell zu sein und die Ergebnisse auch dieser Arbeit zu beeinflussen. Im Einklang hierzu steht die in der vorliegenden Arbeit festgehaltene Beobachtung der Tendenz einer höheren Plaquebelastung des B6/SJL- im Vergleich zu dem des B6-Hintergrundes.

\subsection{Ausblick}

Zusammenfassend konnten in dieser Arbeit Erkenntnisse über die verstärkte Histopathologie bei weiblichen Individuen gesammelt werden, die mit den in der bisherigen Alzheimer-Forschung gewonnenen übereinstimmen: Sowohl in Tiermodellen als auch beim Menschen lässt sich eine stärkere alzheimertypische Histopathologie in weiblichen Individuen nachweisen.

Das 5xFAD-Mausmodell eignet sich gut zur imitierenden Darstellung zunächst der ADtypischen Histopathologie aufgrund des rapiden Progresses, der dem Modell zu eigen ist. Jedoch ist eine Aussage über eine Korrelation zu der klinischen Manifestation der Erkrankung einerseits als auch zu deren Substrat, i.e. ein Neuronenverlust oder eine synaptische Dysfunktion, andererseits in der vorliegenden Arbeit nicht möglich. 
Insbesondere der rapide Progress im Mausmodell unterscheidet sich deutlich von der natürlichen Krankheitsentstehung im Menschen, bei der über Jahre hinweg eine Auseinandersetzung des Organismus mit den Substraten der Erkrankung besteht. Zudem forciert das 5xFAD-Modell lediglich die $\beta$-Amyloidpathologie, wohingegen die Tau-Pathologie als zweiter bedeutender Mitspieler in der Krankheitsentstehung nicht beleuchtet werden kann.

Um die hier gewonnenen Erkenntnisse zu validieren und einen weiteren Nachweis der Geschlechtsabhängigkeit der AD-Entstehung zu erbringen, müssen weitere Studien am 5xFAD-Mausmodell mit größeren Populationen und höherem Alter sowohl mit dem Fokus auf die geschlechtsspezifischen Unterschiede als auch auf die klinische Ausprägung der Histopathologie z.B. im Rahmen von Verhaltensstudien durchgeführt werden. Zudem werden aufgrund der limitierten Übertragbarkeit der Ergebnisse auf den Menschen klinisch kontrollierte Studien notwendig sein, die in vergleichbarer Weise die Histopathologie untersuchen, um diese mit Risikofaktoren, insbesondere dem Geschlecht, zu attributieren. Jedoch ist die Durchführbarkeit aufgrund von logistischen, finanziellen und vor allem ethischen Gründen erschwert. Doch besteht hierzu höchste Notwendigkeit, um die Suche nach Präventions- und Heilungsmöglichkeiten voranzutreiben und so die individuellen und gesellschaftlichen Folgen der AD für diese und die kommenden Generationen zu mildern. 


\section{Zusammenfassung}

Die Alzheimer-Demenz ist eine progrediente, degenerative Erkrankung kortikaler und subkortikaler Hirnstrukturen, die den Verlust für den Menschen äußerst wichtiger kognitiver Fähigkeiten bis hin zur vollständigen Pflegebedürftigkeit zur Folge haben kann. Es ist die häufigste der verschiedenen Demenzformen und zeigt eine steigende Prävalenz in den industrialisierten Ländern, woraus sich eine gravierende Belastung für Gesellschaft und Ökonomie ergeben wird. Nicht zuletzt wird es erhebliche Anstrengungen kosten, eine patientengerechte Versorgung aufrechtzuerhalten.

Durch immense Forschungsanstrengungen konnten multiple Risikofaktoren zur Entwicklung der AD identifiziert werden. Die Beobachtung, dass Frauen häufiger von der Erkrankung betroffen sind, zog Studien nach sich, die ihr Augenmerk auf einen möglichen Geschlechtseinfluss auf die typische histopathologische Ausprägung der AD mit $\beta$-Amyloidablagerung in Form von Plaques und löslichem $A \beta$, neurofibrillären Tangles und Neuronenverlust legten.

Die vorliegende Arbeit nahm sich zum Ziel, anhand eines Mausmodels der AlzheimerErkrankung (5xFAD), das genetisch so modifiziert wurde, dass die pathophysiologischen Prozesse der AD beschleunigt und verstärkt ablaufen, einen Einfluss von Geschlecht und genetischem Hintergrund (B6 vs. B6/SJL) auf die Ausprägung der Erkrankung auf histopathologischer Ebene nachzuweisen und diesen Nachweis anhand zweier für Kognition und Regulation wichtiger Hirnregionen, CA1-Hippocampus und Thalamus, zu führen. Es konnte ein Geschlechtseffekt auf die $\beta$-Amyloidbelastung mittels Plaqueloadbestimmung zu Ungunsten der weiblichen Tiere in beiden Regionen festgestellt werden. Ein Unterschied in der stereologisch erhobenen Neuronenzahl der untersuchten Regionen ergab sich weder zwischen den Geschlechtern noch zwischen den genetischen Hintergründen. Jedoch konnte ein verringertes CA1-Volumen der männlichen B6/SJL-Mäuse im Vergleich zu den männlichen B6-Mäusen gefunden werden. Die Ergebnisse unterstützen die Hypothese, dass das weibliche Geschlecht einen verstärkenden Effekt auf die Histopathologie der $A D$ hat und zeichnen das 5xFAD-Modell als suffizientes Werkzeug für die Alzheimer-Forschung aus. Weitere Untersuchungen an diesem Modell können helfen, die Erkenntnisse über die Risikofaktoren zu erweitern und Möglichkeiten zur Prävention und Therapie der Erkrankung zu schaffen. 


\section{Anhang}

Abbildungsverzeichnis

Abbildung 1: Prävalenz von Demenz-Erkrankungen 13

Abbildung 2: Schematische Darstellung der APP-Prozessierung 24

Abbildung 3: Histopathologische Merkmale der Alzheimer-Erkrankung 30

Abbildung 4: Hirnatrophie. Oben: Gehirn eines Alzheimer-Patienten. Unten: Gehirn eines gesunden Menschen. http://commons.wikimedia.org/wiki/File:AD versus CO.jpg. (03.11.2013)

Abbildung 5: Histologischer Schnitt des Hippocampus. http://commons.wikimedia.org/wiki/File:HippocampalRegions.jpg (03.11.2013)...........33

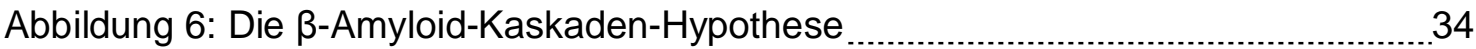

Abbildung 7: Die modifizierte $\beta$-Amyloid-Kaskaden-Hypothese 35

Abbildung 8: Schematische Darstellung des APP-Gens mit Swedish-, Florida-, LondonMutation und des PS1-Gens 38

Abbildung 9: Schematische Darstellung der untersuchten Hirnabschnitte 42

Abbildung 10: Vergleich der Neuronenzahlen im CA1-Hippocampus 54

Abbildung 11: Vergleich der Neuronenzahlen im Thalamus 54

Abbildung 12: Vergleich des Volumens des CA1-Hippocampus 55

Abbildung 13: Vergleich des Volumens des Thalamus. 55

Abbildung 14: Vergleich des Flächenanteils des AßN-Antikörpers an der Gesamtfäche des CA1-Hippocampus 58

Abbildung 15: Vergleich des Flächenanteils des 4G8-Antikörpers an der Gesamtfäche des CA1-Hippocampus

Abbildung 16: Vergleich des Flächenanteils des A $\beta N$-Antikörpers an der Gesamtfäche des Thalamus. 59

Abbildung 17: Vergleich des Flächenanteils des 4G8-Antikörpers an der Gesamtfäche des Thalamus.

Abbildung 18: Qualitative Darstellung der im CA1-Hippocampus gefundenen APP- und $\mathrm{A} \beta$-Belastung

Abbildung 19: Qualitative Darstellung der im Thalamus gefundenen APP- und A Belastung. 
Tabellenverzeichnis

Tabelle 1: Einteilungsformen der Demenzen. 11

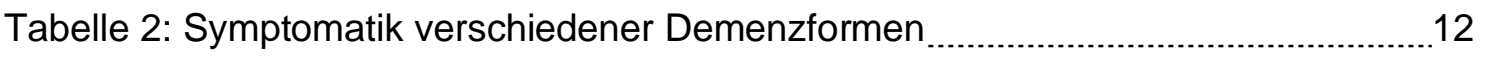

Tabelle 3: Parametereinstellung zur stereologischen Neuronenzählung ........................43

Tabelle 4: Auflistung der verwendeten Mauslinien mit jeweiligem Antikörper 47

Tabelle 5: Gesamtneuronenzahl des CA1-Hippocampus von

5xFAD-B6-Mäusen 48

Tabelle 6: Gesamtneuronenzahl des CA1-Hippocampus von

5xFAD-B6/SJL-Mäusen 49

Tabelle 7: Gesamtneuronenzahl des Thalamus von 5xFAD-B6-Mäusen. 50

Tabelle 8: Gesamtneuronenzahl des Thalamus von 5xFAD-B6/SJL-Mäusen 50

Tabelle 9: Gesamtvolumen des CA1-Hippocampus von 5xFAD-B6-Mäusen 51

Tabelle 10: Gesamtvolumen des CA1-Hippocampus von 5xFAD-B6/SJL-Mäusen. 52

Tabelle 11: Gesamtvolumen des Thalamus von 5xFAD-B6-Mäusen. 53

Tabelle 12: Gesamtvolumen des Thalamus von 5xFAD-B6/SJL-Mäusen 53

Tabelle 13: Anteil der durch ABN gefärbten Fläche an Gesamtfläche des CA1Hippocampus 56

Tabelle 14: Anteil der durch 4G8 gefärbten Fläche an Gesamtfläche des CA1Hippocampus 56

Tabelle 15: Anteil der durch A $A N$ gefärbten Fläche an Gesamtfläche des Thalamus ...57

Tabelle 16: Anteil der durch 4G8 gefärbten Fläche an Gesamtfläche des Thalamus ...57 
Färbeprotokoll für Paraffinschnitte

\begin{tabular}{|c|c|}
\hline \multicolumn{2}{|l|}{ 1.Tag } \\
\hline 1.Deparaffinieren & $\begin{array}{l}2 \times 5 \text { Min. Xylol } \\
10 \text { Min. } 100 \% \text { Ethanol } \\
5 \text { Min. } 95 \% \text { Ethanol } \\
1 \text { Min. } 70 \% \text { Ethanol } \\
1 \text { Min. H20 destilliert }\end{array}$ \\
\hline 2.Peroxidase-Block & 30 Min. $200 \mathrm{ml} \mathrm{PBS}+2 \mathrm{ml} \mathrm{H} 2 \mathrm{O} 2$ \\
\hline 3.Waschen & 1 Min. In H2O destilliert \\
\hline 4. Mikrowellenbehandlung & $\begin{array}{l}10 \text { Min. In } 0,01 \mathrm{M} \text { Citrat Puffer } \mathrm{pH} . \\
6.0 \text { bei } 800 \text { Watt }\end{array}$ \\
\hline 5.Abkühlen & 15 Min. Raumtemperatur \\
\hline 6.Waschen & 1 Min: in $\mathrm{H} 20$ destilliert \\
\hline 7.Waschen & 1 Min. in PBS \\
\hline 9. Säurebehandlung & $\begin{array}{l}3 \text { Min. in } 88 \% \text { Ameisensäure }+2 x \\
1 \text { Min. PBS }\end{array}$ \\
\hline 10.unspezifischer Block & $\begin{array}{l}1 \text { Stunde PBS + 10\% Fetal Calf } \\
\text { Serum (FCS) }+4 \% \text { Milchpulver }\end{array}$ \\
\hline 11.Antikörperinkubation & $\begin{array}{l}\text { Ohne weiteres Waschen Zugabe } \\
\text { des 1.Antikörpers (4G8, APP, } \\
A \beta[N]) \text { in PBS + 10\% FCS über } \\
\text { Nacht }\end{array}$ \\
\hline \multicolumn{2}{|l|}{ 2. Tag } \\
\hline 12.Waschen & 15 Min. in PBS + 0,1\% Triton X-100 \\
\hline 13.Waschen & 1 Min. in PBS \\
\hline 14.Antikörperinkubation & $\begin{array}{l}\text { 2.Antikörper (Anti-Rabbit oder Anti- } \\
\text { Mouse, } 1: 200 \text { mit Biotin) in PBS + } \\
\text { 10\% FCS für } 1 \text { Stunde bei } 37^{\circ} \mathrm{C}\end{array}$ \\
\hline 15.Waschen & 10 Min. in PBS \\
\hline 16. Inkubation mit $\mathrm{ABC}$ & $\begin{array}{l}\text { PBS + 10\% FCS + 1:100 Lösung A } \\
\text { und 1:100 Lösung B des Vectastain } \\
\text { Kit (Vector Laboratories, } \\
\text { Burlingame,USA) für } 90 \text { Min. bei } \\
37^{\circ} \mathrm{C} \text { (ABC-Komplex muss } \\
\text { mindestens } 30 \text { Min. vorher angesetzt } \\
\left.\text { werden, Lagerung bei } 4^{\circ} \mathrm{C}\right)\end{array}$ \\
\hline
\end{tabular}




\begin{tabular}{|c|c|}
\hline 17.Waschen & $3 \times 5$ Min. in PBS \\
\hline 18. Färbung mit Substrat & $\begin{array}{l}5 \mathrm{ml} \text { 0,05M Tris-HCL pH7,5 + } \\
100 \mu \mathrm{l} \text { DAB (3,3- } \\
\text { Diaminobenzidin) Stocklösung + } \\
2,5 \mu \mathrm{l} \mathrm{H} 2 \mathrm{O} 2\end{array}$ \\
\hline 19. Waschen & 10 Min. PBS \\
\hline 20. Gegenfärbung & 40 Sekunden mit Hämatoxylin \\
\hline 21.Aufsteigende Alkoholreihe & $\begin{array}{l}1 \text { Min. } 70 \% \text { Ethanol } 5 \text { Min. } 95 \% \\
\text { Ethanol } 10 \text { Min. } 100 \% \text { Ethanol } 2 \\
\text { x } 10 \text { Min. Xylol }\end{array}$ \\
\hline
\end{tabular}




\section{Literaturverzeichnis}

Alonso AC, Zaidi T, Grundke-lqbal I, lqbal K (1994): Role of abnormally phosphorylated tau in the breakdown of microtubules in Alzheimer disease. Proc Natl Acad Sci U S A 91: 5562-5566

Arendt T, Bigl V, Arendt A, Tennstedt A (1983): Loss of neurons in the nucleus basalis of Meynert in Alzheimer's disease, paralysis agitans and Korsakoff's Disease. Acta Neuropathol 61: 101-108

Bales KR, Verina T, Cummins DJ, Du Y, Dodel RC, Saura J, Fishman CE, DeLong CA, Piccardo P, Petegnief V, et al. (1999): Apolipoprotein $E$ is essential for amyloid deposition in the APP(V717F) transgenic mouse model of Alzheimer's disease. Proc Natl Acad Sci U S A 96: 15233-15238

Barnes LL, Wilson RS, Bienias JL, Schneider JA, Evans DA, Bennett DA (2005): Sex differences in the clinical manifestations of Alzheimer disease pathology. Arch Gen Psychiatry $\underline{62:}$ 685-691

Baudic S, Barba GD, Thibaudet MC, Smagghe A, Remy P, Traykov L (2006): Executive function deficits in early Alzheimer's disease and their relations with episodic memory. Arch Clin Neuropsychol 21: 15-21

Berman KF, Schmidt PJ, Rubinow DR, Danaceau MA, Van Horn JD, Esposito G, Ostrem JL, Weinberger DR (1997): Modulation of cognition-specific cortical activity by gonadal steroids: a positron-emission tomography study in women. Proc Natl Acad Sci U S A 94: 8836-8841

Berr C, Akbaraly TN, Nourashemi F, Andrieu S (2007): [Epidemiology of dementia]. Presse Med 36: 1431-1441

Bertrand E, Brouillet E, Caille I, Bouillot C, Cole GM, Prochiantz A, Allinquant B (2001): A short cytoplasmic domain of the amyloid precursor protein induces apoptosis in vitro and in vivo. Mol Cell Neurosci 18: 503-511

Bezprozvanny I, Mattson MP (2008): Neuronal calcium mishandling and the pathogenesis of Alzheimer's disease. Trends Neurosci 31: 454-463

Bickel H (2000): [Dementia syndrome and Alzheimer disease: an assessment of morbidity and annual incidence in Germany]. Gesundheitswesen 62: 211218

Bitan G, Kirkitadze MD, Lomakin A, Vollers SS, Benedek GB, Teplow DB (2003): Amyloid beta -protein (Abeta) assembly: Abeta 40 and Abeta 42 oligomerize through distinct pathways. Proc Natl Acad Sci U S A 100: 330335

Bobinski M, de Leon MJ, Convit A, De Santi S, Wegiel J, Tarshish CY, Saint Louis LA, Wisniewski HM (1999): MRI of entorhinal cortex in mild Alzheimer's disease. Lancet 353: 38-40 
Breitner JC, Silverman JM, Mohs RC, Davis KL (1988): Familial aggregation in Alzheimer's disease: comparison of risk among relatives of early-and lateonset cases, and among male and female relatives in successive generations. Neurology 38: 207-212

Breyhan H, Wirths O, Duan K, Marcello A, Rettig J, Bayer TA (2009): APP/PS1KI bigenic mice develop early synaptic deficits and hippocampus atrophy. Acta Neuropathol 117: 677-685

Brookmeyer R, Gray S, Kawas C (1998): Projections of Alzheimer's disease in the United States and the public health impact of delaying disease onset. Am J Public Health 88: 1337-1342

Buselmaier W, Tariverdian G: Humangenetik. 4. neubearbeitete Auflage, Springer Medizin Verlag, Heidelberg (2007)

Bush Al (2013): The metal theory of Alzheimer's disease. J Alzheimers Dis $\underline{33}$ Suppl 1: S277-281

Butterfield DA (2002): Amyloid beta-peptide (1-42)-induced oxidative stress and neurotoxicity: implications for neurodegeneration in Alzheimer's disease brain. A review. Free Radic Res 36: 1307-1313

Callahan MJ, Lipinski WJ, Bian F, Durham RA, Pack A, Walker LC (2001): Augmented senile plaque load in aged female beta-amyloid precursor protein-transgenic mice. Am J Pathol 158: 1173-1177

Campion D, Dumanchin C, Hannequin D, Dubois B, Belliard S, Puel M, Thomas-Anterion C, Michon A, Martin C, Charbonnier F, et al. (1999): Early-onset autosomal dominant Alzheimer disease: prevalence, genetic heterogeneity, and mutation spectrum. Am J Hum Genet 65: 664-670

Carroll JC, Rosario ER, Kreimer S, Villamagna A, Gentzschein E, Stanczyk FZ, Pike CJ (2010): Sex differences in beta-amyloid accumulation in 3xTg-AD mice: role of neonatal sex steroid hormone exposure. Brain Res 1366: 233245

Casas C, Sergeant N, Itier JM, Blanchard V, Wirths O, van der Kolk N, Vingtdeux V, van de Steeg E, Ret G, Canton T, et al. (2004): Massive CA1/2 neuronal loss with intraneuronal and N-terminal truncated Abeta42 accumulation in a novel Alzheimer transgenic model. Am J Pathol 165: 1289-1300

Castano EM, Prelli F, Wisniewski T, Golabek A, Kumar RA, Soto C, Frangione B (1995): Fibrillogenesis in Alzheimer's disease of amyloid beta peptides and apolipoprotein E. Biochem J 306 ( Pt 2): 599-604

Cataldo JK, Prochaska JJ, Glantz SA (2010): Cigarette smoking is a risk factor for Alzheimer's Disease: an analysis controlling for tobacco industry affiliation. J Alzheimers Dis 19: 465-480

Christensen DZ, Kraus SL, Flohr A, Cotel MC, Wirths O, Bayer TA (2008): Transient intraneuronal $A$ beta rather than extracellular plaque pathology 
correlates with neuron loss in the frontal cortex of APP/PS1KI mice. Acta Neuropathol 116: 647-655

Clarke R, Smith AD, Jobst KA, Refsum H, Sutton L, Ueland PM (1998): Folate, vitamin B12, and serum total homocysteine levels in confirmed Alzheimer disease. Arch Neurol 55: 1449-1455

Corder EH, Saunders AM, Strittmatter WJ, Schmechel DE, Gaskell PC, Small GW, Roses AD, Haines JL, Pericak-Vance MA (1993): Gene dose of apolipoprotein $\mathrm{E}$ type 4 allele and the risk of Alzheimer's disease in late onset families. Science 261: 921-923

Corder EH, Saunders AM, Risch NJ, Strittmatter WJ, Schmechel DE, Gaskell PC, Jr., Rimmler JB, Locke PA, Conneally PM, Schmader KE, et al. (1994): Protective effect of apolipoprotein $E$ type 2 allele for late onset Alzheimer disease. Nat Genet 7: 180-184

Corso EA, Campo G, Triglio A, Napoli A, Reggio A, Lanaia F (1992): Prevalence of moderate and severe Alzheimer dementia and multi-infarct dementia in the population of southeastern Sicily. Ital J Neurol Sci 13: 215219

Crooks VC, Lubben J, Petitti DB, Little D, Chiu V (2008): Social network, cognitive function, and dementia incidence among elderly women. Am J Public Health 98: 1221-1227

Davies CA, Mann DM, Sumpter PQ, Yates PO (1987): A quantitative morphometric analysis of the neuronal and synaptic content of the frontal and temporal cortex in patients with Alzheimer's disease. J Neurol Sci $\underline{78}$ 151-164

de Jong LW, van der Hiele K, Veer IM, Houwing JJ, Westendorp RG, Bollen EL, de Bruin PW, Middelkoop HA, van Buchem MA, van der Grond J (2008): Strongly reduced volumes of putamen and thalamus in Alzheimer's disease: an MRI study. Brain 131: 3277-3285

De Strooper B (2003): Aph-1, Pen-2, and Nicastrin with Presenilin generate an active gamma-Secretase complex. Neuron 38: 9-12

DeKosky ST, Scheff SW (1990): Synapse loss in frontal cortex biopsies in Alzheimer's disease: correlation with cognitive severity. Ann Neurol 27: 457464

Detoledo-Morrell L, Sullivan MP, Morrell F, Wilson RS, Bennett DA, Spencer S (1997): Alzheimer's disease: in vivo detection of differential vulnerability of brain regions. Neurobiol Aging 18: 463-468

Devi L, Alldred MJ, Ginsberg SD, Ohno M (2010): Sex- and brain regionspecific acceleration of beta-amyloidogenesis following behavioral stress in a mouse model of Alzheimer's disease. Mol Brain 3: 34 
DGN: S3-Leitlinie "Demenzen" (Langversion 23.11.2009) der Deutschen Gesellschaft für Neurologie. Bonn (2009) http://www.dgn.org/images/stories/dgn/pdf/s3_leitlinie_demenzen.pdf

Di Fede G, Catania M, Morbin M, Rossi G, Suardi S, Mazzoleni G, Merlin M, Giovagnoli AR, Prioni S, Erbetta A, et al. (2009): A recessive mutation in the APP gene with dominant-negative effect on amyloidogenesis. Science 323: 1473-1477

Dickson DW (1997): The pathogenesis of senile plaques. J Neuropathol Exp Neurol 56: 321-339

Diener HC, Putzki N, Berlit P, Deuschl G, Elger C, Gold R, Hacke W, Hufschmidt $A$, Mattle $H$, Meier U: Leitlinien für Diagnostik und Therapie in der Neurologie; hrsg. v.; Thieme Verlag, Stuttgart. 2008, 153-204

Duff K, Eckman C, Zehr C, Yu X, Prada CM, Perez-tur J, Hutton M, Buee L, Harigaya Y, Yager D, et al. (1996): Increased amyloid-beta42(43) in brains of mice expressing mutant presenilin 1. Nature $\underline{383: 710-713}$

Eckman CB, Mehta ND, Crook R, Perez-tur J, Prihar G, Pfeiffer E, GraffRadford N, Hinder P, Yager D, Zenk B, et al. (1997): A new pathogenic mutation in the APP gene (1716V) increases the relative proportion of $A$ beta 42(43). Hum Mol Genet 6: 2087-2089

Fernandez-Vizarra P, Fernandez AP, Castro-Blanco S, Serrano J, Bentura ML, Martinez-Murillo R, Martinez A, Rodrigo J (2004): Intra- and extracellular Abeta and PHF in clinically evaluated cases of Alzheimer's disease. Histol Histopathol 19: 823-844

Filley CM, Rollins YD, Anderson CA, Arciniegas DB, Howard KL, Murrell JR, Boyer PJ, Kleinschmidt-DeMasters BK, Ghetti B (2007): The genetics of very early onset Alzheimer disease. Cogn Behav Neurol 20: 149-156

Fillit H, Nash DT, Rundek T, Zuckerman A (2008): Cardiovascular risk factors and dementia. Am J Geriatr Pharmacother 6: 100-118

Folstein MF, Folstein SE, McHugh PR (1975): "Mini-mental state". A practical method for grading the cognitive state of patients for the clinician. J Psychiatr Res 12: 189-198

Folstein MF, Bassett SS, Anthony JC, Romanoski AJ, Nestadt GR (1991): Dementia: case ascertainment in a community survey. J Gerontol $\underline{46}$ : M132-138

Fratiglioni L, Launer LJ, Andersen K, Breteler MM, Copeland JR, Dartigues JF, Lobo A, Martinez-Lage J, Soininen H, Hofman A (2000): Incidence of dementia and major subtypes in Europe: A collaborative study of population-based cohorts. Neurologic Diseases in the Elderly Research Group. Neurology 54: S10-15 
Gao S, Hendrie HC, Hall KS, Hui S (1998): The relationships between age, sex, and the incidence of dementia and Alzheimer disease: a meta-analysis. Arch Gen Psychiatry 55: 809-815

Gauthier S, Reisberg B, Zaudig M, Petersen RC, Ritchie K, Broich K, Belleville S, Brodaty H, Bennett D, Chertkow H, et al. (2006): Mild cognitive impairment. Lancet 367: 1262-1270

Gervais FG, Xu D, Robertson GS, Vaillancourt JP, Zhu Y, Huang J, LeBlanc A, Smith D, Rigby M, Shearman MS, et al. (1999): Involvement of caspases in proteolytic cleavage of Alzheimer's amyloid-beta precursor protein and amyloidogenic A beta peptide formation. Cell 97: 395-406

Glabe CG (2008): Structural classification of toxic amyloid oligomers. J Biol Chem 283: 29639-29643

Glenner GG, Wong CW (1984): Alzheimer's disease: initial report of the purification and characterization of a novel cerebrovascular amyloid protein. Biochem Biophys Res Commun 120: 885-890

Goate A, Chartier-Harlin MC, Mullan M, Brown J, Crawford F, Fidani L, Giuffra L, Haynes A, Irving N, James L, et al. (1991): Segregation of a missense mutation in the amyloid precursor protein gene with familial Alzheimer's disease. Nature 349: 704-706

Gomez-Isla T, Price JL, McKeel DW, Jr., Morris JC, Growdon JH, Hyman BT (1996): Profound loss of layer II entorhinal cortex neurons occurs in very mild Alzheimer's disease. J Neurosci 16: 4491-4500

Gong CX, Shaikh S, Wang JZ, Zaidi T, Grundke-lqbal I, lqbal K (1995): Phosphatase activity toward abnormally phosphorylated tau: decrease in Alzheimer disease brain. J Neurochem 65: 732-738

Gratwicke J, Kahan J, Zrinzo L, Hariz M, Limousin P, Foltynie T, Jahanshahi M (2013): The nucleus basalis of Meynert: A new target for deep brain stimulation in dementia? Neurosci Biobehav Rev

Green RC, Cupples LA, Kurz A, Auerbach S, Go R, Sadovnick D, Duara R, Kukull WA, Chui H, Edeki T, et al. (2003): Depression as a risk factor for Alzheimer disease: the MIRAGE Study. Arch Neurol 60: 753-759

Grundke-lqbal I, lqbal K, Tung YC, Quinlan M, Wisniewski HM, Binder LI (1986 b): Abnormal phosphorylation of the microtubule-associated protein tau (tau) in Alzheimer cytoskeletal pathology. Proc Natl Acad Sci U S A 83: 4913-4917

Haass C, Selkoe DJ (2007): Soluble protein oligomers in neurodegeneration: lessons from the Alzheimer's amyloid beta-peptide. Nat Rev Mol Cell Biol $\underline{8}$ : 101-112

Haass C, Schlossmacher MG, Hung AY, Vigo-Pelfrey C, Mellon A, Ostaszewski BL, Lieberburg I, Koo EH, Schenk D, Teplow DB, et al. (1992): Amyloid 
beta-peptide is produced by cultured cells during normal metabolism. Nature 359: 322-325

Hardy J, Allsop D (1991): Amyloid deposition as the central event in the aetiology of Alzheimer's disease. Trends Pharmacol Sci 12: 383-388

Hardy J, Selkoe DJ (2002): The amyloid hypothesis of Alzheimer's disease: progress and problems on the road to therapeutics. Science 297: 353-356

Harold D, Abraham R, Hollingworth P, Sims R, Gerrish A, Hamshere ML, Pahwa JS, Moskvina V, Dowzell K, Williams A, et al. (2009): Genome-wide association study identifies variants at CLU and PICALM associated with Alzheimer's disease. Nat Genet 41: 1088-1093

Hartley DM, Walsh DM, Ye CP, Diehl T, Vasquez S, Vassilev PM, Teplow DB, Selkoe DJ (1999): Protofibrillar intermediates of amyloid beta-protein induce acute electrophysiological changes and progressive neurotoxicity in cortical neurons. J Neurosci 19: 8876-8884

Haupt M, Kurz A, Pollmann S, Romero B (1992): [Psychopathologic disorders at the onset of Alzheimer's disease]. Fortschr Neurol Psychiatr 60: 3-7

Hebert LE, Scherr PA, McCann JJ, Beckett LA, Evans DA (2001): Is the risk of developing Alzheimer's disease greater for women than for men? Am J Epidemiol 153: 132-136

Henderson VW (2006): Estrogen-containing hormone therapy and Alzheimer's disease risk: understanding discrepant inferences from observational and experimental research. Neuroscience 138: 1031-1039

Henneman WJ, Sluimer JD, Barnes J, van der Flier WM, Sluimer IC, Fox NC, Scheltens P, Vrenken H, Barkhof F (2009): Hippocampal atrophy rates in Alzheimer disease: added value over whole brain volume measures. Neurology $\underline{72:}$ 999-1007

Hirata-Fukae C, Li HF, Hoe HS, Gray AJ, Minami SS, Hamada K, Niikura T, Hua F, Tsukagoshi-Nagai H, Horikoshi-Sakuraba Y, et al. (2008): Females exhibit more extensive amyloid, but not tau, pathology in an Alzheimer transgenic model. Brain Res 1216: 92-103

Holtzman DM, Bales KR, Tenkova T, Fagan AM, Parsadanian M, Sartorius LJ, Mackey B, Olney J, McKeel D, Wozniak D, et al. (2000): Apolipoprotein E isoform-dependent amyloid deposition and neuritic degeneration in a mouse model of Alzheimer's disease. Proc Natl Acad Sci U S A 97: 28922897

http://www.alzgene.org/ (14.04.2011) AlzGene - Field Synopsis of Genetic Association Studies in AD.

http://www.informatics.jax.org/external/festing/mouse/docs/SJL.shtml (05.11.2013). 
http://www.molgen.ua.ac.be/ADMutations (03.11.2013) Alzheimer Disease \& Frontotemporal Dementia Mutation Database.

Hung AY, Koo EH, Haass C, Selkoe DJ (1992): Increased expression of betaamyloid precursor protein during neuronal differentiation is not accompanied by secretory cleavage. Proc Natl Acad Sci U S A 89: 94399443

lqbal K, Alonso Adel C, Chen S, Chohan MO, El-Akkad E, Gong CX, Khatoon S, Li B, Liu F, Rahman A, et al. (2005): Tau pathology in Alzheimer disease and other tauopathies. Biochim Biophys Acta 1739: 198-210

Iwatsubo T, Mann DM, Odaka A, Suzuki N, Ihara Y (1995): Amyloid beta protein (A beta) deposition: A beta 42(43) precedes A beta 40 in Down syndrome. Ann Neurol 37: 294-299

Jacobs DM, Tang MX, Stern $Y$, Sano M, Marder K, Bell KL, Schofield $P$, Dooneief G, Gurland B, Mayeux R (1998): Cognitive function in nondemented older women who took estrogen after menopause. Neurology 50: $368-373$

Jawhar S, Trawicka A, Jenneckens C, Bayer TA, Wirths O (2012): Motor deficits, neuron loss, and reduced anxiety coinciding with axonal degeneration and intraneuronal Abeta aggregation in the 5XFAD mouse model of Alzheimer's disease. Neurobiol Aging 33: 196 e129-140

Jervis GA (1948): Early senile dementia in mongoloid idiocy. Am J Psychiatry 105: $102-106$

Jiang H, Burdick D, Glabe CG, Cotman CW, Tenner AJ (1994): beta-Amyloid activates complement by binding to a specific region of the collagen-like domain of the C1q A chain. J Immunol 152: 5050-5059

Joachim CL, Morris JH, Selkoe DJ (1989): Diffuse senile plaques occur commonly in the cerebellum in Alzheimer's disease. Am J Pathol 135: 309319

Kalbe E, Kessler J, Calabrese P, Smith R, Passmore AP, Brand M, Bullock R (2004): DemTect: a new, sensitive cognitive screening test to support the diagnosis of mild cognitive impairment and early dementia. Int J Geriatr Psychiatry 19: 136-143

Kawas C, Resnick S, Morrison A, Brookmeyer R, Corrada M, Zonderman A, Bacal C, Lingle DD, Metter E (1997): A prospective study of estrogen replacement therapy and the risk of developing Alzheimer's disease: the Baltimore Longitudinal Study of Aging. Neurology 48: 1517-1521

Khalifa NB, Van Hees J, Tasiaux B, Huysseune S, Smith SO, Constantinescu SN, Octave JN, Kienlen-Campard P (2010): What is the role of amyloid precursor protein dimerization? Cell Adh Migr 4: 268-272

Khlistunova I, Biernat J, Wang Y, Pickhardt M, von Bergen M, Gazova Z, Mandelkow E, Mandelkow EM (2006): Inducible expression of Tau repeat 
domain in cell models of tauopathy: aggregation is toxic to cells but can be reversed by inhibitor drugs. J Biol Chem 281: 1205-1214

Kitt CA, Mitchell SJ, DeLong MR, Wainer BH, Price DL (1987): Fiber pathways of basal forebrain cholinergic neurons in monkeys. Brain Res 406: 192-206

Kiyohara Y, Yoshitake T, Kato I, Ohmura T, Kawano H, Ueda K, Fujishima M (1994): Changing patterns in the prevalence of dementia in a Japanese community: the Hisayama study. Gerontology 40 Suppl 2: 29-35

Kratz S (2009): Untersuchungen genetischer und geschlechtlicher Einflüsse in der Alzheimerpathologie anhand des Mausmodell 5XFAD. Med. Diss. Göttingen

LaFerla FM, Tinkle BT, Bieberich CJ, Haudenschild CC, Jay G (1995): The Alzheimer's A beta peptide induces neurodegeneration and apoptotic cell death in transgenic mice. Nat Genet 9: 21-30

Lambert MP, Barlow AK, Chromy BA, Edwards C, Freed R, Liosatos M, Morgan TE, Rozovsky I, Trommer B, Viola KL, et al. (1998): Diffusible, nonfibrillar ligands derived from Abeta1-42 are potent central nervous system neurotoxins. Proc Natl Acad Sci U S A 95: 6448-6453

Lassalle JM, Halley H, Daumas S, Verret L, Frances B (2008): Effects of the genetic background on cognitive performances of TG2576 mice. Behav Brain Res 191: 104-110

Launer LJ, Andersen K, Dewey ME, Letenneur L, Ott A, Amaducci LA, Brayne C, Copeland JR, Dartigues JF, Kragh-Sorensen P, et al. (1999): Rates and risk factors for dementia and Alzheimer's disease: results from EURODEM pooled analyses. EURODEM Incidence Research Group and Work Groups. European Studies of Dementia. Neurology 52: 78-84

Lautenschlager NT, Cupples LA, Rao VS, Auerbach SA, Becker R, Burke J, Chui H, Duara R, Foley EJ, Glatt SL, et al. (1996): Risk of dementia among relatives of Alzheimer's disease patients in the MIRAGE study: What is in store for the oldest old? Neurology 46: 641-650

Lauter H: Die organischen Psychosyndrome; In: Psychiatrie der Gegenwart; hrsg. v. Kisker KP, Lauter H, Meier JE, Müller C, Strömgren E; Springer Verlag, Berlin. 1988, 4-56

Lee HG, Perry G, Moreira PI, Garrett MR, Liu Q, Zhu X, Takeda A, Nunomura A, Smith MA (2005): Tau phosphorylation in Alzheimer's disease: pathogen or protector? Trends Mol Med 11: 164-169

Lesne S, Koh MT, Kotilinek L, Kayed R, Glabe CG, Yang A, Gallagher M, Ashe $\mathrm{KH}$ (2006): A specific amyloid-beta protein assembly in the brain impairs memory. Nature 440: 352-357

Lindsay J, Laurin D, Verreault R, Hebert R, Helliwell B, Hill GB, McDowell I (2002): Risk factors for Alzheimer's disease: a prospective analysis from the Canadian Study of Health and Aging. Am J Epidemiol 156: 445-453 
Lindwall G, Cole RD (1984): Phosphorylation affects the ability of tau protein to promote microtubule assembly. J Biol Chem 259: 5301-5305

Lobo A, Launer LJ, Fratiglioni L, Andersen K, Di Carlo A, Breteler MM, Copeland JR, Dartigues JF, Jagger C, Martinez-Lage J, et al. (2000): Prevalence of dementia and major subtypes in Europe: A collaborative study of population-based cohorts. Neurologic Diseases in the Elderly Research Group. Neurology 54: S4-9

Lott IT, Head E (2005): Alzheimer disease and Down syndrome: factors in pathogenesis. Neurobiol Aging 26: 383-389

Luber-Narod J, Rogers J (1988): Immune system associated antigens expressed by cells of the human central nervous system. Neurosci Lett $\underline{94}$ : $17-22$

Luchsinger JA, Reitz C, Honig LS, Tang MX, Shea S, Mayeux R (2005): Aggregation of vascular risk factors and risk of incident Alzheimer disease. Neurology 65: 545-551

Lue LF, Kuo YM, Roher AE, Brachova L, Shen Y, Sue L, Beach T, Kurth JH, Rydel RE, Rogers J (1999): Soluble amyloid beta peptide concentration as a predictor of synaptic change in Alzheimer's disease. Am J Pathol 155: 853-862

Luo Y, Bolon B, Kahn S, Bennett BD, Babu-Khan S, Denis P, Fan W, Kha H, Zhang J, Gong Y, et al. (2001): Mice deficient in BACE1, the Alzheimer's beta-secretase, have normal phenotype and abolished beta-amyloid generation. Nat Neurosci 4: 231-232

Ma J, Yee A, Brewer HB, Jr., Das S, Potter H (1994): Amyloid-associated proteins alpha 1-antichymotrypsin and apolipoprotein $\mathrm{E}$ promote assembly of Alzheimer beta-protein into filaments. Nature 372: 92-94

Mahlberg R, Gutzmann H (1995): Diagnostik von Demenzerkrankungen. Deutsches Ärzteblatt 25: 2032-2039

Mancuso R, Olivan S, Mancera P, Pasten-Zamorano A, Manzano R, Casas C, Osta R, Navarro X (2012): Effect of genetic background on onset and disease progression in the SOD1-G93A model of amyotrophic lateral sclerosis. Amyotroph Lateral Scler 13: 302-310

Masliah E, Terry RD, Alford M, DeTeresa R, Hansen LA (1991): Cortical and subcortical patterns of synaptophysinlike immunoreactivity in Alzheimer's disease. Am J Pathol 138: 235-246

Masters CL, Multhaup G, Simms G, Pottgiesser J, Martins RN, Beyreuther K (1985): Neuronal origin of a cerebral amyloid: neurofibrillary tangles of Alzheimer's disease contain the same protein as the amyloid of plaque cores and blood vessels. EMBO J 4: 2757-2763

Masuhr KF, Neumann M: Duale Reihe Neurologie. 6. Auflage,191-210, Thieme Verlag, Stuttgart (2007) 
Mattson MP (1997): Cellular actions of beta-amyloid precursor protein and its soluble and fibrillogenic derivatives. Physiol Rev 77: 1081-1132

Mattsson N, Zetterberg $\mathrm{H}$, Hansson $\mathrm{O}$, Andreasen $\mathrm{N}$, Parnetti L, Jonsson $\mathrm{M}$, Herukka SK, van der Flier WM, Blankenstein MA, Ewers M, et al. (2009): CSF biomarkers and incipient Alzheimer disease in patients with mild cognitive impairment. JAMA 302: 385-393

McGeer PL, Akiyama H, Itagaki S, McGeer EG (1989): Activation of the classical complement pathway in brain tissue of Alzheimer patients. Neurosci Lett 107: 341-346

McKhann G, Drachman D, Folstein M, Katzman R, Price D, Stadlan EM (1984): Clinical diagnosis of Alzheimer's disease: report of the NINCDS-ADRDA Work Group under the auspices of Department of Health and Human Services Task Force on Alzheimer's Disease. Neurology 34: 939-944

Meyer-Luehmann M, Spires-Jones TL, Prada C, Garcia-Alloza M, de Calignon A, Rozkalne A, Koenigsknecht-Talboo J, Holtzman DM, Bacskai BJ, Hyman BT (2008): Rapid appearance and local toxicity of amyloid-beta plaques in a mouse model of Alzheimer's disease. Nature 451: 720-724

Moechars D, Lorent K, De Strooper B, Dewachter I, Van Leuven F (1996): Expression in brain of amyloid precursor protein mutated in the alphasecretase site causes disturbed behavior, neuronal degeneration and premature death in transgenic mice. EMBO J 15: 1265-1274

Morrison JH, Hof PR (1997): Life and death of neurons in the aging brain (Abschnitt Estrogen). Science 278: 412-419

Moya KL, Benowitz LI, Schneider GE, Allinquant B (1994): The amyloid precursor protein is developmentally regulated and correlated with synaptogenesis. Dev Biol 161: 597-603

Mullan M, Crawford F, Axelman K, Houlden H, Lilius L, Winblad B, Lannfelt L (1992): A pathogenic mutation for probable Alzheimer's disease in the APP gene at the N-terminus of beta-amyloid. Nat Genet 1: 345-347

Murphy GM, Jr., Greenberg BD, Ellis WG, Forno LS, Salamat SM, GonzalezDeWhitt PA, Lowery DE, Tinklenberg JR, Eng LF (1992): Alzheimer's disease. Beta-amyloid precursor protein expression in the nucleus basalis of Meynert. Am J Pathol 141: 357-361

Newman J (1995): Thalamic contributions to attention and consciousness. Conscious Cogn 4: 172-193

Oakley H, Cole SL, Logan S, Maus E, Shao P, Craft J, Guillozet-Bongaarts A, Ohno M, Disterhoft J, Van Eldik L, et al. (2006): Intraneuronal beta-amyloid aggregates, neurodegeneration, and neuron loss in transgenic mice with five familial Alzheimer's disease mutations: potential factors in amyloid plaque formation. J Neurosci 26: 10129-10140 
Ohno M, Sametsky EA, Younkin LH, Oakley H, Younkin SG, Citron M, Vassar R, Disterhoft JF (2004): BACE1 deficiency rescues memory deficits and cholinergic dysfunction in a mouse model of Alzheimer's disease. Neuron 41: $27-33$

Padurariu M, Ciobica A, Mavroudis I, Fotiou D, Baloyannis S (2012): Hippocampal neuronal loss in the CA1 and CA3 areas of Alzheimer's disease patients. Psychiatr Danub 24: 152-158

Paganini-Hill A, Henderson VW (1996): Estrogen replacement therapy and risk of Alzheimer disease. Arch Intern Med 156: 2213-2217

Parameshwaran K, Sims C, Kanju P, Vaithianathan T, Shonesy BC, Dhanasekaran M, Bahr BA, Suppiramaniam V (2007): Amyloid beta-peptide Abeta(1-42) but not Abeta(1-40) attenuates synaptic AMPA receptor function. Synapse $\underline{61:}$ 367-374

Pastalkova E, Serrano P, Pinkhasova D, Wallace E, Fenton AA, Sacktor TC (2006): Storage of spatial information by the maintenance mechanism of LTP. Science 313: 1141-1144

Patrick GN, Zukerberg L, Nikolic M, de la Monte S, Dikkes P, Tsai LH (1999): Conversion of p35 to p25 deregulates Cdk5 activity and promotes neurodegeneration. Nature 402: 615-622

Paxinos A, Walton J, Tzannes A, Callanan M, Hayes K, Murrell GA (2001): Advances in the management of traumatic anterior and atraumatic multidirectional shoulder instability. Sports Med 31: 819-828

Paxinos G, Franklin K: The mouse brain in stereotaxic coordinates. 2. Auflage, Academic Press, New York (2001)

Petanceska SS, Nagy V, Frail D, Gandy S (2000): Ovariectomy and 17betaestradiol modulate the levels of Alzheimer's amyloid beta peptides in brain. Exp Gerontol 35: 1317-1325

Phillips SM, Sherwin BB (1992): Variations in memory function and sex steroid hormones across the menstrual cycle. Psychoneuroendocrinology 17: 497506

Pike CJ, Walencewicz AJ, Glabe CG, Cotman CW (1991): In vitro aging of betaamyloid protein causes peptide aggregation and neurotoxicity. Brain Res 563: 311-314

Planel E, Richter KE, Nolan CE, Finley JE, Liu L, Wen Y, Krishnamurthy P, Herman M, Wang L, Schachter JB, et al. (2007): Anesthesia leads to tau hyperphosphorylation through inhibition of phosphatase activity by hypothermia. J Neurosci 27: 3090-3097

Postina R (2012): Activation of alpha-secretase cleavage. J Neurochem $\underline{120}$ Suppl 1: 46-54 
Raiha I, Kaprio J, Koskenvuo M, Rajala T, Sourander L (1996): Alzheimer's disease in Finnish twins. Lancet 347: 573-578

Reiman EM, Chen K, Liu X, Bandy D, Yu M, Lee W, Ayutyanont N, Keppler J, Reeder SA, Langbaum JB, et al. (2009): Fibrillar amyloid-beta burden in cognitively normal people at 3 levels of genetic risk for Alzheimer's disease. Proc Natl Acad Sci U S A 106: 6820-6825

Rogaev El, Sherrington R, Rogaeva EA, Levesque G, Ikeda M, Liang Y, Chi $\mathrm{H}$, Lin C, Holman K, Tsuda T, et al. (1995): Familial Alzheimer's disease in kindreds with missense mutations in a gene on chromosome 1 related to the Alzheimer's disease type 3 gene. Nature 376: 775-778

Rogers J, Cooper NR, Webster S, Schultz J, McGeer PL, Styren SD, Civin WH, Brachova L, Bradt B, Ward P, et al. (1992): Complement activation by betaamyloid in Alzheimer disease. Proc Natl Acad Sci U S A 89: 10016-10020

Roher AE, Lowenson JD, Clarke S, Woods AS, Cotter RJ, Gowing E, Ball MJ (1993): beta-Amyloid-(1-42) is a major component of cerebrovascular amyloid deposits: implications for the pathology of Alzheimer disease. Proc Natl Acad Sci U S A 90: 10836-10840

Rovelet-Lecrux A, Hannequin D, Raux G, Le Meur N, Laquerriere A, Vital A, Dumanchin C, Feuillette S, Brice A, Vercelletto M, et al. (2006): APP locus duplication causes autosomal dominant early-onset Alzheimer disease with cerebral amyloid angiopathy. Nat Genet 38: 24-26

Run X, Liang Z, Zhang L, lqbal K, Grundke-lqbal I, Gong CX (2009): Anesthesia induces phosphorylation of tau. J Alzheimers Dis 16: 619-626

Santacruz K, Lewis J, Spires T, Paulson J, Kotilinek L, Ingelsson M, Guimaraes A, DeTure M, Ramsden M, McGowan E, et al. (2005): Tau suppression in a neurodegenerative mouse model improves memory function. Science $\underline{309}$ : 476-481

Scheuner D, Eckman C, Jensen M, Song X, Citron M, Suzuki N, Bird TD, Hardy J, Hutton M, Kukull W, et al. (1996): Secreted amyloid beta-protein similar to that in the senile plaques of Alzheimer's disease is increased in vivo by the presenilin 1 and 2 and APP mutations linked to familial Alzheimer's disease. Nat Med 2: 864-870

Schmitt H, Gozes I, Littauer UZ (1977): Decrease in levels and rates of synthesis of tubulin and actin in developing rat brain. Brain Res 121: 327342

Schmitz C, Hof PR (2005): Design-based stereology in neuroscience. Neuroscience 130: 813-831

Schupf N, Sergievsky GH (2002): Genetic and host factors for dementia in Down's syndrome. Br J Psychiatry 180: 405-410

Selkoe DJ (2001): Alzheimer's disease: genes, proteins, and therapy. Physiol Rev 81: 741-766 
Serrano-Pozo A, Frosch MP, Masliah E, Hyman BT (2011): Neuropathological alterations in Alzheimer disease. Cold Spring Harb Perspect Med 1: a006189

Seshadri S, Beiser A, Selhub J, Jacques PF, Rosenberg IH, D'Agostino RB, Wilson PW, Wolf PA (2002): Plasma homocysteine as a risk factor for dementia and Alzheimer's disease. N Engl J Med 346: 476-483

Shankar GM, Bloodgood BL, Townsend M, Walsh DM, Selkoe DJ, Sabatini BL (2007): Natural oligomers of the Alzheimer amyloid-beta protein induce reversible synapse loss by modulating an NMDA-type glutamate receptordependent signaling pathway. J Neurosci 27: 2866-2875

Sherrington R, Rogaev El, Liang Y, Rogaeva EA, Levesque G, Ikeda M, Chi H, Lin C, Li G, Holman K, et al. (1995): Cloning of a gene bearing missense mutations in early-onset familial Alzheimer's disease. Nature 375: 754-760

Sherwin BB (1988): Estrogen and/or androgen replacement therapy and cognitive functioning in surgically menopausal women. Psychoneuroendocrinology 13: 345-357

Shumaker SA, Legault C, Rapp SR, Thal L, Wallace RB, Ockene JK, Hendrix SL, Jones BN, 3rd, Assaf AR, Jackson RD, et al. (2003): Estrogen plus progestin and the incidence of dementia and mild cognitive impairment in postmenopausal women: the Women's Health Initiative Memory Study: a randomized controlled trial. JAMA 289: 2651-2662

Sisodia SS, Kim SH, Thinakaran G (1999): Function and dysfunction of the presenilins. Am J Hum Genet 65: 7-12

Small GW, Rabins PV, Barry PP, Buckholtz NS, DeKosky ST, Ferris SH, Finkel SI, Gwyther LP, Khachaturian ZS, Lebowitz BD, et al. (1997): Diagnosis and treatment of Alzheimer disease and related disorders. Consensus statement of the American Association for Geriatric Psychiatry, the Alzheimer's Association, and the American Geriatrics Society. JAMA 278: 1363-1371

Snowdon DA, Greiner LH, Mortimer JA, Riley KP, Greiner PA, Markesbery WR (1997): Brain infarction and the clinical expression of Alzheimer disease. The Nun Study. JAMA 277: 813-817

Sofroniew MV, Vinters HV (2010): Astrocytes: biology and pathology. Acta Neuropathol 119: 7-35

Stewart WF, Kawas C, Corrada M, Metter EJ (1997): Risk of Alzheimer's disease and duration of NSAID use. Neurology 48: 626-632

Strittmatter WJ, Roses AD (1996): Apolipoprotein E and Alzheimer's disease. Annu Rev Neurosci 19: 53-77

Struwe F (1929): Histopathologische Untersuchungen über Entstehung und Wesen der senilen Plaques. Z Ges Neurol Psychiatr 122: 291-307 
Tagliavini F, Giaccone G, Frangione B, Bugiani O (1988): Preamyloid deposits in the cerebral cortex of patients with Alzheimer's disease and nondemented individuals. Neurosci Lett 93: 191-196

Takeda K, Araki W, Tabira T (2004): Enhanced generation of intracellular Abeta42 amyloid peptide by mutation of presenilins PS1 and PS2. Eur $\mathrm{J}$ Neurosci 19: 258-264

Tanapat P, Hastings NB, Reeves AJ, Gould E (1999): Estrogen stimulates a transient increase in the number of new neurons in the dentate gyrus of the adult female rat. J Neurosci 19: 5792-5801

Tang MX, Jacobs D, Stern Y, Marder K, Schofield P, Gurland B, Andrews H, Mayeux R (1996): Effect of oestrogen during menopause on risk and age at onset of Alzheimer's disease. Lancet 348: 429-432

Tang-Wai DF, Keith AJ, Petersen RC: Alzheimer's disease-overview; In: Neurodegenerative Diseases: Neurobiology, Pathogenesis and Therapeutics; hrsg. v. Beal MF, Lang AE, Ludolph A; Cambrigde University Press, Cambridge. 2005, 416-432

Taupin P: The Hippocampus: Neurotransmission and Plasticity in the Nervous System. Seite 5-7, Gazelle Book Services, Lancaster (2007)

Terry RD, Masliah E, Salmon DP, Butters N, DeTeresa R, Hill R, Hansen LA, Katzman R (1991): Physical basis of cognitive alterations in Alzheimer's disease: synapse loss is the major correlate of cognitive impairment. Ann Neurol 30: 572-580

Turner RS, Suzuki N, Chyung AS, Younkin SG, Lee VM (1996): Amyloids beta40 and beta42 are generated intracellularly in cultured human neurons and their secretion increases with maturation. J Biol Chem 271: 8966-8970

Van den Heuvel C, Blumbergs PC, Finnie JW, Manavis J, Jones NR, Reilly PL, Pereira RA (1999): Upregulation of amyloid precursor protein messenger RNA in response to traumatic brain injury: an ovine head impact model. Exp Neurol 159: 441-450

Van der Werf YD, Witter MP, Uylings HB, Jolles J (2000): Neuropsychology of infarctions in the thalamus: a review. Neuropsychologia 38: 613-627

Vassar R, Kovacs DM, Yan R, Wong PC (2009): The beta-secretase enzyme BACE in health and Alzheimer's disease: regulation, cell biology, function, and therapeutic potential. J Neurosci 29: 12787-12794

Venkataramani V, Rossner C, Iffland L, Schweyer S, Tamboli IY, Walter J, Wirths O, Bayer TA (2010): Histone deacetylase inhibitor valproic acid inhibits cancer cell proliferation via down-regulation of the alzheimer amyloid precursor protein. J Biol Chem 285: 10678-10689

Wallesch CW, Förstl H: Demenzen. 1. Auflage, Georg Thieme Verlag, Stuttgart (2005) 
Walsh DM, Selkoe DJ (2007): A beta oligomers - a decade of discovery. J Neurochem 101: 1172-1184

Walsh DM, Klyubin I, Fadeeva JV, Cullen WK, Anwyl R, Wolfe MS, Rowan MJ, Selkoe DJ (2002): Naturally secreted oligomers of amyloid beta protein potently inhibit hippocampal long-term potentiation in vivo. Nature 416: 535539

Wancata J, Musalek M, Alexandrowicz R, Krautgartner M (2003): Number of dementia sufferers in Europe between the years 2000 and 2050. Eur Psychiatry 18: 306-313

Wang J, Tanila H, Puolivali J, Kadish I, van Groen T (2003): Gender differences in the amount and deposition of amyloidbeta in APPswe and PS1 double transgenic mice. Neurobiol Dis 14: 318-327

Wang JZ, Gong CX, Zaidi T, Grundke-lqbal I, lqbal K (1995): Dephosphorylation of Alzheimer paired helical filaments by protein phosphatase-2A and -2B. J Biol Chem 270: 4854-4860

Wharton W, Gleason CE, Lorenze KR, Markgraf TS, Ries ML, Carlsson CM, Asthana S (2009): Potential role of estrogen in the pathobiology and prevention of Alzheimer's disease. Am J Transl Res 1: 131-147

Whitehouse PJ, Price DL, Struble RG, Clark AW, Coyle JT, Delon MR (1982): Alzheimer's disease and senile dementia: loss of neurons in the basal forebrain. Science 215: 1237-1239

Whitmer RA, Quesenberry CP, Zhou J, Yaffe K (2011): Timing of hormone therapy and dementia: the critical window theory revisited. Ann Neurol 69: 163-169

Winslow BT, Onysko MK, Stob CM, Hazlewood KA (2011): Treatment of Alzheimer disease. Am Fam Physician 83: 1403-1412

Wirths O, Multhaup G, Bayer TA (2004): A modified beta-amyloid hypothesis: intraneuronal accumulation of the beta-amyloid peptide--the first step of a fatal cascade. J Neurochem 91: 513-520

Woolley CS, McEwen BS (1992): Estradiol mediates fluctuation in hippocampal synapse density during the estrous cycle in the adult rat. J Neurosci $\underline{12:}$ 2549-2554

Xia W, Zhang J, Kholodenko D, Citron M, Podlisny MB, Teplow DB, Haass C, Seubert P, Koo EH, Selkoe DJ (1997): Enhanced production and oligomerization of the 42-residue amyloid beta-protein by Chinese hamster ovary cells stably expressing mutant presenilins. J Biol Chem 272: 79777982

Yamaguchi H, Hirai S, Morimatsu M, Shoji M, Harigaya Y (1988): Diffuse type of senile plaques in the brains of Alzheimer-type dementia. Acta Neuropathol 77: $113-119$ 
Yu C, Nwabuisi-Heath E, Laxton K, Ladu MJ (2010): Endocytic pathways mediating oligomeric Abeta42 neurotoxicity. Mol Neurodegener 5: 19

Zandi PP, Carlson MC, Plassman BL, Welsh-Bohmer KA, Mayer LS, Steffens DC, Breitner JC (2002): Hormone replacement therapy and incidence of Alzheimer disease in older women: the Cache County Study. JAMA 288: 2123-2129

Zhang Y, McLaughlin R, Goodyer C, LeBlanc A (2002): Selective cytotoxicity of intracellular amyloid beta peptide1-42 through p53 and Bax in cultured primary human neurons. J Cell Biol 156: 519-529

Zubenko GS, Zubenko WN, McPherson S, Spoor E, Marin DB, Farlow MR, Smith GE, Geda YE, Cummings JL, Petersen RC, et al. (2003): A collaborative study of the emergence and clinical features of the major depressive syndrome of Alzheimer's disease. Am J Psychiatry 160: 857866 
Danksagung

Für die Möglichkeit der Promotion möchte ich Prof. Dr. Thomas Bayer danken. Mein Dank gilt zudem der Arbeitsgruppe für Molekulare Psychiatrie um Prof. Dr. Bayer und PD Dr. Oliver Wirths für Hilfestellung und Weitergabe von Erfahrung. 